\title{
Trade, Intellectual Property Rights, and the World Trade Organization
}

\author{
Kamal Saggi* \\ Department of Economics \\ Vanderbilt University
}

\begin{abstract}
This chapter surveys the literature on international trade and the protection of intellectual property rights (IPRs) in the global economy. The discussion is organized around the major questions in the field. How does openness to trade affect national incentives for patent protection? What is the rationale for international coordination over patent policies? Given that countries are highly asymmetric with respect to their technological capabilities, what incentives do lagging countries have for enforcing IPRs and what are the consequences of requiring them to do so? To what extent do empirical studies support the major arguments for and against the Agreement on Trade Related Aspects of Intellectual Property Rights (TRIPS)? Finally, can the structure of TRIPS - both in terms of the core obligations it imposes on WTO members and the flexibilities that it provides them with respect to exhaustion policies and the use of compulsory licensing - be reconciled with existing models of IPR protection in the global economy?

Keywords: intellectual property rights, TRIPS, WTO, innovation, trade, foreign direct investment, imitation, patent protection, welfare, exhaustion policies, compulsory licensing.
\end{abstract}

JEL Codes: F12, F23, F43, F63, O31, O34, O38.

Abbreviated title: The global protection of intellectual property

*E-mail: kamal.saggi@vanderbilt.edu; phone: (+1) 615-322-3237. For helpful comments and discussions, I thank Kyle Bagwell, Kamran Bilir, Lee Branstetter, Eric Bond, Difei Geng, Bernard Hoekman, Olena Ivus, Keith Maskus, Phil McCalman, Petra Moser, Walter Park, Alan Sykes, Robert Staiger, and Mark Wu. All errors are my own. 


\section{Introduction}

Of the eight rounds of multilateral trade negotiations sponsored by the General Agreement on Tariffs and Trade (GATT), the Uruguay Round (1986-1994) was the longest and the most far-reaching. ${ }^{1}$ It involved 125 countries and its coverage was unusually broad in that it included negotiations over trade in services as well as over rules and regulations pertaining to intellectual property rights (IPRs), areas that the multilateral trading system had stayed clear of since GATT's inception in 1947. Negotiations over IPRs were driven by a deep-rooted sense of dissatisfaction in the United States (US) with the state of IPR protection in the global economy, especially with the widespread imitation and piracy occurring in major developing countries despite the existence of major international IPR treaties prohibiting such activities. ${ }^{2}$ Supported by the European Union (EU) and Japan, the US pushed hard to have IPRs included in the multilateral negotiating agenda of the Uruguay Round, the eighth and final round of GATT negotiations. These multilateral negotiations eventually culminated in the form of the Agreement on Trade Related Aspects of Intellectual Property Rights (TRIPS), perhaps the most controversial multilateral trade agreement in existence today.

While TRIPS was preceded by several international IPR treaties, it was unique in that, from its inception, it was part and parcel of the single undertaking nature of the World Trade Organization (WTO). ${ }^{3}$ As a result, TRIPS became the first major interna-

\footnotetext{
${ }^{1}$ While the Doha round of trade negotiations has been ongoing for a longer time period than the Uruguay round, it has so far failed to deliver a bargain acceptable to all sides.

${ }^{2}$ In the mid-to-late 1980s, several major policy reports issued by leading governmental organizations in the US raised concerns about the substantial losses being incurred by key US industries due to the lack of adequate IPR protection in foreign countries. See, for example, USITC (1988), US-Chamber of Commerce (1987), and the annual reports issued by the office of the United States Trade Representative (USTR). Even today, the USTR regularly places many countries on a "watch list" or a "priority watch list" due to their weak protection of IPRs (as perceived by the US), where those on the priority list can be subject to retaliatory sanctions by the US. See Maskus (2000a) for an overview of the international situation prior to TRIPS and Maskus (2012) for some constructive proposals targeted at improving the efficiency and equity of the global IPR system.

${ }^{3}$ Major international IPR treaties that pre-date TRIPS include the Paris Convention for the Pro-
} 
tional IPR treaty to be fully backed by a potent dispute settlement mechanism. Broadly speaking, TRIPS obligates all WTO member countries - regardless of their economic conditions and technological capabilities - to adopt and enforce certain minimum standards of IPR protection. But since most developed countries already had relatively high levels of IPR protection prior to TRIPS, the main practical effect of TRIPS was to force developing countries to align their IPR regulations with those of highly developed countries such as the US and Japan.

Although TRIPS officially took effect on 1 January 1995, it did not require the mandated global adjustments in IPR regulations to occur immediately or equally quickly in all countries: while developed countries were given only one year to make their laws and practices TRIPS compliant, developing countries were given five years (until 2000) whereas the least-developed countries were granted until 2006, a deadline which was further extended to 2013 in general, and to 2016 for pharmaceutical patents and trade secrets in particular. Even so, within the developing world the Uruguay Round was perceived as having created a 'development deficit' primarily because it yielded TRIPS. Policy-makers in major developing countries such as Brazil, India, and China were not the only ones opposed to TRIPS , there was widespread skepticism among academicians and other neutral observers regarding the expansion of the multilateral trading system into the sensitive realm of intellectual property. Indeed, it is fair to say that a shadow of skepticism hangs over TRIPS even today.

From the viewpoint of a typical developing country TRIPS seemed like a bad deal due to the expectation that strengthening local IPR protection would raise domestic prices by increasing the market power of IPR holders without having a substantial effect on the pace of global innovation since its own market constituted a relatively tection of Industrial Property (1883), the Berne Convention for the Protection of Literary and Artistic Works (1886), the International Convention for the Protection of Performers, Producers of Phonograms and Broadcasting Organizations (Rome 1961), and the Treaty on Intellectual Property in Respect of Integrated Circuits (Washington, D.C., 1989). 
insignificant part of the world market. Furthermore, developing countries reasoned that, by restricting local imitation and reverse-engineering, stronger IPR protection would make it harder for them to technologically catch up with developed countries. There are two counter responses to these legitimate concerns. First, the argument for TRIPS rests on raising IPR protection throughout the developing world as opposed to doing so in any one developing country in isolation. Thus, what matters is the collective market size of all developing countries. In this regard, the facts presented in Table 1 are rather illuminating: from 1990-2013, the collective share of lower and upper middle income countries in global GDP increased from approximately $31 \%$ to $47 \%$ whereas that of high income countries declined from $68 \%$ to approximately $52 \%$ (WDI, 2015). ${ }^{4}$ It is difficult to believe that the level of IPR protection in half the world economy, which is roughly what developing countries collectively account for today, can be irrelevant for determining global incentives for innovation. ${ }^{5}$

[Table 1 here]

The second frequently offered counter to the claim that TRIPS is not in the interest of developing countries is that stronger IPR protection in such countries would increase the incentive of firms from developed countries to invest in their markets and to transfer technology to them, both via arms-length arrangements such as technology licensing and through intra-firm transactions between multinational firms and their subsidiaries. ${ }^{6}$

\footnotetext{
${ }^{4}$ Similarly, the high income countries' share of global exports of goods and services declined from over $85 \%$ in 1990 to just over $70 \%$ in 2013 (WDI, 2015).

${ }^{5}$ In this regard, it is worth noting that some of the difficulties underlying the seemingly endless Doha Round of trade negotiations (launched in 2001) may have something to do with the fact that the Doha Round has coincided with a major shift of global economic activity from developed countries to developing ones, perhaps the largest such shift ever to have been witnessed over such a short period of time (10-15 years).

${ }^{6}$ Multinational firms dominate global $R \& D$ to such an extent that $R \& D$ spending of some of the biggest multinationals in the world exceeds that of many developing countries, even large ones. For example, in 2009 the Japanese multinational firm Toyota invested more in R\&D than all of India, a country of roughly 1.2 billion people; in a similar vein, over twenty multinational firms invested more in R\&D than Turkey (UNCTAD, 2010).
} 
While detailed empirical evidence bearing on this issue is discussed in Section 7 of this chapter, the overall stylized facts pertaining to the global flows of foreign direct investment (FDI) seem fairly consistent with this position. As Table 2 shows, the developing countries' share of global FDI inflows increased rather dramatically from around $17 \%$ in 1990 to just over $59 \%$ in 2013. At the same time, the share of FDI inflows of developed countries decreased sharply from just under $83 \%$ in 1990 to roughly $39 \%$ in 2013, a decrease of over 100\% (UNCTAD, 2014).

[Table 2 here]

Since prior to 1990 an overwhelming share of annual FDI inflows typically went to the developed countries, it is useful to briefly consider how the allocation of the global stock of FDI has evolved over time. Table 3 presents this information. As can be seen from Table 3, over the time period 1990-2013, the share of global stock of FDI residing in developing countries has increased by roughly $12 \%$ so that over $36 \%$ of the global FDI stock now lies in the developing world.

[Table 3 here]

Figure 1 provides a rather striking comparison of how fast trade in technology has grown relative to trade in goods and services during 1980-2013. Since the absolute value of global exports of goods and services is much larger than the payments of royalties and licensing fees in any given year, this figure compares an index of global royalty payments with an index of global exports (both as a percentage of world GDP and with the 1980 value of both indices set to unity). As is clear from this figure, while the index of global exports grew by only about $20 \%$ or so from $1998-2013$, the index of global royalty payments more than quadrupled over the same time period.

[Figure 1 here] 
When measured by the payments of royalties and licensing fees, much of the global action in technology transfer is still within developed countries and occurs within the boundaries of multinational firms: estimates vary but in a typical year over 80 percent of global royalty payments for international transfers of technology are made between subsidiaries and their parent firms. In recent years, technology transfer to developing countries by multinationals has increased quite sharply: from 1990 to 2009 the share of developing countries in global technology payments doubled from approximately $13 \%$ to $26 \%$ (UNCTAD, 2010). Furthermore, in recent years, multinationals have also begun to shift more of their R\&D activities to the developing world. For example, in 2009 Japanese multinationals allocated $38 \%$ of their R\&D activities abroad to developing countries, a dramatic increase from 6\% in 1993 (UNCTAD, 2010).

The massive changes in the share of global GDP, royalty payments for technology licensing, and the allocation of global FDI (both in terms of flows and stocks) summarized in Tables 1-3 and Figure 1 show that, as a group, developing countries have become a much larger part of the world economy than ever before. It stands to reason then that their collective policy choices regarding IPRs are likely to have significant implications not just for their own welfare but also for that of the rest of the world. Motivated by this overarching issue, this chapter surveys the international trade literature that addresses some fundamental questions regarding the effects and determinants of the strength of IPR protection in the global economy: Do the incentives for patent protection of an open economy differ from those of a closed one? If so, why? What is the rationale for international coordination over national patent policies? Given that WTO member countries differ dramatically with respect to technological capabilities, what incentives, if any, do lagging countries have to enforce TRIPS? To what extent do empirical studies support the major arguments for and against TRIPS? Can the structure of TRIPS both in terms of the core obligations it imposes on WTO members and the flexibilities that it provides them with respect to exhaustion policies and the use of compulsory 
licensing - be reconciled with existing models of IPR protection in the global economy?

Given that the WTO is primarily concerned with international trade (and the GATT exclusively so), perhaps its best to get one fundamental question out of the way early: are IPRs trade-related? ${ }^{7}$ Broadly speaking, a patent-holder can profit from its proprietary technology in foreign markets via two distinct ways. One, it can explicitly trade in its patented technology by licensing it to independent foreign agents or to partly/fully owned foreign subsidiaries via FDI. Two, instead of transacting in technology, it can choose to export the product embodying the technology. Under the first option, technology explicitly exchanges hands internationally whereas in the latter channel only the product does so. Thus, in a fundamental sense, IPRs are trade-related because they can affect not only the process of technology transfer via licensing and FDI but also the pattern of international trade. ${ }^{8}$ Existing empirical evidence discussed in sections 7.1 and 7.3 demonstrates that these channels are indeed operative in the real world.

At the outset, I should note that the chapter discusses only a selected portion of the vast economic literature on IPRs, i.e., the part that addresses questions pertaining to those aspects of IPRs that are explicitly trade-related, where 'trade' is broadly interpreted to include both international trade in goods/services as well as FDI. In other words, models and empirical studies that focus purely on domestic IPR issues are discussed only to the extent that they are necessary for gaining a clearer understanding of the literature on trade related aspects of intellectual property. There exists a rich and vast literature in industrial organization investigating a wide range of issues related

\footnotetext{
${ }^{7}$ A related but more difficult question, and one that I briefly discuss in the Conclusion of this chapter, is the following: assuming that there is indeed a case for international coordination over IPRs, is the WTO the right organization for undertaking such coordination?

${ }^{8}$ Suppose that a patent-holder in one country is unable to sell its product in a foreign country because its technology has been imitated by a local firm in that country. Then, in effect, such imitation is equivalent to a prohibitive tariff (or a complete ban) on its exports. It is difficult to argue that prohibitive tariffs are problematic but outright theft of intellectual property that makes it impossible for an IPR holder to exploit its asset abroad is not, especially when the property in question has been created via costly investments in R\&D.
} 
to innovation and the patent system surveyed by Rockett (2010). I have chosen not to discuss this literature in this chapter because it focuses almost exclusively on closed economy models. This decision not only reflects my own interests and comparative advantage, but also the overall theme of this Handbook. Even so, given the immense size of the literature on trade and IPRs, I have been forced to make some hard choices about what to leave out. Rather than reducing length by focusing on a narrow set of issues, I have tried to be relatively broad in my coverage of the relevant questions while simultaneously favoring relatively recent contributions in order to control length.

\section{TRIPS and the global distribution of patents}

As per the World Intellectual Property Organization (WIPO), the term intellectual property refers to "creations of the mind" which include inventions; literary and artistic works; and symbols, names and images used in commerce. Thus, intellectual property differs fundamentally from physical property such as land or capital, in the sense that it is not only intangible in nature but is also primarily an outcome of human thought.

In his seminal paper on technological change, Romer (1990) provides an illuminating model of technological change built on the premise that knowledge is a non-rival good: i.e., the usage of a certain type of knowledge by one person, by itself, does not preclude another from using it. Whether or not an agent can prevent others from using a particular piece of knowledge or technology (for commercial exploitation or other purposes) depends on whether he/she can claim ownership over it via a well-defined property right.

The ownership of intellectual property is conferred via the legal recognition and protection of IPRs such as copyrights, patents, industrial designs, utility models, and trademarks. A patent is the grant of a property right by a government to an inventor that allows the inventor to exclude others from making, using, or offering the invention 
for sale within national boundaries for a specific duration (usually twenty years). ${ }^{9}$ Thus, even post TRIPS, each country retains the right to determine whether or not a particular invention merits a patent within its borders. In return for the right to exclude others, patent-holders are generally required to disclose information that makes it easier for others to understand the nature of innovation, thereby potentially generating knowledge spillovers. ${ }^{10}$ While a disclosure rule of some type is a common feature of national patent systems, its specific implementation differs across countries. ${ }^{11}$

The classic argument for why granting temporary monopoly power to inventors is socially justified is that doing so helps provide incentives for innovation. After all, if an agent cannot exclude others from using a novel idea or technology even temporarily, it will have a very weak incentive to invest in creation of that idea/technology since, in the absence of exclusion, competition in the market place will generally erode all rents. By granting an inventor monopoly power for a specific time period, a patent allows the inventor to capture some of the social benefits created by its invention. ${ }^{12}$ But since market power invariably creates a social deadweight loss by causing price to diverge from

\footnotetext{
${ }^{9}$ Copyrights cover literary works, films, music, artistic works, architectural design, as well as performances of artists in their recordings as well as broadcasts via radio and television. An industrial design is an innovation pertaining to the functional, ornamental or aesthetic aspect of a good. Unlike patents, industrial designs can even be purely artistic innovations. A utility model (sometimes called a "petty patent") is an IPR similar to a patent but it is granted for smaller inventions. Finally, a trademark is a word, phrase, symbol, and/or design used to distinguish a good or service of one firm from those of other firms. In what follows, in accordance with the existing literature on the subject of IPRs and international trade, I will focus mostly on patents.

${ }^{10}$ The disclosure requirement can sometimes discourage firms from seeking patent protection if they can better protect their innovations via trade secrecy. Cohen et. al. (2000) and Harhoff and Hoisl (2006) find that secrecy is a more effective means for protecting intellectual property than patents in many industries. See also Moser (2005 and 2011).

${ }^{11}$ Motivated by differences in patent laws between the US and Japan, Aoki and Prusa $(1996,1997)$ examine how the nature of policy rules governing information disclosure affect $R \& D$. In a model where $\mathrm{R} \& \mathrm{D}$ investments determine product quality, Aoki and Prusa show that the incentives for R\&D investment are lower under a rule that requires disclosure at the time at which an inventor files for a patent relative to one that requires it at the time at which the patent is granted.

${ }^{12}$ Note, however, patents will generally create insufficient incentives for innovation because inventors usually cannot fully appropriate the additional consumer surplus generated by their inventions. Furthermore, inventors also do not take into account the positive knowledge spillovers created by their inventions for others.
} 
marginal cost, any positive effect of patents on innovation incentives has to be balanced against their short run welfare costs.

Of course, patents are certainly not the only means via which one can reward innovation; for example, prizes awarded to successful innovators can achieve the same end. However, such alternative mechanisms can have problems of their own, a major one being the lack of information available to policy-makers regarding the value of any particular innovation. Since patents grant monopoly rights for a fixed duration of time irrespective of the market value of a patent, they do not face a similar informational hurdle. ${ }^{13}$ This does not imply, however, that patents are the ideal instrument for encouraging innovation. Indeed, it seems fair to note that the patent system (especially in the US) has come under widespread criticism for a variety of legitimate reasons, prompting the usage of terms such as "our broken patent system," "patent failure," and "the patent crisis" - see Gilbert (2011). ${ }^{14}$ However, given the objective of this chapter, the state of the relevant literature in international trade, and the rules and regulations of the multilateral trading system, I will focus primarily on patents as the instruments for encouraging innovation.

\subsection{TRIPS: main clauses and obligations.}

Like all multilateral agreements governed by the WTO, TRIPS is complex and lengthy. A full treatment of all of the legal nuances of TRIPS is beyond the scope of this chapter and my own expertise. Nevertheless, it is useful to obtain a general sense of the overall structure of TRIPS in order to put the findings of the relevant research into proper context.

\footnotetext{
${ }^{13}$ See also Gallini and Scotchmer (2002) and Hopenhayn et. al. (2006). Kremer (1998) proposes and analyses an auction based system that uses prizes to incentivize innovation without needing information on the social value of potential innovations.

${ }^{14}$ Boldrin and Levine (2013) offer perhaps the strongest criticism of the patent system. Indeed, they go so far as to assert that protection of intellectual property in the form of patents and copyrights is not only unnecessary but actually socially harmful, i.e., the world would be better off without it.
} 
TRIPS contains seven parts. Part I lays down some general provisions and principles that WTO members are obligated to follows. Part II describes in detail the minimum standards of IP protection that member states must provide with respect to all major types of IPRs. ${ }^{15}$ General obligations pertaining to enforcement are contained in part III which also includes provisions on civil and criminal procedures and special requirements related to border measures. Part IV describes rules and procedures related to acquisition of IPRs such as the application process for various types of IPRs. Part V deals with the prevention and settlement of disputes while part VI describes transitional arrangements pertaining to developing countries as well as issues of technical cooperation and technology transfer. Part VII contains some final provisions related to the protection of existing subject matter and security exceptions. Since there exist many comprehensive discussions of the overall structure of TRIPS, in what follows I highlight those aspect of the Agreement that have received significant attention in the formal economics literature.

Article 1 of TRIPS clarifies that TRIPS establishes certain minimum standards of IPR protection that all WTO members must provide in that "members may, but shall not be obliged to, implement in their law more extensive protection than is required by this Agreement." For example, TRIPS requires all members to offer patent protection for at least twenty years, leaving countries free to offer patents of longer duration. This minimum standards requirement has often been interpreted as the harmonization of IPR protection across countries although the two are clearly not the same.

TRIPS pays due heed to all of the major international IPR treaties that precede it. Article 2 requires WTO members to comply with Articles 1 through 12, and Article 19, of the Paris Convention and it explicitly states that nothing in TRIPS "shall derogate from existing obligations that Members may have to each other under the Paris Convention,

\footnotetext{
${ }^{15}$ IPRs covered by TRIPS include not just copyrights, industrial designs, patents, and trademarks but also geographical indicators, layout designs of integrated circuits, and undisclosed information (trade secrets and test data).
} 
the Berne Convention, the Rome Convention and the Treaty on Intellectual Property in Respect of Integrated Circuits."

As in GATT, the principle of non-discrimination is fundamental to TRIPS. The notion of national treatment prescribed in Article 3 says that "each Member shall accord to the nationals of other Members treatment no less favourable than that it accords to its own nationals with regard to the protection of intellectual property," where the term "protection" includes matters related to availability, acquisition, scope, maintenance, and enforcement of IPRs. The most-favored-nation (MFN) clause is contained in Article 4 and it forbids WTO members from discriminating amongst their trading partners in all matters related to the protection of intellectual property.

A major objective of TRIPS - stated in Article 7 - is that the "promotion and enforcement of IPRs should contribute to the promotion of technological innovation and to the transfer and dissemination of technology, to the mutual advantage of producers and users of technological knowledge." From an international perspective, this is a key issue since technology transfer has the potential to make TRIPS a win-win for both developed and developing countries, as opposed to primarily being a vehicle for transferring income from developing countries to the developed ones.

To some degree, the various obligations imposed by TRIPS are counterbalanced by several major 'flexibilities' it provides to all WTO members, developing and developed alike. Perhaps the two most important such flexibilities are the right to implement exhaustion policies of one's choosing and the ability to invoke compulsory licensing of patents. These flexibilities have been an active area of research in recent years, particularly because they have important implications for public health due to their effects on consumer access to patented pharmaceuticals. Below I provide an overview of these flexibilities and then discuss the formal literature analyzing them in sections 5 and 6 .

Exhaustion policies determine the legality of parallel trade. - i.e. the type of trade that occurs when a product protected by an IPR offered for sale by the rights holder in 
one country is re-sold in another country without the right holder's permission. ${ }^{16}$ As is clear, the incentive to engage in such trade naturally arises in the presence of significant international price differences (Scherer and Watal, 2002).

While TRIPS makes far-reaching demands of WTO members in the realm of IPRs, it leaves exhaustion policies completely at their discretion. Indeed, Article 6 of TRIPS explicitly states that "nothing in this Agreement shall be used to address the issue of the exhaustion of intellectual property rights". Such latitude raises an obvious question: what sort of international spillovers, if any, are created by the freedom that WTO members have to pursue exhaustion policies of their own choosing? The relevant literature addressing this question is discussed in section 5 .

When faced with no or limited access to a patented foreign product, TRIPS rules permit a country to engage in compulsory licensing, i.e., an authorization granted by a government to someone other than the patent-holder to produce the product without the patent-holder's consent. ${ }^{17}$ Article 31 of TRIPS (which pertains to "use without authorization of the right holder") lays down the conditions that govern the use of compulsory licensing of patented products. This Article requires that the entity (a company or a national government) seeking a compulsory license should have been unable to obtain a voluntary licence from the right holder on "reasonable" commercial terms and that "adequate remuneration" must be paid to the patent-holder in the event of compulsory licensing. Furthermore, it does not permit exclusivity and requires that any sales under compulsory licensing should be predominantly for the domestic market. However, in order to make compulsory licensing accessible to those countries that lacked the capability to produce pharmaceuticals domestically, the 2001 Doha Ministerial conference

\footnotetext{
${ }^{16}$ Maskus (2000b) provides a discussion of the observed variation in exhaustion policies across countries.

${ }^{17}$ Even Article 5 of the Paris Convention of 1883, allowed legislative measures "for the grant of compulsory licenses to prevent the abuses which might result from the exercise of the exclusive rights conferred by the patent, for example, failure to work" (Pozen, 2008).
} 
modified TRIPS rules by allowing compulsory licenses to be issued to producers in third countries.

\subsection{The protection and global distribution of patents}

Assessing the degree of protection afforded to IPRs in a country is a complex task. A commonly used index for measuring the degree of patent protection provided by a country is the Ginarte-Park (GP) index. This index is the sum of scores earned by a country in five separate categories pertaining to patent protection: coverage, membership in international treaties such as TRIPS, duration of protection, enforcement mechanisms, and restrictions (such as compulsory licensing) that limit a patent-holder's control over its invention. The scores range from 0 to 5 . Table 4 reports the evolution of the GinartePark index for selected countries during 1990-2010 to provide a brief glimpse of how the protection and enforcement of patents in the global economy has been altered due to TRIPS. ${ }^{18}$

[Table 4 here]

As one might expect, the degree of patent protection in the US remained essentially flat and near the maximum possible value of 5.0 for the entire time period. Of the countries covered in Table 4, the sharpest changes in patent protection occurred in China and India: the value of the index for India increased sharply from 1.03 in 1990 to almost 3.76 while that for China, the index almost doubled from 2.12 to 4.21. These are large changes with potentially important economic implications not just for India and China but also for the rest of the world. ${ }^{19}$

\footnotetext{
${ }^{18}$ I thank Walter Park for providing me with the latest version of the Ginarte-Park index.

${ }^{19}$ As I noted in the Conclusion of this chapter, while aggregate indices of IPR protection are useful, we need more detailed information on how TRIPS has affected the actual enforcement of IPRs in developing countries at various stages of the legal system (ranging from the prevention of IPR violations to their effective prosecution via local courts).
} 
How has global patenting evolved during the post TRIPS era? In the year that TRIPS was ratified (i.e. 1995), over 420,000 patents were granted in the world, over $92 \%$ of which were granted by high income countries (HICs) and only about $6 \%$ by upper middle income countries (UMICs). By contrast, of the over 1.4 million patents granted world-wide in 2013, approximately $77 \%$ were issued by HICS while almost $22 \%$ were granted by UMICs.

[Table 5 here]

Since patents are typically granted for 20 years, a reasonable approximation of the distribution of global stock of patents can be obtained by summing all patents granted in the world during 1993-2013. Table 6 presents this information. Observe that over $83 \%$ of the patents granted world-wide during this time period were granted by HICs whereas the share of LICs was a measly $0.38 \%$ while that of MICS (i.e. all LMICs and UMICs) was $16 \%$.

[Table 6 here]

How globalized is contemporary patenting? Of the roughly 1.4 million patents granted world-wide during 2013, roughly $39 \%$ accrued to non-residents. Figure 2 plots the five year moving average of the share of patents granted by various groups of countries during 2000-2013. The most noteworthy aspect of this figure is that while the average share of non-residents in patents granted by HICs remained relatively stable at around $37 \%$, the corresponding share for UMICs declined from over $75 \%$ to roughly $44 \%$, while that for LMICs increased from around $44 \%$ to almost $74 \%$. The share of non-resident patenting aggregated over all groups of countries resembles that of the HICs since they dominate global patenting overall and this share was relatively stable over 2000-2013. These facts raise interesting questions and they reflect not only changes in 
the pattern of local innovation but also the increased incentives that inventors have to seek patent protection in foreign markets during the post-TRIPS era.

[Figure 2 here: Ratio of non-resident to resident patenting]

Figure 3 disentangles resident and non-resident patenting in LMICs by plotting the five year moving averages of these series during 2000-2013. As is clear from the figure, non-resident patenting in LMICs increased whereas resident patenting actually declined: the average number of patents granted to non-residents by LMICs roughly tripled during 2000-2013 while those granted to residents fell by almost $40 \%$.

[Figure 3 here: Ratio of non-resident to resident patenting in LMIC]

One possible interpretation of these trends is that TRIPS made it more attractive for foreigners to take out patents in LMICs without having a similar effect on domestic innovation, suggesting a possible crowding out of local innovation (or at least patenting). Examination of domestic and foreign patenting in the other two groups of countries shows that both resident and non-resident patenting increased fairly sharply in UMICs, with the growth in non-resident patenting outstripping that in resident patenting whereas both types of patenting increased only moderately in HICs. The UMICs not only have larger domestic markets than LMICs, they also possess a greater ability to innovate. As a result, the strengthening of patent protection in UMICs is likely to have elicited a relatively sharper response in resident patenting. Finally, the moderate and relatively similar increase in resident and non-resident patenting in HICs reflects the fact that patent protection was fairly high and did not change much over the relevant time period.

TRIPS made it mandatory (after some time lags) for developing countries to reform their IPR regimes so as to harmonize them with those of developed countries. The asymmetry inherent to this monumental change is easy to grasp: much of the world's existing intellectual property - as measured by patents, trademarks, and copyrights - 
is held by the developed world. Although it is difficult to obtain precise estimates at the global level, data from the US Patent Office (USPTO) shown in Table 7 sheds some light on the extent to which the ownership of world's intellectual property is concentrated within developed countries.

[Table 7 here]

Table 7 shows that during 1995-2014, the US granted over 3.5 million patents roughly $49 \%$ of which were granted to foreign residents. High income (OECD) countries accounted for an overwhelming share (94\%) of the patents granted by the US to foreign residents; Japan alone received over $40 \%$ of these patents. By contrast, the share of all UMICs stood at a paltry $2.56 \%$, with China being the leader at $1.73 \%$ followed by India at $0.80 \%$. However, the share of both Asian giants has increased steadily during the post-TRIPS era: during 1995-99 China received only $0.10 \%$ of the patents granted by the US to foreign residents whereas over 2010-2014, its share stood at 3.8\%. Similarly, over the same time periods, India's share increased from $0.10 \%$ to $1.51 \%$. All in all, while the stock of intellectual property controlled by major developing countries is still small, it has been increasing steadily during the post-TRIPS era.

The patent data presented in Table 7 fit nicely with data on global investment in research and development $(\mathrm{R} \& \mathrm{D})$ presented in Table 8. This Table shows that major developing countries significantly increased their $R \& D$ intensity (defined as the ratio of total R\&D to GDP) during 1996-2011, with the largest such increase occurring in China whose R\&D intensity more than tripled over these fifteen years. In fact, in 2011, China invested more in R\&D than Japan and almost half as much as the US, by far the largest investor in R\&D in the world. While Japan has historically dwarfed all Asian countries in terms of patent applications and grants, it was overtaken by China in 2011. Indeed, so salient has been China's rise that patent filings in China during 2011 exceeded even those in the US, making China the country with the largest number of patents filed 
(and granted) in world during 2011. ${ }^{20}$ Geng and Saggi (2015a) highlight the startling statistic that in 2011 the State Intellectual Property Office of the People's Republic of China accounted for roughly $25 \%$ of all patent applications filed in the world. ${ }^{21}$

[Table 8 here]

With a broad overview of TRIPS and global trends in R\&D and patenting in hand, I now discuss the literature examining the need for international coordination over the protection of intellectual property in the global economy.

\section{Economics of international patent protection}

My discussion of optimal patent policies in an open economy setting is based on Grossman and Lai (2004) who extend the classic work of Nordhaus (1969) in order to examine not only the need for international coordination of national patent policies but also the consequences of their international harmonization.

\subsection{The rationale for international coordination}

Consider a world economy comprising two countries: home $(H)$ and foreign $(F)$. In each country, there are two sectors: a traditional sector that produces a homogeneous good and a modern one that invents a variety of differentiated goods through R\&D. The

\footnotetext{
${ }^{20} \mathrm{Hu}$ and Jefferson (2009) investigate the surge in Chinese patenting during the post-TRIPS era and argue that the intensification of R\&D in China explains only a small percentage of the observed increase. Their analysis points to increased FDI as a significant explanatory factor behind the shapr increase in Chinese patenting, along with the changes in Chinese patent law that took place in 2000 and in 2001 during China's accession to the WTO.

${ }^{21}$ Geng and Saggi (2015a) also note that the Chinese inventors show a much lower inclination toward patenting abroad than Japanese and US inventors: for example in 2010, while patents granted to US residents in foreign markets accounted for roughly $44 \%$ of their total number of patents, the corresponding percentage for Chinese inventors was only $6 \%$. They argue that such a low share of foreign patenting raises doubts about the overall quality of the patents being issued to Chinese residents since inventors have a strong incentive to protect their most important inventions in foreign markets (Eaton and Kortum, 1996).
} 
life span of each differentiated good is assumed to be $\bar{\tau}$ after which consumers derive no utility from it. There are $M_{i}$ consumers in country $i$, where $i=H, F$, so that $M_{i}$ measures country $i$ 's market size for differentiated goods.

In both countries, the representative consumer maximizes lifetime utility

$$
U(t)=\int_{t}^{\infty} e^{-\rho z} u(z) d z
$$

where $\rho$ is the subjective discount rate and $u(z)$ is the instantaneous utility function given by

$$
u(z)=y(z)+\int_{0}^{n(z)} h(x(k, z)) d k
$$

where $y(z)$ and $x(k, z)$ represent respectively the consumptions of the homogeneous good and the $k$ th differentiated good at time $z$ and $n(z)$ denotes the measure of differentiated goods still alive at time $z$. The function $h(\cdot)$ satisfies the following regularity conditions (i) $h^{\prime}>0$ and $h^{\prime \prime}<0$; (ii) every variety of differentiated goods is purchased in equilibrium (i.e. $h^{\prime}(0)=\infty$ ); and (iii) the optimal monopoly price of a typical differentiated good is finite (i.e. $-x h^{\prime \prime} / h^{\prime}<1$ ).

R\&D requires two factors of production: labor $(L)$ and human capital $(K)$. The flow of innovations in country $i$ at time $z$ equals:

$$
\phi_{i}(z)=\left(L_{I i}(z) / a_{i}\right)^{\alpha}\left(K_{i}\right)^{1-\alpha}
$$

where $L_{I i}(z)$ is the labor input into innovation, $a_{i}$ represents (inverse) labor productivity, and $K_{i}$ the fixed stock of human capital. ${ }^{22}$

Since the market for the homogeneous good is assumed to be perfectly competitive, the wage rate in each country simply equals the marginal product of labor in the traditional sector: i.e. $w_{i}=1 / a_{i}$. Given the technology specified for innovation in (3),

\footnotetext{
${ }^{22}$ Grossman and Lai (2004) show that their major results hold when the R\&D production function has a CES form of the type $\phi_{i}(z)=A\left[\alpha\left[L_{I i}(z) / a_{i}\right]^{\beta}+(1-\alpha) K_{i}^{\beta}\right]^{1 / \beta}$ with $\beta \leq 0$. As is well-known, the Cobb-Douglas is a special case of this CES function with $\beta=0$.
} 
$\phi_{i}(z)+\phi_{j}(z)$, newly invented goods become available in country $i$ during each time pe$\operatorname{riod} z$, where $j=H, F$ and $j \neq i$. Furthermore, a measure of $\phi_{i}(z-\bar{\tau})+\phi_{j}(z-\bar{\tau})$ existing goods die and exit during each period. As a result, the increase in the measure of differentiated goods at a given point in time equals $\dot{n}_{i}(z)=\phi_{i}(z)-\phi_{i}(z-\bar{\tau})+\phi_{j}(z)-\phi_{j}(z-\bar{\tau})$. In what follows, like Grossman and Lai (2004), I focus on the steady state where $\dot{n}_{i}(z)=0$ so that the measure of differentiated goods in both markets remains constant over time.

Once invented, a differentiated good can be targeted by imitators unless it is protected by a patent. While the patent is in effect, a differentiated good producer charges its optimal monopoly price $p_{m}$ and collects instantaneous (per-capita) profit $\pi$ where $\pi=\left(p_{m}-a_{i} w_{i}\right) x_{m}$ and $w_{i}=1 / a_{i}$. Grossman and Lai (2004) focus on patent policies that abide by the non-discrimination principle of national treatment under which each country must offer the same level of patent protection to domestic and foreign innovators. Define country $i$ 's index of patent protection for both domestic and foreign inventors as $T_{i}=\left(1-e^{-\rho \tau_{i}}\right) / \rho$ where $\tau_{i}$ denotes patent length and $\rho$ the rate of time preference. Once the patent for a product expires, it is imitated costlessly in both markets and imitation drives the price of each differentiated good to its competitive level so that the post-imitation profits of an innovator equal zero. The present value of per-capita profits generated by an invention in country $i$ over its lifetime therefore equals $\pi T_{i}$.

Let $C_{m}$ and $C_{c}$ be the instantaneous (per capita) consumer surplus under monopoly and competition respectively, i.e. $C_{m}=h\left(x_{m}\right)-p_{m} x_{m}$ and $C_{c}=h\left(x_{c}\right)-p_{c} x_{c}$. The discounted surplus over the life of a differentiated product enjoyed by a typical consumer in country $i$ equals $C_{m} T_{i}+C_{c}\left(\bar{T}-T_{i}\right)$ where $\bar{T}=\left(1-e^{-\rho \bar{\tau}}\right) / \rho$.

A firm from country $i$ that is successful in innovation earns total profit $\pi M_{i} T_{i}$ in the home market and $\pi M_{j} T_{j}$ overseas. The value of a typical innovating firm from country $i$ therefore equals $v_{i}=\pi P_{i}$, where $P_{i}=M_{i} T_{i}+M_{j} T_{j}$ is the effective global patent protection available to country $i$ 's firms. The first-order condition determining labor demand for R\&D in country $i$ is $v_{i} \partial F_{i}\left(L_{I i}, K_{i}\right) / \partial L_{I i}=w_{i}$. 
Let $\Lambda_{i 0}$ denote the welfare that country $i$ derives from goods invented prior to the implementation of its patent policy. We may then write country $i$ 's national welfare as the sum of $\Lambda_{i 0}$, wages earned by workers in the numeraire sector, the consumer surplus enjoyed by domestic consumers from local goods and imports, and the profits enjoyed by domestic innovators at home and abroad:

$$
W_{i}\left(T_{i}, T_{j}\right)=\Lambda_{i 0}+\frac{w_{i}}{\rho}\left(L_{i}-L_{I i}\right)+\frac{M_{i}\left(\phi_{i}+\phi_{j}\right)}{\rho}\left[C_{m} T_{i}+C_{c}\left(\bar{T}-T_{i}\right)\right]+\frac{\pi \phi_{i}}{\rho}\left(M_{i} T_{i}+M_{j} T_{j}\right)
$$

We are now ready to derive optimal patent policies. Taking $T_{j}$ as given, country $i$ chooses $T_{i}$ to maximize $W_{i}$. The first order condition for this problem yields the best response curve for country $i$ :

$$
C_{c}-C_{m}-\mu_{i} \pi=\gamma \frac{M_{i}}{M_{i} T_{i}+M_{j} T_{j}}\left[\left(C_{m}-C_{c}\right) T_{i}+C_{c} \bar{T}\right]
$$

where $\mu_{i}=\phi_{i} /\left(\phi_{i}+\phi_{j}\right)$ is the proportion of global innovation that occurs in country $i$ and $\gamma=\alpha /(1-\alpha)$ represents the responsiveness of innovation to the value of an innovation in elasticity form. ${ }^{23}$ Given that that the R\&D production function is Cobb-Douglas in nature, it turns out that $\mu_{i}=K_{i} /\left(K_{i}+K_{j}\right)$, i.e., $\mu_{i}$ is determined solely by the relative human capital stocks of the two countries.

To obtain intuition for the first order condition in (5), it is useful to first consider the patent protection policy for a closed economy which can be recovered from (5) by setting $\phi_{j}=0$ and $M_{j}=0$. We have

$$
C_{c}-C_{m}-\pi=\gamma\left[C_{m}+C_{c}\left(\frac{\bar{T}-T_{i}}{T_{i}}\right)\right]
$$

The left hand side of (6) measures the marginal cost of patent protection since it equals the total surplus foregone by prolonging a monopolistic market structure whereas the right hand side measures the social marginal benefit of patent protection that is not

\footnotetext{
${ }^{23}$ Suppressing the country subscript, the first order condition for allocation of labor to R\&D yields $d v / d L=-F_{L} / v F_{L L}$. Using this relationship, the elasticity of innovation with respect to the value of an innovation $\gamma$ can be written as $\gamma=-F_{L}^{2} / \phi F_{L L}$. Since $F=A\left[L / a_{i}\right]^{\alpha}(K)^{1-\alpha}$ we have $\gamma=\alpha /(1-\alpha)$.
} 
taken into account by inventors: during the duration of the patent $\left(T_{i}\right)$, the additional surplus generated by a newly invented variety equals $C_{m}$ whereas for the rest of the useful life of the product (which equals $\bar{T}-T_{i}$ ) it increases to $C_{c}$. The parameter $\gamma$ on the right hands captures the additional innovation induced by strengthening patent protection. As can be seen from (6), the optimal degree of patent protection for a closed economy increases with the useful life of a product, the patience of consumers, and the responsiveness of innovation to patent protection. ${ }^{24}$

It is now easy to see how and why incentives for patent protection of an open economy differ from those of a closed economy. Comparing (5) and (6), first note that since $0<\mu_{i}<1$ the marginal cost of patent protection for an open economy is higher than that of a closed economy. This is because the profits earned by foreign innovators do not enter into a country's welfare calculus. Reinforcing this is the fact that the marginal benefit of patent protection is lower for an open economy since it has a weaker ability to stimulate innovation owing to the fact that the profits earned by innovators in the foreign market depend upon the degree of patent protection available there. This latter effect introduces interdependence between the patent protection policies of the two countries. Since the benefits of innovation accrue to consumers world-wide while the costs of patent protection depend upon a country's own patent protection policy, each country would prefer the other to provide stronger patent protection thereby itself bearing less of the deadweight cost of patent protection while sharing equally in the benefits of any resulting innovation. ${ }^{25}$ As a result of this free-riding incentive, the degree of patent protection of an open economy tends to be lower than that of a closed one. ${ }^{26}$

\footnotetext{
${ }^{24}$ The local market size $M_{i}$ does not appear in (6) since the marginal benefit and marginal cost of additional patent protection are proportional to $M_{i}$. Grossman and Lai (2004) show that if the production function for R\&D is of the CES type, the local market size does play a role in determining a closed economy's patent protection policy via its effect on $\gamma$ (which depends upon $M_{i}$ for the CES case). In the Cobb-Douglas case examined here, $\gamma$ is independent of local market size $M_{i}$.

${ }^{25}$ As we will see below, in the presence of trade costs, the national origin of innovation starts to matter.

${ }^{26}$ While much of the literature makes the assumption that IPR protection is enforced costlessly by
} 
In addition, Grossman and Lai (2004) establish four additional results. First, provided the elasticity of innovation is non-increasing in the value of a patent, national patent protection policies act as strategic substitutes, i.e., an increase in patent protection provided by country $i$ lowers country $j$ 's marginal benefit of patent protection. Second, they show that a larger market offers more patent protection because global innovation is relatively more responsive to its patent policy. Intuitively, if one market is significantly larger in size then its incentives for patent protection are much like those of a closed economy, which generally offers more protection than an open economy. Third, and perhaps most importantly Grossman and Lai (2004) show that even though there is under-protection in Nash equilibrium, the complete harmonization of patent protection across countries (as mandated by TRIPS) is neither necessary nor sufficient for achieving global efficiency. Finally, in a North-South type setting where the North has a larger market size and more human capital than the South, they show that efficient harmonization does call for strengthening patent protection in the South even though this benefits the North at the expense of the South. ${ }^{27}$ Thus, their results show that while TRIPS may have gone too far in requiring international harmonization of patent policies, there does exist a case for increasing patent protection in developing countries.

In a North-South model with quasi-linear preferences, Lai and Qiu (2003) show that

governments, Eicher and Garcia-Peñalosa (2008) explicitly introduce enforcements costs into a Romer (1990) type endogenous growth model. They assume that firms must allocate resources to protect their inventions, much like they do to create them. In such a model, multiple equilibria arise: one featuring a strong level of IPR protection and a high growth rate; another with weak IPR protection and a low growth rate; and a third with no IPR protection and zero innovation (which constitutes a poverty trap).

${ }^{27}$ In similar spirit, Chu et al. (2014) present a distance to frontier type growth model in which the optimal IPR protection for a developing country increases as the local economy closes the gap with respect to the global technology frontier. Chung and $\mathrm{Lu}$ (2014) argue that differences in per-capita income within developing countries imply that they all do not face the same trade-off with respect to IPR protection. Assuming non-homothetic preferences, they show that the incentive for IPR protection on the part of middle-income countries are stronger than those of low-income countries because their consumption basket is similar to that of high-income countries so that they have less need to protect IPRs in order to incentivize innovation targeting their specific needs. Indeed, their model can help account for the U shaped relationship between the degree of IPR protection and per capita income found by Maskus (2000a) and Chen and Puttitanun (2005). 
both regions can gain from a multi-sector agreement that requires the South to harmonize its patent protection policy with that of the North in return for which the North agrees to liberalize its traditional goods market (in which there is no innovation). Lai and Qiu (2003) model these negotiations as a Nash bargaining game where the threat point is such that the South maintains its unilaterally optimal patent length while the North imposes its optimal tariff on Southern exports in the traditional sector. The solution of this bargaining problem depends upon the distribution of bargaining power between the two sides in the usual manner.

Lai and Yan (2013) extend the Grossman and Lai (2004) model by adding three useful features to it: trade and FDI barriers, firm heterogeneity, and a preference for producer profits in the government's objective function that is intended to capture the influence of political economy forces on patent protection policies. They perform a calibration exercise in a multi-country setting which shows that, in their amended model, even requiring all countries to harmonize their patent protection levels to that of the US does not lead to over-protection of IPRs in the global economy because the magnitude of

the free-riding problem increases with the number of countries (so that a two country North-South type model may very well understate the true extent of the under-protection problem in the global economy).

\subsection{Is there a case for non-discrimination?}

The model of Grossman and Lai (2004) can be fruitfully extended to examine the implications of the non-discrimination constraint on patent policies imposed by the national treatment clause of TRIPS. While Grossman and Lai (2004) only examine nondiscriminatory patent policies, Geng and Saggi (2015b) allow countries to discriminate between domestic and foreign firms by implementing patent protection levels that depend upon the national origin of firms. They first derive equilibrium patent policies under discrimination and then impose the national treatment constraint on each coun- 
try to see how it affects the equilibrium outcome and welfare. My discussion below follows their approach.

First suppose international trade is not subject to any barriers or frictions so that, all else equal, patent protection abroad is just as valuable to firms as patent protection in their domestic markets. As we will see below, the presence of trade barriers breaks this equivalence which, in turn, has important implications for the nature of equilibrium policies and welfare.

Let $T_{i i}$ and $T_{i j}$ denote the degree of patent protection country $i$ grants to local and foreign innovators respectively. Following the discussion in section 3.1, the first order condition determining country $i$ 's domestic patent protection $T_{i i}$ can be written as:

$$
C_{c}-C_{m}-\pi=\frac{\gamma M_{i}}{M_{i} T_{i i}+M_{j} T_{j i}}\left[\left(C_{m}-C_{c}\right) T_{i i}+C_{c} \bar{T}\right]
$$

Equation (7) describes country $i$ 's best response $T_{i i}$ to the degree of patent protection that country $j$ extends to country $i$ 's firms $\left(T_{j i}\right)$. Since $C_{m}-C_{c}<0$, it is easy to see from (7) that $T_{i i}$ varies inversely with $T_{j i}$ : country $i$ 's reduces the patent protection it grants to local firms if they start to receive more protection from the other country. Thus, even under discrimination, patent policies act as strategic substitutes for one another. Observe, however, that a change in country $j$ 's domestic protection $\left(T_{j j}\right)$ has no direct effect on country $i$ 's decision regarding how much protection to grant to its domestic firms $\left(T_{i i}\right)$. This is not the case under national treatment since a country cannot choose its domestic and foreign patent policies separately.

Similarly, the best response curve for country $i$ 's foreign patent protection, $T_{i j}$, can be written as

$$
C_{c}-C_{m}=\frac{\gamma M_{i}}{M_{i} T_{i j}+M_{j} T_{j j}}\left[\left(C_{m}-C_{c}\right) T_{i j}+C_{c} \bar{T}\right]
$$

Note from the above equation that country $i$ 's marginal cost of strengthening foreign protection $T_{i j}$ is not mitigated by the per-capita flow profit $\pi$, because the monopoly profits of foreign innovators do not affect country $i$ 's welfare. It follows that a country's 
marginal cost of foreign patent protection is always larger than that of domestic protection, which provides it an incentive to implement discriminatory patent policies. Thus, the first key result is simply that national treatment is a binding constraint for governments: in its absence, each country has an incentive to discriminate against foreign firms so that $\Delta T_{i}^{*} \equiv T_{i i}^{*}-T_{i j}^{*}>0 .{ }^{28}$

It turns out that when countries implement discriminatory patent policies, the effective patent protection available to firms in the global economy does not depend upon their national origin: i.e. $P_{i}^{*}=M_{i} T_{i i}^{*}+M_{j} T_{j i}^{*}=P_{j}^{*}=M_{i} T_{i j}^{*}+M_{j} T_{j j}^{*}$. A direct implication of this result is that the relative degree of discrimination $\left(\Delta T_{i}^{*} / \Delta T_{j}^{*}\right)$ practised by a country is inversely proportional to its relative market size $\left(M_{i} / M_{j}\right)$. This suggests that larger countries ought to be less opposed to non-discrimination rules.

Observe from the relevant first order conditions (5), (7), and (8) that country $i$ 's marginal cost of patent protection under national treatment is strictly bound by in the marginal costs of granting patent protection to domestic firms and foreign firms under discrimination: $C_{c}-C_{m}-\pi<C_{c}-C_{m}-\mu_{i} \pi<C_{c}-C_{m}$. Thus, national treatment forces each country into a scenario where the marginal cost of patent protection is a weighted average of the marginal costs associated with the discriminatory protection levels accorded to domestic and foreign firms. As a result, under national treatment each country selects a level of patent protection that exceeds the protection it grants to foreign firms under discrimination but falls short of that which it gives to its domestic firms: $T_{i j}^{*}<T_{i}^{N T}<T_{i i}^{*}$.

However, Geng and Saggi (2015b) show that despite such discrimination, the effective global protection available to firms as well as global welfare under national treatment turns out to be the same as that under discrimination: $P_{i}^{N T}=M_{i} T_{i}^{N T}+M_{j} T_{j}^{N T}=P_{i}^{*}$.In

\footnotetext{
${ }^{28}$ Aoki and Prusa (1993) examine the effects of alternative standards of intellectual property protection in a one-shot $R \& D$ game where higher $R \& D$ expenditures increase the probability of a successful innovation. They show that discriminatory protection regimes increase domestic innovation while lowering foreign innovation (relative to a non-discriminatory patent regime).
} 
other words, what each firm gains in terms of protection abroad if discrimination is replaced by national treatment is exactly offset by what it loses at home so that effective global protection facing firms remains unaffected. Since a firm's incentive for innovation depends upon the level of effective global protection available to it, both national treatment and discrimination yield the same the rate of innovation and aggregate global welfare provided goods can be traded freely so that innovating firms profit equally from domestic and foreign markets.

Intuition suggests that this welfare invariance result may not be robust to the presence of trade barriers. To investigate this issue, let the degree of trade openness between countries by $\theta$, where $0 \leq \theta \leq 1$ and $\theta=1$ represents free trade while $\theta=0$ indicates prohibitive trade barriers. In the presence of trade barriers, the consumer surplus derived from a patented import equals $\theta C_{m}$ and the export profits of a typical firm equal $\theta \pi .{ }^{29}$ The overseas profit earned by a firm from country $i$ equals $\theta \pi M_{j} T_{j i}$ so that the presence of trade frictions $(\theta<1)$ makes patent protection in export markets relatively less valuable for firms than protection in their domestic markets.

How do trade frictions affect incentives for discrimination? Geng and Saggi (2015b) show that a reduction in trade barriers reduces the incentive to discriminate against foreign firms and that bilateral trade liberalization increases the degree of effective global patent protection in both countries, i.e., $\frac{\partial P_{i}^{*}(\theta)}{\partial \theta}>0$ where $P_{i}^{*}(\theta)=M_{i} T_{i i}^{*}(\theta)+\theta M_{j} T_{j i}^{*}(\theta)$. Furthermore, trade barriers make each country's patent protection towards foreign firms less effective in inducing innovation abroad. However, by forcing countries to treat domestic and foreign firms in a non-discriminatory manner, national treatment blunts the effectiveness of patent protection for incentivizing innovation so that, in equilibrium, the effective degree of protection is lower when countries cannot discriminate against

\footnotetext{
${ }^{29}$ Lai and Yan (2013) show that this formulation of trade costs can be explicitly derived by assuming (i) a CES type demand function $h(x)=\zeta^{1 / \varepsilon} \frac{\varepsilon}{\varepsilon-1} x^{\frac{\varepsilon-1}{\varepsilon}}$ where $\varepsilon>1$ and $\zeta>0$ and (ii) ice-berg type trade barriers. Under these assumptions, Lai and Yan (2013) show that trade liberalization helps alleviate the problem of under-protection in Nash equilibrium.
} 
foreign firms. Thus, somewhat paradoxically, in the presence of trade barriers allowing countries to discriminate against foreign nationals with respect to patent protection actually leads to more innovation in the global economy. Indeed, it is straightforward to establish that in the presence of trade barriers (i.e. $\theta<1$ ), social optimality calls for each country to discriminate against foreign firms. ${ }^{30}$ Thus, in the presence of trade barriers, not only the level of patent protection but also its composition matters for global innovation and welfare.

Scotchmer (2004) develops a simple partial equilibrium model to investigate the incentives countries have for adopting national treatment (both unilaterally and on a reciprocal basis). Assuming national treatment increases incentives for innovation, Scotchmer (2004) shows that a country would find it beneficial to grant national treatment to foreign innovators if the benefits of additional innovation induced by doing so exceed the loss in consumers' surplus suffered on each invention. While much of the literature on IPR protection ignores the fact that a substantial share of the R\&D in the US and OECD countries is government sponsored, Scotchmer (2004) argues that ignoring the public investment in $R \& D$ is problematic since an important aspect of economic efficiency - i.e. the appropriate mix of private and public R\&D - goes unaddressed. In other words, in the face of no patent protection, the alternative to private investment might be public investment as opposed to no investment, which is the maintained assumption of much of the literature. Incorporating public R\&D investment in the model, Scotchmer (2004) shows that the welfare effects of harmonization are ambiguous. An interesting result of her analysis is that harmonization can lead an innovation to be protected in both markets even though protection in a single market is efficient (in the sense of providing an optimal incentive for innovation).

While historically countries could implement rules and regulations that explicitly

\footnotetext{
${ }^{30}$ Bond (2005) has shown that it can be socially efficient to internationally discriminate with respect to patent protection if the elasticity of innovation with respect to patent protection differs across countries.
} 
discriminated against foreign innovators, this is no longer permitted under TRIPS. ${ }^{31}$ However, even today discrimination can arise in the granting of IPRs as well as in their enforcement via local courts. In a recent paper, Webster et al. (2014) present convincing evidence that patent examination outcomes at the European and Japanese patent offices are systematically biased against foreign patent applicants. As they correctly note, one cannot infer the presence of discrimination merely from a lower propensity to grant foreign patent applications on the part of a country since the quality of patent applications filed across various national patent offices can differ. However, this problem does not plague their analysis since it is based on a matched sample of 47,947 patent applications at the European and Japanese patent offices during 1990-1995. ${ }^{32}$ Their major finding is that, all else equal, both in Europe and Japan, domestic inventors are more likely to receive a patent: in their fixed effects linear probability model, the applications with a domestic inventor are 10 percentage points more likely to be granted whereas in their fixed effects logit model, the corresponding probability difference is 17 percentage points. Furthermore, they find the domestic bias to be stronger in areas of technological specialization of the domestic economy.

\section{North-South models of technology transfer}

A fairly well-developed strand of the relevant literature - i.e. that which develops NorthSouth product cycle models of international trade and technology transfer - motivates differences in incentives for patent protection on the part of developing and developed countries by assuming that innovation is concentrated in the North (so that the South has a strong incentive to permit imitation). This literature investigates how the degree of

\footnotetext{
${ }^{31}$ According to Lerner (2002), discrimination against foreign patent applications was quite common during the mid 19th century through-out the world. Discriminatory measures used against foreign inventors included shorter duration of patents, higher application fees, shorter extensions and premature patent expirations. See also Goldstein (2001).

${ }^{32}$ They are unable to test for the presence of discrimination in the US since they do not observe patent applications refused by the USPTO.
} 
patent protection in the South affects trade, FDI, innovation, and welfare. An important distinguishing feature of this literature is that it considers the effects of marginal changes in Southern patent protection as opposed to an outright harmonization of international patent protection.

The product cycle literature builds on two types of growth models analyzed in great detail in Grossman and Helpman (1991a) - the variety expansion model and the quality ladders model. Since the literature utilizing the variety expansion approach has greater continuity and because the analytical approaches underlying the two frameworks are rather similar, I discuss this literature in depth and provide a relatively brief discussion of the quality ladders approach.

\subsection{Variety expansion approach}

The classic paper by Vernon (1966) cast the standardization of production technology as the driving force behind the international product cycle. Vernon (1966) started with the observation that most goods were invented in richer/bigger markets and argued that once the production technology for a new good has gone through sufficient refinement and standardization, the incentive to lower production costs leads firms to establish overseas production facilities via FDI so that rich countries eventually end up importing goods that they initially exported, thereby completing the international product cycle. While intuitively appealing, Vernon's conceptualization of the international product cycle has several shortcomings. First, the story is silent on the process of standardization; indeed, this key driving phenomenon is treated essentially as a black box. Second, since standardization generally takes time, it is not clear to what extent Vernon's paradigm applies to newly patented products.

Krugman (1979) provides a crisp formalization of Vernon's story and his analysis sheds light on several important questions that go beyond the scope of Vernon's original paradigm, even though it too treats international technology transfer as an exogenous 
phenomenon. Subsequent product cycle models have made a serious attempt to get inside the black box of technology creation and transfer by modeling them as endogenous phenomena and are therefore particularly relevant for patented products. Nevertheless, since these latter models build on Krugman's simple framework, it is useful to begin with it. In Krugman (1979), "new" goods are invented and produced by the North while "old goods" are produced by the South. By definition, a newly invented good becomes old when its production technology is imitated by the South. Both innovation and imitation occur at exogenously given rates (more on this below). Labor is the only factor of production and region $i$ 's labor supply equals $L^{i}, i=S, N$.

In either region, one unit of labor makes one unit of any good, new or old. The wage rate in region $i$ is denoted by $w^{i}$. All goods are produced under perfect competition and are therefore priced at marginal cost $\left(p^{i}=w^{i}\right.$ where $\left.i=S, N\right)$. Instantaneous utility of a representative consumer is given by

$$
u=\left[\int_{0}^{n} x(j)^{\alpha} d j\right]^{\frac{1}{\alpha}}, 0<\alpha<1
$$

As is well known from the work of Dixit and Stiglitz (1977), this utility function exhibits love of variety: all else equal, an increase in the number of varieties makes consumers better off. Static utility maximization implies

$$
\frac{x(i)}{x(j)}=\left[\frac{p^{i}}{p^{j}}\right]^{-\varepsilon}=\left[\frac{w^{i}}{w^{j}}\right]^{-\varepsilon}
$$

where $\varepsilon=\frac{1}{1-\alpha}>1$ is the elasticity of substitution between any two goods.

Let $n_{i}$ denote the number of goods produced by each region. Then, using the labor market clearing conditions $\left(n_{i} x^{i}=L^{i}\right)$ allows us to write

$$
w^{R} \equiv \frac{w^{N}}{w^{S}}=\frac{p^{N}}{p^{S}}=\left[\frac{L^{S}}{L^{N}} \frac{n_{N}}{n_{S}}\right]^{1 / \varepsilon}
$$

Thus, the relative wage of the North $\left(w^{R}\right)$ increases in the number of goods the North produces relative to the South as well as on the relative size of its labor force. Regarding 
the factors that determine the ratio of number of goods produced by the North relative to the South, Krugman (1979) shows that if the rate of Northern innovation equals $g$ and the rate of Southern imitation equals $\mu$, then in a steady state where each region's share of global production remains fixed, we must have $n_{N} / n_{S}=g / \mu$.

Innovation contributes to output and welfare by generating new goods while imitation does so by shifting production to a lower cost location. At the same time, these processes alter the distribution of global income. Since the relative price of new goods equals the Northern relative wage, an increase in the rate of imitation or a decrease in the rate of innovation worsens the North's terms of trade. ${ }^{33}$ To the extent stronger IPR protection in the South slows down imitation and/or increases innovation, it increases the Northern relative wage. Though Southern workers experience a decline in real income when the rate of innovation increases, because variety is valuable both regions gain from an increase in innovation. ${ }^{34}$

Though it provided several novel insights, Krugman's (1979) model of international technology transfer took the most important phenomenon of interest - the rates of innovation and imitation - to be exogenously given. As a result, the model is not capable of shedding light on the incentives of various agents involved in these processes. Grossman and Helpman (1991b) undertook the important step of endogenizing both imitation and innovation, thereby providing a more satisfactory framework for answering the questions at hand. While static consumer preferences in Grossman and Helpman (1991b) are the same as in Krugman (1979), consumers maximize lifetime utility where the instantaneous utility function is given by (9). The optimal spending rule allocating

\footnotetext{
${ }^{33}$ Since both imitation and innovation are exogenous in Krugman's model, they can move independently of each other.

${ }^{34}$ Antràs (2005) develops a North-South product cycle model where the incompleteness of international contracts determines the choice between arms length technology transfer and FDI. His analysis shows that the effects of changes in the rate of technological standardization on the North-South relative wage are quite different from those of changes in the rate at which new goods appear. This suggests that the effects of Southern IPR protection on wages in the two regions might also vary with the type of technological change being considered.
} 
aggregate expenditure $E$ over time obeys $\dot{E} / E=r-\rho$ so that in steady state $(\dot{E}=0)$ we have $r=\rho$.

Given that the market structure is monopolistically competitive, the optimal price of a typical innovating firm equals $p^{N}=w^{N} / \alpha$ with the associated post innovation profits $\pi^{N}=(1-\alpha) p^{N} x^{N}$. The pricing behavior of a Southern firm that is successful in imitation depends upon the North-South wage gap. When $w^{S} \leq \alpha w^{N}$, a successful imitator can charge its optimal monopoly price $p^{S}=w^{S} / \alpha$ and still undercut the Northern firm whose product it has copied; whereas when $w^{S}>\alpha w^{N}$ it must charge the limit price $\alpha w^{N}$. In what follows, I focus on the former case. Given this, the profits earned by a successful Southern imitator equal $\pi^{S}=(1-\alpha) p^{S} x^{S}$.

Both imitation and innovation require deliberate investments on the part of firms. Development of a new variety requires $a_{N} / K_{N}$ units of labor where $a_{N}$ measures productivity of R\&D and $K_{N}$ measures North's knowledge stock. For simplicity, I assume $K_{N}=n$. This assumption embeds inter-generational knowledge spillovers into the model and plays a crucial role in sustaining steady-state growth in the long run. Imitation of a variety requires $k a_{I} / K_{S}$ units of labor where $a_{I}$ measures productivity of R\&D and $K_{S}=n_{S}$ measures South's knowledge stock and $k$ is an index of Southern patent protection - the higher is $k$, the more costly is imitation. ${ }^{35}$

The steady state value of an imitator equals $v^{S}=\pi^{S} /(\rho+g)$ while that of an innovator equals $v^{N}=\pi^{N} /(\rho+g+\mu)$, where $g \equiv \dot{n} / n$ is the rate of innovation and $\mu \equiv \dot{n}_{S} / n_{N}$ the rate of innovation, i.e., i.e. at any given instant, of the $n_{N}$ goods produced by the North $\mu n_{N}$ of them are imitated by the South. Observe that when calculating firm values, the flow profit of imitators is discounted not just by the interest rate (which equals the discount rate in steady state) but also the rate of innovation since future

\footnotetext{
${ }^{35}$ Note that if an increase in $k$ slows down the rate of imitation, it effectively means that innovators enjoy their profit streams for a longer time period. Thus, $k$ is reasonable proxy for the strength of patent protection in the South.
} 
products compete with existing ones (i.e. no products ever disappear). In addition to these factors, innovators also face the risk of imitation. Free entry into imitation requires $v^{S}=w^{S} k a_{I} / n_{S}$ i.e. the value of imitating a good equal the up-front cost of doing so. Similarly, we have $v^{N}=w^{N} a_{N} / n$.

To solve for the steady state equilibrium, we need to account for the labor market constraints in each region. In the South, at each instant $n_{S} x^{S}$ workers are allocated to production and $k a_{I} n / n_{S}$ to imitation. Similarly, in the North $\dot{n} a_{N} / n$ workers are allocated to innovation and $n_{N} x^{N}$ to production. Let $\sigma \equiv n_{N} / n$ measure the fraction of goods produced in the North and consider a steady state equilibrium where $\sigma$ is constant. As in Krugman (1979), $\sigma=g /(g+\mu)$ in steady state except that both $g$ and $\mu$ are now determined within the model. ${ }^{36}$ Using the labor market equilibrium conditions for the two regions $k a_{I} n / n_{S}+n_{S} x^{S}=L^{S}$ and $\dot{n} a_{N} / n+n_{N} x^{N}=L^{N}$ and the long-run equilibrium conditions for imitation and innovation allows us to write the Northern labor market equilibrium condition in steady state as

$$
\frac{(1-\alpha)\left(L^{N} / a_{N}-g\right)}{\alpha g /(g+\mu)}=g+\mu+\rho
$$

It is straightforward to show that along this curve, we have $\partial g / \partial \mu>0$ : in other words, there is a positive feedback between imitation and innovation. Similarly, in the South we must have

$$
k a_{I} g+\frac{k a_{I} \alpha(\rho+g)}{(1-\alpha)}=L^{S} \Leftrightarrow g=(1-\alpha) L^{S} / k a_{I}-\alpha \rho
$$

We can now assess the affects of strengthening patent protection in the South on the steady state equilibrium. Suppose the degree of patent protection in the South (i.e. $k$ ) increases. Observe immediately from equation (13) that the Northern rate of innovation (g) necessarily decreases. Given the positive feedback between imitation and innovation

\footnotetext{
${ }^{36}$ In steady state $g \equiv \frac{\dot{n}}{n}=\frac{n_{N}}{n_{N}}=\frac{n_{S}}{n_{S}}$.
} 
implied by (12), it follows that the Southern rate of imitation also decreases. Furthermore, as in Krugman (1979), it turns out that the Southern share of global production as well as the Southern relative wage fall due a strengthening of Southern IPR protection.

Building on these results, Helpman (1993) provides a comprehensive welfare analysis of changes in the degree of Southern IPR protection (modeled as a decline in an exogenously given rate of imitation). In order to examine welfare along the transition path, and not just the steady state, Helpman considers several simplified variants of product cycle models that are useful for highlighting the various channels via which Southern patent protection affects welfare. In his first cut, Helpman provides a welfare analysis of a slightly modified version of Krugman (1979) where the product market in the North is characterized by monopolistic competition as opposed to perfect competition. As in Krugman (1979), it turns out that

$$
\frac{p^{N}}{p^{S}}=\left[\frac{L^{S}}{L^{N}} \frac{n_{N}}{n_{S}}\right]^{1 / \varepsilon}
$$

which implies that the North's terms of trade improve as Southern patent protection is strengthened since the North's share of global production increases. The second major channel via which welfare of the two regions is affected is that an increase in the share of goods produced by the North hurts consumers in both regions since $p^{N}>p^{S}$. In fact, the overall consumer price index can be written as

$$
P=\int_{0}^{n} p(j)^{1-\varepsilon} d j=n^{\frac{1}{1-\varepsilon}}\left[\sigma\left(p^{N}\right)^{1-\varepsilon}+(1-\sigma)\left(p^{S}\right)^{1-\varepsilon}\right]^{\frac{1}{1-\varepsilon}}
$$

so that $P$ increases with $\sigma$.

An important conclusion of Helpman's analysis is that a tightening of Southern patent protection hurts the South through both channels: not only do its terms of trade worsen, real spending (and therefore) flow of utility also decline due to an increase in the price index $P$. As is clear, from the perspective of the North, the two effects work against each other. Helpman shows that provided the rate of imitation is not too high, 
a tightening of Southern patent protection also hurts the North. In other words, a little bit of imitation is good for both sides. Observe that in a typical North-South product cycle model, as long as imitation does not occur a newly invented good continues to be produced by the innovating firm. Thus, the result that the North also benefits from some degree of imitation is another way of stating that it is optimal to grant monopoly power to innovators for only a limited time duration, a finding that is at the core of the literature on optimal patent protection discussed in section 3.1.

Helpman (1993) also finds that there exist a range of feasible imitation rates for which a reduction in the rate of imitation benefits the North at the expense of the South. Next, Helpman (1993) shows that expanding the model to allow for endogenous innovation along the lines of Grossman and Helpman (1991b) does not materially affect these conclusions since the rate of innovation rises only temporarily when Southern patent protection is tightened; the long run effect on innovation is actually negative, as it is in Grossman and Helpman (1991b).

An important assumption of all of the variants of product cycle models that have been discussed thus far is that North-South technology transfer occurs only via imitation. In the real world, Northern innovators often transfer technologies internationally via FDI. Indeed, as Table 6 indicates, the share of global stock of FDI residing in developing countries has increased substantially over the last few decades. Helpman (1993) incorporates FDI in his analysis under the assumption that both imitation and innovation are exogenously given and that the risk of imitation facing multinationals is the same as that faced by firms that produce in the North. In such a set-up, FDI leads to wage equalization across the two regions (or else firms would prefer to produce in only one region). Given that $p^{N}=w^{N} / \alpha$ and $p^{S}=w^{S}$, wage equalization implies that the North-South terms of trade are unaffected by changes in Southern patent protection in the presence of FDI $\left(p^{N} / p^{S}=1 / \alpha>1\right)$. But the South continues to lose from stronger patent protection due to an increase in the price index $P$. Accommodating FDI does not 
alter the effect of stronger Southern patent protection on the North: provided the rate of imitation is not too high, stronger patent protection in the presence of FDI makes the North better off since Northern income increases due to an expansion in the number of multinationals (who earn profits in the product market).

Lai (1998) builds on Grossman and Helpman (1991) by allowing FDI in an environment where the risk of imitation faced by multinationals differs from that faced by firms that produce in the North. As in Helpman (1993), Lai considers the effect of stronger patent protection in the South by treating it as a reduction in an exogenously given rate of imitation. An important contribution of his paper is to compare the effects of Southern patent protection across two scenarios: one where technology transfer occurs only via imitation - as it does in Grossman and Helpman (1991b) - and another where it occurs only via FDI. In order to capture the intuitive idea that geographical proximity facilitates imitation, Lai assumes that only multinationals can be imitated by Southern firms. Given this assumption, the value of a multinational firm equals $v^{M}=\pi^{M} /(\rho+g+\mu)$ where $\pi^{M}=(1-\alpha) p^{M} x^{M}$ where $p^{M}=w^{S} / \alpha$. Similarly, the value of a firm that produces in the North equals $v^{N}=\pi^{N} /(\rho+g)$ where $\pi^{N}=(1-\alpha) p^{N} x^{N}$ where $p^{N}=w^{N} / \alpha$. Since any Northern firm can undertake FDI, we must have $v^{N}=v^{M}$. After some manipulation, this equality yields

$$
w^{R}=\left[1+\frac{\mu}{\rho+g}\right]^{\frac{1}{\varepsilon-1}}
$$

Observe from equation (16) that if the Southern rate of imitation increases, the relative wage of the North falls - a finding which is in direct contrast to Grossman-Helpman (1991b). In addition, Lai (1998) finds that when FDI is only channel of international technology transfer, the rate of Northern innovation increases when the rate of imitation declines, a finding that confirms the common intuition that imitation is bad for innovation. However, Lai (1998) derives this negative relationship between imitation and innovation by assuming that the rate of imitation is exogenously given, whereas 
Grossman and Helpman (1991b) and Helpman (1993) argue convincingly that imitation requires costly investments much like innovation.

In a recent contribution, Branstetter and Saggi (2011) build on Lai (1998) by endogenizing Southern imitation. Like Lai, they assume that Southern imitation only targets multinationals. Furthermore, in order to provide Southern imitators an incentive to imitate multinationals (who produce in the same location as them and therefore face the same wage rate for workers), they assume that a multinational needs $\theta \geq 1$ workers per unit of output to produce in South whereas local imitators need only one worker per unit of output. Intuitively, this assumption reflects the idea that multinationals operate in a unfamiliar environment relative to Southern firms. Indeed, the theory of the multinational enterprise argues that such firms rely on 'ownership' advantages derived from technological assets and/or brand names in order to offset the disadvantages they face relative to local firms - see Markusen (1995) and Antràs and Yeaple (2014). The optimal price of a multinational is $p^{M}=\theta w^{S} / \alpha$. When $\theta>1$, the marginal cost of Southern imitators lies below that of multinationals, and this provides them with an incentive to engage in costly imitation. If successful in imitating a multinational, a Southern firm charges can charge its optimal price $p^{S}=w^{S} / \alpha$ provided $p^{S}<\theta w^{S} \Leftrightarrow \theta \alpha>1$, an inequality that is assumed to hold in what follows. ${ }^{37}$

In Branstetter and Saggi (2011), a strengthening of patent protection in the South (modeled as an increase in the cost of imitation) reduces the incentive of Southern firms to imitate multinationals, which in turn has two important consequences for production and innovation in the global economy. First, the South becomes a more attractive production location from the viewpoint of Northern firms so that the steady state number of multinationals $n_{M}$ increases while the number of Southern imitators $n_{I}$ decreases. ${ }^{38}$

\footnotetext{
${ }^{37}$ When this inequality fails, the imitator engages in limit pricing by setting its price equal to $\theta w^{S}$, which is the marginal cost of the multinational it imitates.

${ }^{38}$ It is worth noting here that product cycle models generally ignore strategic considerations that arise in oligopolistic models and when these are accounted for, a decline in imitation risk does not
} 
Second, since all Northern firms are free to locate production in the South, an increase in the value of a typical multinational firm strengthens Northern incentives for innovation since the value of a typical Northern firm that does not produce in the South also increases. They also show that the intra-regional reallocation of Southern production (from imitators to multinationals) that results from a strengthening of Southern patent protection is more than offset by the accompanying inter-regional reallocation of production (from Northern firms to multinationals) so that the South's share of the global basket of goods $\left(n_{M}+n_{I}\right) / n$ actually increases. Furthermore, by making the South a more attractive location for production and thereby shifting aggregate labor demand from the North to the South, a strengthening of patent protection in the South lowers the Northern relative wage. ${ }^{39}$ It is worth emphasizing the role FDI plays in this context: in the absence of FDI, in a variety expansion product cycle model such as Grossman and Helpman (1991b), the Northern market labor constraint is actually upward sloping in the $(g, \mu)$ space, i.e., there is a positive relationship between imitation and innovation. This is because when imitation is the only channel via which production is reallocated from the North to the South, an increase in the rate of imitation frees up Northern labor for use in innovation. By contrast, when imitation targets multinationals, it reduces FDI and an increase in the rate of imitation actually reallocates Northern resources from innovation to production, resulting in a lower rate of innovation.

Since multinationals charge lower prices relative to firms that produce in the North (i.e. $p^{M}<p^{N}$ ), the increase in FDI that results from stronger patent protection in the South helps lower the overall price index $P$ which, owing to the fact that multinationals

always lead to more FDI. For example, in the duopoly model of Lin and Saggi (1999) where firms make decisions on the timing of their switch from exporting to FDI, by delaying its rival's switch, an increase in imitation risk can make it more attractive for the leading firm to undertake FDI.

${ }^{39}$ Thus, their result contrasts with those of Krugman (1979) and Grossman and Helpman (1991b) but are in line with those of Lai (1998). As noted above, these results differ because imitation targets multinationals in Branstetter and Saggi (2011) and Lai (1998) whereas it targets Northern producers in the other two models. 
charge different prices than Southern imitators, is now written as

$$
P=n^{\frac{1}{1-\varepsilon}}\left[\frac{n_{M}}{n}\left(p^{M}\right)^{1-\varepsilon}+\frac{n_{I}}{n}\left(p^{S}\right)^{1-\varepsilon}+\frac{n_{N}}{n}\left(p^{N}\right)^{1-\varepsilon}\right]^{\frac{1}{1-\varepsilon}}
$$

However, this beneficial effect on prices is partially offset by the intra-regional reallocation of Southern production from local imitators to multinationals since a typical multinational charges a higher price than an imitator. Due to the nature of pricing behavior under Dixit-Stiglitz (1977) preferences (prices are mark-ups over marginal costs), these changes in prices and nominal wages translate into clear-cut effects on real wages in the two regions: while Northern real wages decline due to stronger Southern IPR protection, Southern real wages increase. More specifically, the purchasing power of Southern workers in terms of Northern goods increases whereas their ability to purchase goods produced by imitators and multinationals remains unaffected due to IPR reform.

One factor likely to be important in determining the overall effect of TRIPS on multinational activity and technology transfer is the variation in imitation risk across industries, something that all of the models discussed above neglect. For example, it is well recognized that patent protection is crucial for the pharmaceutical industry because the cost of imitation in this industry is minuscule relative to the cost of innovation. On the other hand, developing countries have found it extremely difficult, if not outright impossible, to imitate complex manufactured goods such as machinery and transport equipment even though local IPR policy (prior to TRIPS) hardly prevented them from doing so. Motivated by this idea, Ivus et al. (2015a) develop a simple general equilibrium North-South model in which industries differ with respect to their technological complexity and therefore in the risk of imitation faced by them. Firms in each industry produce horizontally differentiated products and the number of products grows exogenously over time.

In their model, a Northern firm wishing to sell in the South chooses between $(i)$ producing in the North; (ii) establishing a fully owned subsidiary in the South by un- 
dertaking FDI; or (iii) licensing its proprietary technology to an arm's-length Southern firm. Each of these options has its pros and cons. Confining production to the North eliminates the risk of imitation but precludes the cost savings arising from lower wages in the South. FDI lowers production costs due to lower Southern wages but it also exposes the firm to the risk of imitation. Finally, arm's length licensing avoids both the costs of establishing a subsidiary and the higher wage in the North, but requires profit sharing with the licensee while also carrying the highest risk of imitation.

Ivus et al. (2015a) show that a strengthening of IPR protection in the South (modeled as a reduction in the risk of imitation) affects technology transfer in two ways. First, within each industry, total multinational production carried out via licensing and FDI increases at the expense of imitated production controlled by Southern firms. This within-industry reallocation is strongest in industries whose products are easiest to imitate. Second, the total number of industries that engage in multinational activity increases. This increase in the extensive margin of multinational activity is primarily driven by more industries choosing to engage in licensing. In fact, the set of industries in which multinational production occurs via wholly-owned subsidiaries does not necessarily increase and can even shrink. ${ }^{40}$ In a follow up paper, using data on multinational activities of US firms, Ivus et al. (2015b) provide an empirical verification of these predictions.

While the product cycle models discussed above are susceptible to the "scale effects" critique of Jones (1995), it is relatively straightforward to modify them to remove such effects. For example, Gustaffson and Segerstrom (2010) present a North-South model of variety expansion with diminishing returns in $R \& D$ where the cost of developing a new product variety equals $a_{N} / n^{\theta}$ where $\theta<1$ so that the cost of innovation decreases

\footnotetext{
${ }^{40}$ This result fits quite well with the argument that the incentive to internalize transactions by establishing a wholly owned subsidiary declines when market exchange of technology becomes more secure - see Markusen (1995, 2001) and Ethier and Markusen (1996).
} 
with the number of products at a decreasing rate. Growth is sustained by allowing for an exogenous expansion in the labor force over time. Gustaffson and Segerstrom (2011) build on this framework by allowing for North-South FDI where technology transfer requires affiliates to make costly investments in adaptive $R \& D$. They show that stronger IPR protection in the South (modeled as a decrease in the exogenously given rate of imitation) increases adaptive $R \& D$ by affiliates as well as the rate of technology transfer within multinational firms.

\subsection{Quality ladders approach}

In the quality ladders approach to product cycles developed by Grossman and Helpman (1991c) and further elaborated upon in Grossman and Helpman (1991a), consumers choose from a continuum of products indexed by $j \in[0,1]$. A representative consumer's utility function is given by

$$
\log u_{i}(t)=\int_{0}^{1} \log \sum_{m} \lambda^{m} x_{i m}(j, t) d j
$$

where $x_{i m}(j, t)$ is consumption by consumers from country $i$ of quality level $m$ of product $j$ at time $t$. Quality level $m$ of product $j$ equals $q_{m}(j) \equiv \lambda^{m}$. By definition, newer generations of a product are better than the old: $q_{m}(j)>q_{m-1}(j) \rightarrow \lambda^{m}>\lambda^{m-1}$. All products start at time $t=0$ at quality level $m=0$, so the base quality is $q_{0}(j)=\lambda^{0}=1$. Since consumers are willing to pay a premium for quality, Northern firms invest in improving the quality of existing products. Owing to their cost advantage in production, Southern firms imitate Northern products. In product cycle models based on variety expanding innovation, once a product has been imitated by the South it is forever produced there. By contrast, in the quality ladders framework, once a Northern firm innovates over an existing quality level that has been imitated by the South, production of the newest vintage occurs in the North till it too is imitated. Thus, production reverts back and forth between the two regions depending upon whether the latest vintage of a 
product has been imitated by the South or not.

How does stronger patent protection in the South affect the rate of innovation and imitation? The answer to this key question turns out to depend upon whether innovation in the North is conducted by firms who developed the most recent quality improvement (leaders) or by others (followers). One might imagine that, owing to their experience in having successfully designed the current highest quality level, leaders enjoy a cost advantage in further improving quality. In this case of "inefficient followers", the relationship between imitation and innovation mirrors that of the variety based product cycle model of Grossman and Helpman (1991a): both decline with stronger IPR protection. However, when followers conduct quality improving R\&D as opposed to leaders, while the rate of innovation decreases with stronger patent protection in the South, the rate of imitation can increase or decrease (Grossman and Helpman, 1991c).

Glass and Saggi (2002a) incorporate FDI into the quality ladders product cycle model of Grossman and Helpman (1991c). Their model is unique in that it allows for two types of endogenous imitation: one type targets firms that produce in the North while the other targets multinationals producing in the South. They assume that targeting multinationals is cheaper than targeting Northern firms. This assumption reflects the idea that moving production in close proximity to Southern firms lowers the cost of imitation because Southern firms can more easily learn about the production techniques of multinationals than those of Northern firms. For example, a Southern firm targeting a multinational's product can hire away some of the multinational's workers, spy on the multinational's production facilities or use similar means of acquiring information that are more feasible with proximity. ${ }^{41}$ Also, any modifications that multinationals make to their production technologies to make them more suitable for the Southern economic

\footnotetext{
${ }^{41}$ Glass and Saggi (2002b) provide a formal oligopoly model of inter-firm technology transfer via worker mobility from a multinational to its local competitor. In their model, the multinational can prevent labor turnover by paying workers a wage premium.
} 
environment can also help facilitate imitation.

The model of Glass and Saggi (2002a) delivers three major results. First, the imitation exposure of multinationals relative to Northern firms turns out to be independent of the degree of Southern IPR protection: while multinationals become safer from imitation with a strengthening of Southern IPR protection, so do Northern firms. Second, the fraction of North-South technology transfer that occurs through imitation of Northern firms relative to FDI increases with a strengthening of Southern IPR protection. Third, they reconfirm the positive feedback between imitation and innovation found by several earlier studies. A key mechanism underlying their results is that when imitation becomes costlier, aggregate Southern resources allocated to imitation increase so that stronger IPR protection creates a resource crunch in the South and squeezes out FDI. The Southern resource crunch is then transmitted to the North via FDI: a reduction in FDI causes Northern workers to be reallocated from innovation to production thereby reducing innovation.

Glass and Wu (2007) uncover results similar to those of Glass and Saggi (2002a) even for the case where the rate of imitation is exogenously given. They argue that the fact that their findings differ from those of the variety expansion product cycle model of Lai (1998) which also takes imitation to be exogenous suggests that the effects of imitation on innovation may depend upon the nature of innovation: when innovation improves the quality of existing products, the feedback between imitation and innovation is positive whereas when innovation creates new varieties of differentiated products, this feedback is negative. ${ }^{42}$ Furthermore, their analysis together with that of Dinopoulos and Segerstrom

\footnotetext{
${ }^{42}$ Tanaka and Iwaisako (2014) argue that the conclusions of Glass and Wu (2007) hold only if the economy happens to begin in the steady state. They point out that when only industry leaders conduct $R \& D$ (after their product has been imitated), the steady state examined by Glass and Wu (2007) is unstable if neither FDI nor R\&D are subsidized. Allowing for such subsidies generates a stable steady state, the comparative statics of which resemble those of the variety expansion models of Lai (1998) and Branstetter and Saggi (2011). Finally, they find that if imitation is costly then their analysis yields conclusions that match those of Glass and Saggi (2002a). All in all, it appears that the literature has not yet achieved full clarity on why the effects of IPR protection differ so dramatically across different
} 
(2010) clarifies that the Glass and Saggi (2002a) assumption that R\&D is conducted only by industry leaders is not innocuous: when followers also conduct $R \& D$, a decline in the rate of imitation can lead to more innovation even in the absence of FDI. The quality ladders type model of Dinopoulos and Segerstrom (2010) also reinforces an important conclusion of the variety-expanding product cycle models of international trade, i.e., whether North-South technology transfer occurs via imitation of Northern producers or that of multinational firms proves critical in determining the effects of raising IPR protection in the South. In light of the facts discussed in the Introduction of this chapter, it is clear that FDI is a major channel of international technology transfer in the real world; however, whether FDI is more or less important than imitation is difficult to say with confidence since we do not have accurate measures of the extent of imitation that goes on in the world. ${ }^{43}$

To capture the notion of limited absorptive capacity in the South, Glass and Saggi (1998) build a product cycle model in which the South can host high-quality FDI in a product only if indigenous firms have successfully imitated the low quality level of that product. ${ }^{44}$ According to this perspective, there can be a positive dynamic feedback between Southern imitation and FDI: imitation builds technological capacity in the South which in turn allows Northern firms to shift production of state of the art products to the South. As a result of this mechanism, weaker IPR protection in the South makes high-quality FDI more attractive to Northern firms who remain immune from local imitation till the next vintage of their product gets invented in the North. ${ }^{45}$

types of product cycle models.

${ }^{43}$ Yang and Maksus (2001) consider arms length licensing as a source of North-South technology transfer and stronger IPRs in the South are assumed to lower the upfront cost of licensing (perhaps by making it easier to find a suitable local partner) while also increasing the share of rents collected by the licensor. They find that an increase in Southern IPR protection promotes innovation and North-South licensing.

${ }^{44}$ In their model, due to consumer heterogeneity two quality levels of each product sell in equilibrium, so FDI can involve production of high or low quality levels.

${ }^{45}$ While much of the relevant literature focuses on the rate of introduction of new qualities taking the quality increment to be exogenously given, Borota (2012) presents a product cycle model in which the 
Eaton and Kortum (1996) explicitly introduce the patenting decision of inventors into a multi-country variant of the quality ladders model of Grossman and Helpman (1991d). In their model, final output is produced using intermediate inputs subject to a Cobb-Douglas production function. While the range of inputs $J>1$ is fixed, their quality increases over time as a result of inventions. The step size or the quality improvement of an invention is assumed to be a random variable $Q$ drawn from an exponential distribution where $\operatorname{Pr}(Q<q]=1-e^{-\theta q}$ so that the average inventive step or quality improvement equals $1 / \theta$. Each country is assumed to generate a flow of inventions at some given rate and the process of international technology diffusion is captured by another exogenous parameter. The model is designed to focus on the international patenting decisions of inventors and permits an assessment of the degree to which growth in a country is driven by foreign innovations. An attractive feature of the model is that patenting abroad reduces the risk of imitation facing an inventor. Since the value of a patent increases with the quality of the invention and patenting carries a fixed cost, in equilibrium only inventions that exceed a certain quality threshold are worth patenting. ${ }^{46}$ By lowering the risk of imitation, an increase in the degree of patent protection in a country makes it more likely that a particular invention is patented in its market.

Eaton and Kortum (1996) estimate their model using data from 19 OECD countries for 1988. They report the striking result that over $50 \%$ of the growth in each country in their sample was driven by innovation in just three countries: US, Germany, and Japan. This finding points to the significant international spillovers generated by R\&D quality step is endogenous but the rate of innovation is not. In such a setting, stronger IPR protection hampers the South's ability to catch up with the North and can lower welfare in both regions via its affect on the quality improvements undertaken by both regions.

${ }^{46}$ As Eaton and Kortum (1996) note, if patenting were costless it would be optimal for an inventor to seek patent protection in all countries. They highlight two types of patenting costs. First, to be able to patent an invention abroad, the inventor has to publish the specification of the invention in the local language to fulfill the disclosure requirement. Second, a patentee has to pay filing fees as well as agent fees. 
and underscores the need for international coordination over IPR protection. Eaton and Kortum (1996) also find that only a few countries earn significant income from patented inventions - a theme to which we will return in section 7. In Eaton and Kortum (1999), they build on this analysis by building a two-factor model with endogenous innovation which they estimate using date from five major OECD countries that account for a majority of the OECD's R\&D and patenting. They argue that the fact that inventors patent much more at home than abroad is driven by the weaker protection provided by foreign patents. A thought-provoking observation made by them that is that differences in productivity levels across countries are far smaller than differences in R\&D investment rates. This observation is consistent with the existence of significant international knowledge spillovers in the global economy. ${ }^{47}$ Nevertheless, Eaton and Kortum (1999) estimate that the world is not yet at a point where national origin of ideas does not matter since research performed in other countries appears to be only two-thirds as potent as domestic research. Finally, Eaton and Kortum (1999) estimate that eliminating imitation has a significant effect on productivity and R\&D.

Having discussed the literature that explores the effects of implementing the core TRIPS mandate of raising IPR protection in the global economy, I now turn to the literature that explores the economics of the two main flexibilities contained in TRIPS i.e. the right of WTO members to pursue exhaustion policies of their choosing and the option to use compulsory licensing to provide local consumers access to foreign patented products.

\footnotetext{
${ }^{47}$ Saggi (2002) provides a comprehensive discussion of the role trade and FDI play in the initial transfer of novel technologies across national boundaries as well as their subsequent diffusion within host countries.
} 


\section{Exhaustion of IPRs}

In what follows, I discuss the effects of various types of exhaustion policies and the incentives countries have to pursue them. As noted earlier, a country can essentially choose among three types of exhaustion policies: national, international, or regional. If a country follows national exhaustion, it prohibits parallel imports into its market since a right holder's IPR over a product is deemed to expire only in the country of first sale, making it possible for the right holder to block the resale of its product in other markets. Under international exhaustion, the relevant IPR expires globally upon the first sale of a product in any market so that parallel trade is allowed to occur freely. Finally, under regional exhaustion, the right expires upon first sale anywhere within a well-defined region comprising a group of countries but not outside it. By nature, regional exhaustion is discriminatory in the sense that it allows free parallel trade within a region but prohibits parallel imports from the rest of the world. ${ }^{48}$

Do exhaustion policies matter? Since such policies determine the legality of parallel trade, one way to gauge the importance of these policies is to examine data on parallel trade. However, data on parallel trade are scarce since it can be difficult to distinguish imports from re-imports. Even so, it is well known that parallel trade usually occurs among geographically proximate countries (such as US-Canada, member countries of the EU, Australia-Southeast Asia) in products such as footwear and leather goods, musical recordings, consumer electronics, domestic appliances, cosmetics, clothing, pharmaceuticals, soft drinks, and some other consumer products (NERA, 1999). Both from a quantitative and welfare perspective, parallel trade is perhaps most important in the market for pharmaceuticals. By some estimates, several billion dollars of such trade occurs annually within the EU and it currently accounts for roughly $10 \%$ of EU's total

\footnotetext{
${ }^{48}$ There is significant variation in observed exhaustion policies across the world. For example, the US practises a policy of national exhaustion while many developing countries (but not all) follow international exhaustion (Maskus, 2000). The EU practises regional or community exhaustion of IPRs.
} 
medicine trade. Yet, the observed volume of parallel trade likely understates the consequences of a country's exhaustion policy since the pricing behavior of firms depends upon whether parallel trade is permitted or not. In the canonical model of parallel trade described in the next sub-section, actual parallel trade does not arise even when it is freely permitted because, when faced with potential competition from arbitrage induced parallel imports, a firm is better off setting a common international price to preempt such imports.

\subsection{Scope of exhaustion policies}

Malueg and Schwartz (1994) were the first to compare the global welfare effects of various types of exhaustion policies but they took such policies to be exogenously given. In their model, when confronted with the possibility of arbitrage-induced parallel imports, a monopolist chooses to serve only markets where demand is relatively inelastic (i.e. price is high) since parallel imports from low-price markets lower its total profit. ${ }^{49}$ The central question addressed by Malueg and Schwartz (1994) was a normative one: should firms be allowed to establish exclusive sales territories internationally? Subsequent literature has argued that it is important to also identify the incentives that individual governments have to allow or restrict parallel imports from a national welfare perspective.

Several recent papers build on the work of Malueg and Schwartz (1994) to derive nationally optimal exhaustion policies. The basic economic framework underlying this line of work is as follows. Suppose a single patent-holder can potentially sell its product in two markets: North and South. There are a continuum of Southern consumers of measure 1, each of whom buys (at most) one unit of the product. If a consumer buys the product at price $p$, his utility is given by $U=\theta q-p$ where $q$ measures quality and

\footnotetext{
${ }^{49}$ While this is an important insight, subsequent literature has argued that openness to parallel imports does not necessarily lower a firm's profit when there is strategic interaction between the firm and another party. See, for example, Pecorino (2002) and Roy and Saggi (2012a and 2012b).
} 
$\theta \geq 0$ captures the willingness to pay for quality.

The two markets are asymmetric in two key respects. First, the Northern market is larger: there are $n_{i}$ consumers in region $i$ where where $n_{N}=n \geq 1=n_{S}$. Second, and more importantly, Northern consumers are assumed to value quality relatively more than Southern ones: the preference parameter $\theta$ is distributed uniformly over the interval $\left[0, \mu_{i}\right]$ in region $i=N, S$ where $\mu_{N}=\mu \geq \mu_{S}=1 .^{50}$ The key question of interest is: what determines the North's optimal exhaustion policy? To address this, suppose the North first chooses its exhaustion policy and then the firm/patent-holder (assumed to be of Northern origin) decides whether or not export to the South. Exporting carries the fixed (sunk) cost $\varphi \geq 0$. If it exports, the firm's pricing in the two markets depends upon the exhaustion policy set by the North.

Consider the firm's pricing strategy as a function of Northern exhaustion policy assuming that the fixed cost $\varphi$ has been incurred. Under international exhaustion, the firm must set a common price in both markets to avoid losing profit to arbitrage induced parallel imports whereas under national exhaustion, it is free to price discriminate internationally. It is straightforward to show that the optimal uniform $p^{u}$ is a weighted average of the optimal discriminatory prices for the two markets: $p^{u}=\omega p_{N}^{d}+(1-\omega) p_{S}^{d}$ where $\omega=\eta /(\eta+\mu)$ and $0<\omega<1$. Observe that the weight $(\omega)$ on the optimal Northern price $\left(p_{N}^{d}\right)$ is increasing in the relative size of the Northern market $(n)$.

An important property of the model that follows from the assumption that $\theta$ is uniformly distributed over the interval $\left[0, \mu_{i}\right]$ is that total global sales of the firm under uniform pricing and price discrimination are equal: $\Sigma_{i} x_{i}^{u}=\Sigma_{i} x_{i}^{d}=(n+1) / 2$. As a result, relative welfare under price discrimination and uniform pricing does not depend upon the total output produced under the two types of pricing. This makes uniform

\footnotetext{
${ }^{50}$ For simplicity, much of the literature assumes that $\theta$ is uniformly distributed over its domain and I make the same assumption in what follows. However, this assumption is not completely harmless, particularly when it comes to a welfare comparison of different pricing regimes.
} 
pricing more attractive from an aggregate welfare perspective since it equalizes prices across markets. ${ }^{51}$

If the North opts for international exhaustion, the firm chooses to export to the South iff its profit under uniform pricing $\left(\pi^{u}\right)$ net of the fixed cost exceeds its profit from selling only in the North $\left(\pi_{N}^{d}\right)$ i.e. $\pi^{u}-\varphi \geq \pi_{N}^{d} \Leftrightarrow \varphi \leq \varphi^{u}=\pi^{u}-\pi_{N}^{d}$. Note that $\frac{\partial \varphi^{u}}{\partial \mu}<0$ and $\frac{\partial \varphi^{u}}{\partial \eta}<0$ - i.e. as demand asymmetry increases across the two markets, entry into the Southern market under uniform pricing becomes less attractive to the firm. Similarly, the firm exports under national exhaustion iff its Southern profit at the optimal discriminatory price $p_{S}^{d}$ exceeds the fixed cost of exporting: $\pi_{S}^{d} \geq \varphi \Leftrightarrow \varphi \leq$ $\varphi^{d}=\pi_{S}^{d}$. Note that $\varphi^{d} \geq \varphi^{u}$ i.e., selling in the South is less attractive to the firm under international exhaustion since doing so requires it to lower price in the larger, more lucrative Northern market.

Now the trade-off determining the North's optimal exhaustion policy is easy to see. If the North can implement international exhaustion without compromising its firm's incentive to export, it will necessarily choose to do so. However, if the firm exports only when it can earn its optimal discriminatory profit - i.e. when $\varphi \in\left(\varphi^{u}, \varphi^{d}\right]$ - the North implements national exhaustion. Intuitively, an outcome where the firm refrains from exporting is not in the interest of the North. Under national exhaustion, the firm's incentive to export is perfectly aligned with the Northern government's preferences: when there is no link between prices in two markets, exporting benefits the North iff it increases the firm's total profit. However, under international exhaustion, the firm's incentive to export is too weak from the perspective of overall Northern welfare: since exporting lowers the firm's profit in the North by forcing it to lower its local price, when choosing whether to export or not the firm fails to take into account the benefit

\footnotetext{
${ }^{51}$ Under alternative assumptions regarding the distribution of the taste parameter $\theta$, it is possible for price discrimination to welfare dominate uniform pricing if it leads to an expansion in total output: see Schmalensee (1981) and Varian (1985). If so, some of the welfare implications of various exhaustion policies discussed above would need to be modified.
} 
of this price reduction to local consumers. Conditional on the firm exporting, there is a direct clash between the preferences of the two regions: market coverage as well as welfare in the South are lower under uniform pricing relative to discrimination whereas the opposite is true in the North due to the fact that $p_{S}^{d}<p^{u}<p_{N}^{d}$.

To analyze regional exhaustion, Saggi (2014) extends the North-South model of parallel trade presented above to a three-country world to examine when and why two countries find it in their mutual interest to adopt such an exhaustion policy. Firms in two Northern countries produce distinct patented goods while the South is a pure consumer of those goods. As might be expected, each firm serves all markets at a uniform price - a market outcome called global integration - only when the two Northern countries are open to parallel imports and the degree of demand asymmetry across markets is not too large. Furthermore, if the two Northern countries implement regional exhaustion then their markets become fully integrated whereas that of the South is segmented from them. Under such partial global integration, each firm charges a common price in the North while selling at its optimal discriminatory price (which is lower) in the South.

In equilibrium, if the degree of market asymmetry is small, the two Northern countries implement international exhaustion and global integration obtains. However, when the Northern countries are relatively symmetric and the South is sufficiently low-income relative to them, they opt for regional exhaustion and partial global integration obtains as the equilibrium outcome. This result fits well with the 1998 directive of the European Court of Justice in favor of regional exhaustion, a ruling that was in contrast to the historical exhaustion policies of several major EU members: Austria, Germany, Netherlands, Finland, and the UK all followed international exhaustion provided parallel imports were essentially identical in quality to locally sold goods with the standard for what constituted "material difference" between the two set of goods differing somewhat across countries. ${ }^{52}$ One interpretation of this change in the exhaustion policies of these

\footnotetext{
${ }^{52}$ To be sure, not every EU member followed international exhaustion of trademarks: for example,
} 
European nations is that with the formation of the EU, the combined market size of the region came to dictate the exhaustion policy of the region as opposed to the individual market size of each country.

The consequences of being able to discriminate with respect to exhaustion policies can be isolated by raising the following counter-factual question: what if countries could only implement non-discriminatory exhaustion policies? Saggi (2014) shows that this counterfactual analysis provides two crucial insights. First, the degree of market integration achieved in the global economy is lower when the freedom to discriminate with respect to exhaustion policies is absent since regional integration - a market outcome under which firms sell at a common price in the Northern countries but do not sell in the South at all - ends up replacing partial global integration. Second, and more importantly, market outcomes when regional exhaustion is an available option (weakly) Pareto-dominate those that obtain when only non-discriminatory exhaustion policies can be implemented.

\section{$5.2 \quad$ Vertical pricing}

In the canonical model of parallel trade presented above, openness to parallel trade leads the monopolist to price in a manner such that no parallel trade occurs. Ganslandt and Maskus (2007) show that this mechanism does not necessarily arise in the presence of vertical pricing where a manufacturer sets wholesale prices in two markets that are integrated at the retail level via openness to parallel trade. The key empirical observation motivating their model is that there remains considerable retail price divergence within the EU despite the fact that it follows a policy of regional (or community) exhaustion that permits free parallel trade within the common market.

Ganslandt and Maskus (2007) consider two markets where demand in market $B$ is larger than that in $A$. A single manufacturer $M$ serves each market via an independent Italy, France, and Greece did not follow this doctrine. See Baudenbacher (1998). 
distributor. ${ }^{53}$ The model assumes that while the manufacturer cannot prevent the distributor in market $B$ from selling in market $A$, the distributor in market $A$ does not enjoy the same freedom, perhaps because the two countries differ with respect to their exhaustion regimes (which are taken to be exogenously given).

The timing of decision is as follows. First, the manufacturer offers the distributor in market $i$ a contract of the form $\left(w_{i}, T_{i}\right)$ where $w_{i}$ is the wholesale price and $T_{i}$ is a transfer payment (which can be interpreted as a franchise fee) from the retailer to the manufacturer. Next, in a Cournot-Nash fashion, the two distributors decide how much to sell in their respective markets.

Let $w=\left(w_{A}, w_{B}\right)$ and denote the output sold by distributor $A$ in the two markets as $q_{A}^{*}$ and $q_{B}^{*}$ and that sold by distributor $B$ by $q_{B}$. The amount of parallel trade in the model is measured by $q_{B}^{*}$. The manufacturer sets its wholesale prices to maximize

$$
\pi(w)=p_{A}(w)\left(q_{A}^{*}(w)+q_{B}^{*}(w)\right)-t q_{B}^{*}+p_{B}(w) q_{B}
$$

where $t$ measures trade costs. Whether or not parallel trade occurs at the retail level depends upon the level of trade costs and the manufacturer sets wholesale prices recognizing taking this into account. In the model, parallel trade creates two distinct problems for the manufacturer. One, it generates competition between distributors and lowers market price which reduces the maximum profit that the manufacturer can extract via the transfer fee. Two, since the products sold by the two distributors are identical and trade is costly, parallel trade is wasteful - after all, any units sold in market $B$ by firm $A$ could just as well have been supplied by firm $B$. In addition to these two effects, the manufacturer also has to contend with the standard double marginalization problem that afflicts any vertical relationship. Ganslandt and Maskus (2007) show that these three effects interact to yield a rather counter-intuitive result: retail prices can diverge

\footnotetext{
${ }^{53}$ Ganslandt and Maskus (2007) note that the strategy of having exclusive national dealers is quite commonplace in the recorded music industry and it generally arises to provide market-specific services and advertising.
} 
if trade costs decline even as the volume of parallel imports increases.

Raff and Schmitt (2007) highlight another novel aspect of parallel trade in the presence of vertical pricing, i.e., that such trade can actually benefit a manufacturer. Their motivation is to help explain why manufacturers in a variety of consumer products - such as automobiles, clothes, toys etc. - appear to be quite tolerant of parallel trade. They show that manufacturers benefit from allowing parallel trade provided four conditions are met. First, retailers must place orders before knowing the state of demand (i.e. there is demand uncertainty). Second, inventories must be costly. Third, the states of demand must differ across markets with a positive probability. And, fourth, demand fluctuations should affect the quantity demanded by consumers as opposed to their willingness to pay.

They consider a manufacturer that sells to a continuum of retailers (in two different countries $A$ and $B$ ) all of whom are risk-neutral. Unlike Ganslandt and Maskus (2007), Raff and Schmitt do not allow a two-part contract and the manufacturer is assumed to simply set the wholesale price $w_{i}$ for each market. ${ }^{54}$ Given these prices, retailers order their inventories $\left(x_{i}\right)$ prior to knowing the state of demand. Production costs at both levels are normalized to zero. Furthermore, inventories left unsold are assumed to have no value. While demand in country $A$ is deterministic (and given by $p_{A}=1-q_{A}$ ), that in country $B$ is stochastic: $p_{B}=1-q_{B} / s$ where $s=1$ with probability $1-\lambda$ and $\theta<1$ with probability $\lambda$.

The key role played by parallel trade is now clear: when demand in market $B$ is low (which happens with probability $\theta$ ), parallel trade provides retailers in market $B$ the opportunity to sell any unsold inventories in market A. As Raff and Schmitt (2007) note, such parallel trade indirectly transmits demand uncertainty from market $B$ to $A$ so that, in equilibrium, parallel trade can flow in either direction. The volume of parallel

\footnotetext{
${ }^{54}$ However, since the retail sector is assumed to be competitive in their model this assumption appears to be harmless.
} 
trade adjusts to equalize retail prices across countries in both states of the world. Using the volume of parallel trade and the zero profit condition for retailers, Raff and Schmitt (2007) show that the manufacturer's profit in the presence of parallel trade increases in $\theta$. A comparison of this equilibrium profit with that which is earned by the manufacturer in the absence of parallel trade shows that the manufacturer's expected overall profit is higher with parallel trade provided demand in the low-state is not too low. Intuitively, by opening up another market for their product when local demand turns out to be low, parallel trade gives retailers an incentive to place larger orders from the manufacturer thereby raising its profit.

Maskus and Stähler (2014) offer an agency-based explanation for why the volume of retail-level parallel trade is small within the EU despite the presence of significant international price differences within the EU. It is important to be careful here: the key empirical observation motivating their model is that most parallel trade occurs at the wholesale distributor level. The model considers two markets where a manufacturer sells abroad via an independent foreign retailer over which it has no direct control - i.e., as in Raff and Schmitt (2007), the retailer is free to sell the quantity it purchases from the manufacturer in either market. The incentive to hire the retailer arises because it is assumed to have better information about local demand than the manufacturer. Thus, the key contribution of Maskus and Stähler (2014) is to highlight the role asymmetric information can play in explaining some stylized facts about parallel trade. It is worth noting that even in the standard model of parallel trade (in which the retail sector is competitive and there is no asymmetric information), parallel trade does not arise when it is permitted since a firm will choose to set a common price across markets to eliminate such trade; so the key value-added of Maskus and Stähler (2014) is to show that why parallel trade can fail to arise even in the presence of price differentials across markets. 


\subsection{Innovation, imitation, and parallel trade}

A commonly advanced argument against parallel trade is that it reduces innovation incentives by undermining the ability of IPR holders to profit from their R\&D investments. Much of the literature that explores the relationship between openness to parallel imports and innovation has shown that the traditional argument fails to hold under a variety of reasonable circumstances.

$\mathrm{Li}$ and Maskus (2006) provide a formalization of this argument in the vertical pricing model of one-way parallel trade developed by Maskus and Chen (2004) and Ganslandt and Maskus (2007). ${ }^{55}$ Essentially, they add an R\&D stage to this vertical pricing model where the manufacturer decides whether or not to invest in a cost-reducing process innovation. Specifically, by making an investment $k$, the manufacturer can lower its production cost from $c_{h}$ to $c_{l}$, where $c_{h}>c_{l}$, with probability $\alpha(k)$, where $\alpha^{\prime}(k)>0$ and $\alpha^{\prime \prime}(k)<0$. As in related models, any parallel trade undertaken by the distributor is subject to trade costs. Their model captures the traditional intuition that the manufacturer's incentive for innovation is lower if parallel trade is permitted relative to when it is not since openness to parallel imports reduces its operating profits. However, their analysis also clarifies that the manufacturer's incentive for $R \& D$ depends upon trade costs (of parallel trade) in a non-linear way: this incentive first decreases with trade costs, then increases, and eventually is unaffected by the magnitude of such costs.

The framework of Li and Maskus (2006) is extended by Li and Robles (2007) to consider product innovation. More specifically, they allow the manufacturer to make a costly $R \& D$ investment that yields a new product (that could either be a substitute or a complement to the existing product). Their major result is that parallel trade actually increases the incentive for innovation provided two conditions hold: first, the new product has to be a sufficiently close substitute for the existing product and second,

\footnotetext{
${ }^{55}$ However, Valletti (2006) shows that parallel trade can actually encourage cost reducing R\&D when differential pricing is cost based.
} 
the transportation costs for the two products need to be sufficiently different from each other. While the possibility of parallel trade encouraging innovation in such a model is interesting, it seems difficult to conjure up very many real world examples where two products that are close substitutes for each other involve rather different trading costs.

Valletti (2006) argues that whether or not parallel trade encourages R\&D in the monopoly model depends upon the underlying reason for price discrimination on the part of the monopolist. His model generalizes the standard model to a setting of $n$ countries where the cost of selling in each market is different (perhaps due to transport costs or trade barriers). Furthermore, as in the standard model, the markets differ according to the maximum-willingness-to pay on the part of consumers. Thus, in the model there exist two independent reasons for the monopolist to price discriminate across markets. Valleti (2006) shows that when such discrimination is demand-based (as it is commonly assumed) then incentives for quality improvement on the part of the monopolist are indeed lower when parallel trade can occur. However, when discrimination is costbased, the opposite holds true. As Valleti (2006) notes, while his analysis provides an important new insight, it does so under the assumption that all markets are necessarily served regardless of whether parallel trade is permitted or not. This assumption tends to bias results against price discrimination since it does not allow any market expanding effects of price discrimination to arise. ${ }^{56}$

Grossman and Lai (2008) extend their analysis of optimal patent protection in an open economy setting in Grossman and Lai (2004) (discussed at length in section 3.1) to analyze strategic policy choice in a North-South setting where the South determines its price control policy in response to the exhaustion policy chosen by the North. In contrast to conventional wisdom, they show that the incentives for product innovation

\footnotetext{
${ }^{56}$ Valletti and Szymanksi (2006) analyze how the incentives for quality improvement on the part of a monopolist are affected by the possibility of parallel trade where price discrimination is demand based and the monopolist faces generic competition.
} 
in the North (as well as its aggregate welfare) can be higher when the North permits parallel imports relative to when it does not. My discussion below focuses on their benchmark case where the North faces no price controls and the South does not invest in innovation; Grossman and Lai (2008) show that their main results do not depend upon these assumptions.

Consider the South's optimal price control under national exhaustion. When arbitrage across markets is not possible, the trade-off facing the South is quite simple: for all price controls below an innovating firm's optimal monopoly price, raising the price control increases the rate of innovation via its effect on the value of an innovation (captured by the first term in the following first order condition) while it simultaneously lowers local consumer surplus on all existing products (captured by the second term):

$$
\frac{d \phi_{N}}{d v} \frac{d v^{N E}}{d p_{S}}\left[T C\left(p_{S}\right)+(\widetilde{T}-T) C_{C}\right]+\phi_{N} T C^{\prime}\left(p_{S}\right)=0
$$

Using $v^{N E}=M_{N} \pi\left(p_{M}\right)+M_{S} \pi\left(p_{S}\right) ; C^{\prime}\left(p_{S}\right)=x\left(p_{S}\right)$ and assuming that the R\&D production function is Cobb-Douglas (i.e. $\phi_{N}=(1 / \alpha)\left[L_{R N}\right]^{\alpha}\left(K_{N}\right)^{1-\alpha}$ ) the above first order condition can be rewritten as

$$
\frac{\alpha}{1-\alpha}\left(C\left(p_{S}\right)+\left(\frac{\widetilde{T}-T}{T}\right) C_{C}\right)\left(\frac{\pi^{\prime}\left(p_{S}\right)}{x\left(p_{S}\right)}\right)=\pi\left(p_{S}\right)+\frac{M_{N}}{M_{S}} \pi\left(p_{M}\right)
$$

The optimal Southern price control under national exhaustion satisfies this equation and can equal the marginal cost of production $c$ when the Northern market is very large relative to the Southern one so that allowing a price above marginal cost in the South has a negligible effect on the rate of innovation.

Suppose now that the North implements international exhaustion (i.e. permits parallel imports). If costless arbitrage across markets is possible across markets, either a patent-holder must sell its product for the same price in both markets or charge its optimal monopoly price in the North $\left(p_{M}\right)$ while simultaneously setting its price in the South so high that no sales occur there (which eliminates any possibility of North-South 
arbitrage). These alternative pricing strategies yield equal profits to the patent-holder at some price $\widetilde{p}$ defined by

$$
\left(M_{N}+M_{S}\right) \pi(\widetilde{p})=M_{N} \pi\left(p_{M}\right)
$$

where $M_{i}$ is the market size of region $i$. Thus, if the South sets a price ceiling below $\widetilde{p}$ a typical patent-holder in the North will choose not to sell in the South, an outcome that can never be in in the interest of the South. The other consideration facing the South is the potential effect of its price control on Northern incentives for innovation.

Ignoring the constraint imposed by the patent-holder's market serving strategy and maximizing Southern welfare over its price control yield

$$
\frac{d \phi_{N}}{d v} \frac{d v^{I E}}{d p_{S}}\left[T C\left(p_{S}\right)+(\widetilde{T}-T) C_{C}\right]+\phi_{N} T C^{\prime}\left(p_{S}\right)=0
$$

where the first term captures how a change in the Southern price control alters the rate of innovation $\phi_{N}$ via its effect on the value of a successful innovation under international exhaustion $v^{I E}$ while the second term captures how a small change in the Southern price control affects the consumer surplus effect over all existing products.

Using $v^{I E}=\left(M_{N}+M_{S}\right) \pi\left(p_{S}\right)$ and utilizing the assumption that R\&D technology is Cobb-Douglas, the above first order condition can be rewritten as

$$
\frac{\alpha}{1-\alpha}\left(C\left(p^{*}\right)+\left(\frac{\widetilde{T}-T}{T}\right) C_{C}\right)\left(\frac{\pi^{\prime}\left(p^{*}\right)}{x\left(p^{*}\right)}\right)=\pi\left(p^{*}\right)
$$

where $p^{*}$ is the South's optimal price ceiling if the South can implement its price control without worrying about the firm not serving its market. It follows then that the South's optimal policy under international exhaustion is $p_{S}^{I E}=\max \left\{p^{*}, \widetilde{p}\right\}$.

The first central result of Grossman and Lai (2008) is that $p_{S}^{I E}>p_{S}^{N E}$ - i.e. the South sets a more lenient price control when the North adopts international exhaustion. The intuition is that under international exhaustion the Southern price control spills over to the North so that its negative effect on innovation incentives is larger. By contrast, 
under national exhaustion, the Southern price control's adverse effect on innovation is smaller since it arises only from the reduced profitability of an innovator in the smaller Southern market. Recognizing this, the South allows for a more lax price control when the North sets a policy of international exhaustion.

The second major result of Grossman and Lai (2008) follows from the fact that $p_{S}^{I E}>$ $p_{S}^{N E}$. Under some reasonable conditions, the global profit of a typical innovator - and therefore the incentive for innovation - are higher when the North pursues international exhaustion and the South sets the price control at $p_{S}^{I E}$ compared to when the North chooses national exhaustion and the South implements the price control $p_{S}^{N E}$. The North is therefore clearly better off under international exhaustion: not only does it enjoy a faster rate of innovation, the price for each product faced by consumers is lower, and the value of each patent net of cost of $R \& D$ is higher. The South on the other hand loses when the North opts for international exhaustion. Thus, the conflict between North and South over exhaustion policies remains even when the South can avail itself of a price control to combat the monopoly power of Northern innovators.

An important assumption of Grossman and Lai (2008) is that the South sets its price control before firms make their R\&D decisions. The need for this assumption is clear cut: if the South were to choose its price control after a good had been invented then it would want to set price equal to marginal cost. Foreseeing this, firms would have no incentive to invest in R\&D. Bennato and Valletti (2014) highlight the role the level of commitment on the part of the South (which in their model is endogenously chosen by the South) plays in determining how openness to parallel trade affects R\&D incentives.

Saggi (2013) builds on the benchmark monopoly model of parallel trade presented in section 5.1 to study the interaction between exhaustion policies and incentives for IPR protection. The analysis is based on the insight that the extent to which IPR holders can exercise their market power in world markets depends upon both $(i)$ the degree of protection available to them against potential imitators and $(i i)$ the extent to which 
they can price discriminate across national markets. The model works as follows. In the first stage, the North chooses between international and national exhaustion while the South decides whether or not to protect IPRs. If the South does not protect IPRs, a competitive Southern industry that produces an imitated (lower quality) version of the monopolist's product comes into existence. Next, the firm decides whether to incur the fixed (sunk) cost necessary to export to the South. Finally, the firm chooses its price(s) and consumption and trade occur.

In equilibrium, each region's policy takes into account the firm's pricing behavior, its incentive to export, as well as the other region's policy. If the fixed cost of exporting is so low that the firm exports to the South regardless of the policies chosen by the two regions, then the North chooses international exhaustion while the South does not protect intellectual property. However, when the export decision of the firm is policy dependent, the two regions end up in a policy stand-off: each region has to take into account whether or not the other would be willing to induce the firm to export by choosing to implement its less preferred policy. While both national exhaustion and IPR protection are substitutes in the sense that the increase the firm's market power, the governments of the two regions view them quite differently since, holding the firm's export decision constant, national exhaustion lowers Northern welfare while protecting intellectual property harms the South.

Together with the endogeneity of the firm's export decision, the presence of strategic interdependence at the policy setting stage allows the model to shed new light on the effects of forcing the South to offer IPR protection while leaving the North free to implement the exhaustion policy of its choice. ${ }^{57}$ The key result is that shutting down Southern imitation increases global welfare if and only it is necessary for inducing the firm to export to the South. In other words, if the firm exports to the South despite im-

\footnotetext{
${ }^{57}$ Recall that Article 6 of TRIPS essentially left member countries free to implement policies of their choice.
} 
itation or if it does not sell there even if its technology is protected, TRIPS enforcement lowers world welfare. An important practical implication of this welfare result is that the case for strengthening IPR protection in developing countries hinges critically on how such a change affects the extensive margin of exports from developed to developing countries. The relevant empirical evidence (discussed in detail in section 7.2), shows that a strengthening of IPR protection in developing countries can indeed increase the variety of exports flowing to their markets from developed countries.

\subsection{International policy spillovers}

Much of the literature on parallel imports abstracts from strategic considerations, both from the product market and at the policy-setting stage. Roy and Saggi (2012a) address two key questions that attempt to fill this hole: First, how do national exhaustion policies affect oligopolistic competition in global markets? Second, what is the nature of strategic interdependence between exhaustion policies of individual countries? They address these questions in the North-South model introduced above with one key modification: the product market is assumed to be a vertically differentiated duopoly where the Northern firm sells the high quality and the Southern firm the low quality. The timing of decisions in their model is as follows. First, governments simultaneously choose their exhaustion policies - i.e. whether to implement national or international exhaustion. Next, each firm chooses whether or not to offer its product for sale in the foreign market. Finally, firms compete in prices and international trade and consumption occur.

Thus, to some extent, Roy and Saggi (2012a) unify two strands of the literature on parallel imports: one that studies interaction between firms taking government policies as given - such as Malueg and Schwartz (1994) and another that analyzes the impact of alternative government policies but abstracts from strategic interaction between firms such as Richardson (2002). ${ }^{58}$ In such an environment, in addition to the two frequently

\footnotetext{
${ }^{58}$ Richardson (2002) considers the case of many importing countries facing a single supplier and shows
} 
analyzed market structures of uniform pricing and price discrimination, an asymmetric scenario where the low quality sells in both markets while the high quality firm sells only in the North plays a crucial role in determining the policy equilibrium. Such an asymmetric market structure can arise because the lure of the lucrative Northern market is stronger than that of the Southern market. Furthermore, strategic price competition under such a market structure tends to be rather subtle. To see why, suppose the North permits parallel imports while the South does not. Under such a policy configuration, if demand is relatively similar across countries the low quality firm charges its optimal monopoly price in the South while both firms charge their optimal discriminatory prices in the Northern market. However, if the structure of demand is sufficiently asymmetric across countries, the low quality firm's monopoly price in the South is lower than its discriminatory price in the North when competing with the high quality firm. Given that, the North's openness to parallel imports induces the low quality firm to set a common international price that actually exceeds its optimal monopoly price for the Southern market. The resulting softening of price competition in the North, in turn, makes forsaking the Southern market more attractive for the Northern firm.

In equilibrium, when the degree of demand asymmetry between the two markets is high, in order to ensure that its firm exports, the North chooses national exhaustion and international price discrimination prevails; otherwise, it chooses international exhaustion and uniform pricing obtains. ${ }^{59}$ This policy prediction accords quite well with the actual exhaustion policies observed in the world: recall that the two largest markets in the

that, in equilibrium, all countries will choose to allow parallel imports in order to ensure that the good is available locally at the lowest possible price. This model is useful for capturing the incentives of importing nations but its main prediction does not fit well with the actual nature of parallel import policies observed in the world - see Maskus (2000b).

${ }^{59}$ It should be noted here that the literature on economic integration contains analyses of international oligopoly where integration or segmentation is exogenously given. See, among others, Smith and Venables (1988) and Venables (1990). Markusen and Venables (1988) examine optimal trade and industrial policy in this context. In the approach taken by Roy and Saggi (2012a and 2012b), national policies endogenously determine whether markets are segmented or integrated. 
world - the EU and the US - prohibit parallel imports from most of the rest of the world. ${ }^{60}$ Furthermore, the adoption of these policies on the part of the EU and the US makes smaller developing countries indifferent between their policy options since what they do does not affect market outcomes. Such indifference on their part is consistent with the fact that we do not observe a common exhaustion regime across the developing world..$^{61}$

In addition to openness to parallel trade, the use of external reference pricing (ERP) policies is another important channel of international spillovers, especially in the context of patented pharmaceuticals. Under an ERP policy, the price that a country permits in its local market for a particular product is based on the prices of the same product in a well-defined set of other countries, commonly called its reference basket. ${ }^{62}$ While some countries - such as France and Spain - require that a seller's local price should be equal to the lowest price in its reference basket, others - such as Canada and Netherlands are willing to accept a local price that equals either the average or the median price in their reference baskets. As many as 24 of 30 OECD countries and approximately 20 of 27 EU countries use ERP, with the use being mostly restricted to patented medicines (WHO, 2013).

Existing empirical evidence indicates that not only does the use of ERP by rich countries create negative international price spillovers for developing countries, but it can also lead pharmaceutical companies to not sell some products in low-price markets. For example, using data on 1444 drugs produced by 278 firms in 134 therapeutic classes

\footnotetext{
${ }^{60}$ Furthermore, in several recent bilateral trade agreements that have been dubbed "TRIPS-Plus" the US has insisted that the partner country not allow parallel imports from abroad, a policy that goes beyond TRIPS since it takes away the partner country's freedom to pick the exhaustion regime of its choosing but is consistent with safeguarding the profits of US industries in its market.

${ }^{61}$ Indeed, even within Africa, there is significant variation in exhaustion policies: while Ghana, Namibia, South Africa, and Zimbabwe follow international exhaustion, Botswana, Madagascar, Mozambique, and Nigeria have opted for national exhaustion (Roy and Saggi, 2012a).

${ }^{62}$ Although reference pricing within a closed economy setting has been studied extensively in the health economics literature, formal models of ERP policies are scarce in the international trade literature - Geng and Saggi (2015c) make a start.
} 
from 1980-1999, Kyle (2007) finds that firms are less likely to follow the launch of a new drug in a low-price country with launch in a high-price country. Danzon and Epstein (2012) uncover similar effects in their analysis of drug launches in 15 European countries over 12 different therapeutic classes during 1992-2003, i.e., the delay effect of a prior launch in a high-price EU country on a subsequent launch in a low-price EU country is stronger than the corresponding effect of a prior launch in a low-price EU country. Using data from drug launches in 68 countries between 1982 and 2002, Lanjouw (2005) shows that price regulations and the use of ERP by industrialized countries contributes to launch delay in developing countries. Goldberg (2010) provides an insightful discussion of much of this evidence.

\section{Compulsory licensing under TRIPS}

While the notion of compulsory licensing precedes TRIPS, actual incidents of compulsory licensing in the international context have started to emerge only during the post-TRIPS era. During 1995-2011 there were 24 compulsory licensing "episodes" involving patented medicines (Beall and Kuhn, 2012). ${ }^{63}$ Prior to TRIPS, there were few, if any, such international episodes. ${ }^{64}$ The lack of compulsory licensing prior to 1995 is fundamentally linked to the virtual absence of IPR protection in many developing countries during the pre-TRIPS era: after all, the issuance of a compulsory license is premised on the legal recognition of a patent. With developing countries increasingly coming under pressure to enforce their TRIPS obligations, a more salient role for compulsory licensing as a tool

\footnotetext{
${ }^{63}$ As per Beall and Kuhn (2012), a compulsory licensing episode is one when compulsory licensing is discussed between the government a country and a foreign patent-holder (although it need not necessarily be the end result of such negotiations).

${ }^{64}$ The limited use of compulsory licensing by developing countries during the pre-TRIPS era likely reflects another aspect of the relevant WTO rules: prior to 2001 a country could only issue a compulsory license to a local producer, requirement that essentially made compulsory licensing inaccessible to many technologically lagging countries. This local production requirement was loosened by the WTO in 2003 by allowing the import of necessary pharmaceuticals via compulsory licenses issued to firms in other countries.
} 
for improving consumer access to patented products in such countries may have started to emerge during the post-TRIPS era.

\subsection{Access to patented goods}

Bond and Saggi (2014) utilize a simple partial equilibrium North-South framework to analyze the dual roles compulsory licensing and price controls play in determining access Southern consumers enjoy to foreign patented goods. They analyze the following threestage game between the South and a Northern patent-holder whose patent lasts for $\tau$ periods. In the first stage, the South chooses the price control $\bar{p}$ to be imposed on the product. Next, the patent-holder decides whether to enter the Southern market, to voluntarily license the product to a local firm, or to not sell in the South. If the product does not sell in the South in the first period, the South can issue a compulsory license to a local firm who produces a lower quality version of the patented product and pays a per-period royalty $R$ to the patent-holder for the remaining duration of the patent.

The structure of this game is intended to capture features of the TRIPS agreement and the actual experience of developing countries with compulsory licensing. The TRIPS requirement that applicants for a compulsory license should first make an effort to obtain a voluntary license is reflected in the assumption that the third stage of compulsory licensing only arises if the patent-holder neither enters nor issues a voluntary license at the second stage. The fee received by the patent-holder, $R$, reflects the TRIPS requirement of a "adequate remuneration" to the patent-holder. In what follows, I present their main results when the South lacks a price control and then briefly discuss whether and how the availability of a price control alters the role of compulsory licensing.

If the patent-holder decides to enter the Southern market and produce the good itself then its quality level equals $q$. To be able to undertake local production, the patentholder has to incur the fixed entry $\operatorname{cost} \varphi$ where $\varphi$ captures the costs of obtaining any necessary approval from local authorities as well as the costs of establishing an effective 
marketing and distribution network. ${ }^{65}$

Let $\beta \in[0,1)$ be the per period discount factor and let the marginal cost of production equal zero. Normalizing utility under no purchase to zero, the per-period demand $d(p, q)$ in the South for the patented product in the absence of imitation is given by $d(p, q)=$ $1-p / q$. Over the life of the patent, in each period the patent-holder chooses its price $p$ to maximize $\pi_{E}(p)=p(1-p / q)$. Solving this problem yields the patent-holder's optimal monopoly price $p^{m}=q / 2$. Thus, the maximized payoff from entry to the patent-holder equals $v_{E}=(1+T) \pi_{E}\left(p^{m}\right)$ where $T=\sum_{t=1}^{\tau} \beta^{t}$ while that to the South equals $w_{E}^{S}=(1+T) s_{E}\left(p^{m}\right)$ where $s_{E}(p)$ denotes consumer surplus at price $p$.

Bond and Saggi (2014) assume that there is only a single local firm with sufficient capability to be an effective licensee and voluntary licensing offers the patent-holder the advantage of being able to use the local licensee's existing distribution and retail network so that the fixed cost of voluntary licensing is lower than that of entry and it equals $\alpha \varphi$ where $0<\alpha<1$. The disadvantage of voluntary licensing is that, owing to the limited technological capability of the local licensee, the quality of production under voluntary licensing is lower and is denoted by $\gamma q$, where $\gamma \leq 1$.

The monopoly price for the licensee equals $p_{L}^{*}=\gamma q / 2$ and the maximum gross profits accruing to the licensee over the life of the patent are:

$$
v_{L}(\gamma)=(1+T) \pi_{L}(\gamma) \text { where } \pi_{L}(\gamma) \equiv p_{L}^{*}\left(1-p_{L}^{*} / \gamma q\right)
$$

Southern welfare under voluntary licensing equals

$$
w_{L}(\gamma)=(1+T)\left[S\left(p_{L}^{*}, \gamma q\right)+\pi_{L}(\gamma)\right]-f
$$

where $f$ is the licensing fee paid to the patent-holder.

\footnotetext{
${ }^{65}$ While some small developing countries approve drugs conditional on prior approval in developed countries (Kremer, 2002), this is not the case for the larger developing countries such as Brazil and India. In her extensive discussion of the likely effects of the introduction of pharmaceutical patents in India, Lanjouw (1998) notes that patent-holders sometimes deliberately chose to not introduce their new drugs in India because of the administrative costs involved.
} 
At stage three, given that the product is not sold locally in the first period, the South decides whether or not to grant a compulsory license. A compulsory license provides the licensee with the right to produce the good for $\tau-1$ periods and quality of production under compulsory licensing is the same as that under voluntary licensing, as is the fixed cost. The fixed cost level at which compulsory licensing yields zero profits to the licensee equals $\varphi_{Z}=T \pi_{L}(\bar{p}, \gamma) / \alpha \beta$. Note that the South is assumed to be able to compensate the local licensee for any losses under the compulsory license.

Southern welfare under a compulsory license equals:

$$
w_{C L}=T\left[S\left(p_{L}^{*}, \gamma q\right)+\pi_{L}(\gamma)-R\right]-\alpha \beta \varphi
$$

compulsory licensing is a credible threat iff $w_{C L}>0$, a condition that holds provided the quality of licensed production is not so low that the total surplus generated for Southern consumers and the local licensee is insufficient to cover the royalty $R$ paid to the patent-holder and the fixed cost incurred by the licensee.

Given that compulsory licensing is a credible threat, consider the patent-holder's decision regarding how to best utilize its patent in the South. If the patent-holder enters the South, it earns a return of $v_{E}-\varphi$. Under voluntary licensing, the patent-holder makes a take it or leave it offer to the Southern firm. The best that the patent-holder can do under voluntary licensing is to make the Southern firm indifferent between agreeing to a voluntary license in the first period and waiting for a compulsory license in the next period, which yields the licensing fee under voluntary licensing:

$$
f_{L}^{C}(\varphi)=\left\{\begin{array}{cc}
\pi_{L}(\gamma)-\alpha(1-\beta) \varphi & \varphi \leq \varphi_{Z} \\
v_{L}(\gamma)-\alpha \varphi & \varphi>\varphi_{Z}
\end{array}\right.
$$

When $\Omega \pi_{L}(\bar{p}, \gamma)>\alpha \beta \varphi$, the licensee earns a strictly positive payoff under compulsory licensing and the possibility of compulsory licensing induces profit-shifting from the patent-holder to the local licensee since it reduces the licensing fee under voluntary licensing. 
What are the equilibrium effects of the option of compulsory licensing? Bond and Saggi (2014) show that the option of using compulsory licensing expands the range of parameters for which Southern consumers enjoy access to the patented good while simultaneously reducing the range of fixed costs for which the patent-holder serves the market. Furthermore, due to the profit-shifting effect described above, the threat of compulsory licensing can cause the patent-holder to switch from voluntary licensing to entry and when this happens, the South benefits at the expense of the patent-holder while the effect on joint welfare is ambiguous. Whenever voluntary licensing is replaced by compulsory licensing, joint welfare necessarily declines since the quality of the production under both modes is the same and compulsory licensing delays access to the product. Finally, and perhaps most interestingly, when compulsory licensing replaces an outcome where the patent-holder does not sell in the South it makes both parties better off: the South benefits since local consumers gain access to the patented product while the patent-holder gains because the royalty payment under compulsory licensing yields a strictly positive payoff.

When the South can utilize a price control, the threat of compulsory licensing has two potentially favorable effects from its perspective. First, the South can obtain the product at marginal cost due to the ability of the Southern government to subsidize the local licensee. Second, the profit shifting effect of compulsory licensing reduces the rent collected by the patent-holder. ${ }^{66}$

\subsection{Could compulsory licensing be the new imitation?}

The framework of Bond and Saggi (2014) can be enriched to evaluate the value of compulsory licensing to the South when its patent protection policy is optimally chosen

\footnotetext{
${ }^{66}$ However, these two positive effects are counter-balanced by one potentially unfavorable effect that arises when the South sets a price control that makes the patent-holder indifferent between serving its market or not: the option of obtaining a royalty payment under compulsory licensing forces the South to permit a higher price to induce the patent-holder to serve its market.
} 
(as opposed to being determined by TRIPS). To focus on endogenous patent protection, Bond and Saggi (2015a) abstract from voluntary licensing and focus on entry as the means via which the patent-holder can work its patent in the South. They analyze the following three stage game. In the first stage, the South chooses whether or not to implement patent protection. Next, the patent-holder decides whether to enter the South by incurring the fixed cost $\varphi$. At the third stage, the South can issue a compulsory license to a local firm provided the patent-holder does not sell in its market in the first period.

An important feature of their model is that, from the South's perspective, imitation - which occurs whenever the South does not offer patent protection - dominates compulsory licensing since it avoids the delay period required under compulsory licensing while also not requiring any compensation to be paid to the patent-holder. As a result, if the South is free to deny patent protection, it never utilizes compulsory licensing - a result that accords well with the rare observance of compulsory licensing in developing countries during the pre-TRIPS era.

Bond and Saggi (2015a) show that the option to use compulsory licensing reduces the South's willingness to offer patent protection, i.e., there exist parameter regions under which the South offers patent protection only if compulsory licensing is unavailable. The intuition for this result is that whenever the patent-holder prefers compulsory licensing to entry, the South chooses not to offer patent protection since it prefers imitation to compulsory licensing. Thus, the South is better off preempting compulsory licensing by not implementing patent protection. Furthermore, if the South is free to deny patent protection, not only does compulsory licensing fail to arise in equilibrium, the option to use it makes both parties worse off since the possibility of compulsory licensing further reduces the South's incentive to offer patent protection thereby undermining the patentholder's incentive to enter. If the South is forced to offer patent protection, compulsory licensing can not only emerge as an equilibrium outcome, the option to use compulsory 
licensing can even make both parties better off. This finding argues in favor of Article 31 of TRIPS.

\subsection{Bargaining in the shadow of compulsory licensing}

The idea that the threat of compulsory licensing can affect the nature of bargaining between multinationals selling patented products and the governments of developing countries is formally developed in Bond and Saggi (2015b). They analyze a Rubensteintype alternating offers bargaining game between a multinational and the government of a developing country (called South). An agreement between the two parties consists of the price that the multinational is allowed to charge in the South and a lump sum transfer payment. Since Article 31 requires that a patent-holder must be given a reasonable amount of time to work its patent before a compulsory license can be issued, assume that there exists an exogenous given time limit that must elapse before the South can unilaterally terminate the bargaining problem by issuing a compulsory license.

The model allows the multinational's Southern price to partly spill over to its home market (North) perhaps due to the possibility of parallel imports and/or the presence of an external reference pricing policy on the part of the North. The loss in its Northern profits suffered by the multinational due to the price spillover raises the possibility that the additional surplus generated by its entry into the South is actually negative. Second, if the quality of the product produced by the Southern licensee is not sufficiently high, compulsory licensing generates lower surplus than entry. However, more interestingly, compulsory licensing can also yield higher surplus than entry because, as per WTO rules, any sales under compulsory licensing have to be restricted to the Southern market so that compulsory licensing can help curtail the international price spillover that the multinational suffers under entry.

Bond and Saggi (2015b) show that if the surplus generated by entry is positive and exceeds that under compulsory licensing, entry occurs but the threat of compulsory 
licensing redistributes surplus from the multinational to the South. However, even if the surplus generated by entry is negative, the multinational may make a preemptive offer just prior to the deadline to prevent the imposition of a compulsory license. If this happens, the threat of compulsory licensing benefits the South at the expense of the multinational because it provides Southern consumers access to the patented product; absent the threat of compulsory licensing, when entry generates a negative surplus the multinational simply stays out of the South. When does compulsory licensing arise in equilibrium? First, compulsory licensing occurs if yields a higher surplus than entry and the required delay period preceding its implementation is not too long. The latter condition is important because even if compulsory licensing yields a higher surplus than entry, it may not be worth delaying agreement too much to obtain that higher level of surplus.

\section{Empirical evidence on the effects of IPR protec- tion}

The broad stylized facts presented in section 2.2 suggest that non-resident patenting has been on the rise in the world economy, as have global royalty payments made for the international flow of technology across countries. I now discuss rigorous empirical studies that attempt to measure the impact of international patent protection on the pattern of trade, consumer welfare, FDI, and the flow of technology across national boundaries. Finally, in subsection 7.4, I discuss empirical studies that use historical data to assess the effects of IPR protection on innovation and technology transfer.

\subsection{Are IPRs trade related?}

In a seminal paper, Maskus and Penubarti (1995) investigate whether and how the level of IPR protection in large developing countries affects the manufacturing exports of 
developed countries. As they note, the relationship between the degree of IPR protection faced by a firm in a foreign market and its exports to that market is not clear a priori. On the one hand, the elimination of competition from imitated products should shift the demand facing the firm outward thereby inducing it to export more. On the other hand, the increased market power provided by stronger IPRs can make it optimal for the firm to raise its price which should reduce its foreign sales. Thus, the firm should export more only if the market expansion effect of stronger IPR protection dominates the market power effect.

Given this ambiguous theoretical prediction, Maskus and Penubarti (1995) use an augmented version of the Helpman-Krugman (1985) bilateral import equation to provide the first bit of systematic evidence on whether differential patent laws affect the pattern of international trade. The essential idea is to correlate industry level differences in the observed volume of trade and that predicted by the Helpman-Krugman model of monopolistic competition with income, trade barriers, and patent laws as measured by the Rapp and Rozek (1990) index of patent protection. Using 1984 data for 28 manufacturing sectors of OECD countries and 25 developing countries, Maskus and Penubarti (1995) show that across all sectors and countries, a strengthening of patent protection raises a country's bilateral imports (relative to those predicted by the Helpman-Krugman model) with the effect being stronger in developing countries. This is strong evidence for the claim that IPRs are trade-related. When they divide their set of industries according to the importance of patents to each industry, they find that the impact of patent rights on trade is weakest in the most sensitive industries, a finding that suggests that the market power effect of increased patent protection is stronger in such industries. ${ }^{67}$ At the country level, they find a stronger impact for the larger developing countries in

\footnotetext{
${ }^{67}$ Their set of patent sensitive industries includes those industries that tended to report the most significant losses from the inadequate patent protection in foreign markets during the pre-TRIPS era (USTIC, 1988).
} 
their sample such as Mexico, Brazil, Argentina, and Korea.

Smith (1999) builds on the work of Maskus and Penubarti (1995) by introducing the intuitive idea that the strength of patent protection ought to matter more in those developing countries that possess a greater ability to imitate. How high the threat of imitation is in a particular country is assumed to be a function of local R\&D intensity and the degree of IPR protection. Based on these two considerations, Smith (1999) divides her sample into four groups with the threat of imitation assumed to be the highest in countries such as India, Turkey, and Romania that had a high R\&D intensity and weak patent protection and the lowest in countries such as Finland, Greece, and Malaysia that had the opposite configuration. A major finding of her analysis is that weak patent rights in countries that have the capacity to imitate act as a significant barrier to US exports. Smith (1999) also finds that the elasticities of US exports with respect to patent protection are higher in patent-sensitive manufactures relative to others.

More recently, using export data at the 3-digit ISIC level from 1962-2000, Ivus (2010) investigates the impact of TRIPS induced IPR reforms in 53 developing countries on the exports of developed countries to their markets. An important insight underlying the approach of this paper is that over the relevant time period, several former colonies of England and France strengthened their IPR protection earlier than countries that did not have a colonial past so that the IPR reforms undertaken by the latter set during 1990-2005 could be legitimately interpreted as an exogenous imposition of TRIPS. This difference between the time pattern of IPR reform of former colonies and non-colonies naturally motivates an empirical approach in which the growth rates of exports from the developed to the developing world are differenced along two dimensions: one based on colonial heritage and a second based on patent sensitivities of industries. ${ }^{68}$ Ivus (2010)

\footnotetext{
${ }^{68}$ Since IPR reforms may be a set of a larger reform package, grouping industries according to their patent-sensitivity is useful since IPR reforms ought to be of value primarily to patent-sensitive industries whereas general market reforms are valuable to all industries.
} 
reports two major results. First, the strengthening of IPR protection undertaken by 18 non-colonies to make their IPR regimes TRIPS compliant increased the annual value of developed country exports to their markets in patent-sensitive industries by about $\$ 35$ million, which is equivalent to an $8.6 \%$ increased in the value of patent sensitive imports by the developing countries in her sample. Second, she finds that relative changes in the prices of patent-sensitive products do not differ significantly across the two country groups: i.e. the increases in the value of imports seem to have been driven largely by changes in quantities as opposed to prices. This latter finding is particularly important when considering the welfare impact of IPR reforms in developing countries - an issue I discuss in greater detail in section 7.2 below.

In a follow up paper, using data at the 10-digit HMS level, Ivus (2015) investigates the effects of stronger IPR protection on US exports to 64 developing countries. The data allow her to assess the effects of stronger IPR protection in developing countries on the variety of US exports to their markets. She finds that changes in the IPR regimes of developing countries induced by TRIPS increased the annual value of US exports in industries that rely heavily on patent protection (such as pharmaceuticals) by roughly $16 \%$ and that almost the entire increase in exports was driven by an expansion in product variety.

By examining the time pattern of the introduction of top 60 grossing Hollywood movies to 37 countries during 1997, McCalman (2004) provides rather novel evidence on the effects of international variation in the strength of IPR protection on the sale of new products by foreign multinationals. As he notes, IPR protection is crucial in the movie industry because of the existence of high up-front costs and the relatively low cost of imitation. Furthermore, since foreign markets account for a significant proportion of the share of revenue of major Hollywood studios and the life-cycle of films is rather short, international IPR protection is a major factor determining product launch decisions. When choosing their launch dates for foreign markets, a studio has an incentive to 
initially release the movie in only the US market to better gauge its profitability in foreign markets. On the other hand, the longer the delay period the higher the revenue lost to piracy. McCalman (2004) develops a simple model that captures this trade-off and finds empirical support for its key prediction - i.e. if IPR protection is low then strengthening it reduces launch delay whereas when it is high, the effect is opposite in nature. The model delivers this result because stronger IPRs allow studios to economize on advertising effort by relying on word of mouth advertising to enhance demand. When the level of IPRs is weak, it is optimal for a studio to rely exclusively on word-ofmouth advertising and when this is the case, by reducing the share of the market that consumes the pirated version stronger IPR protection shortens the release date. The most important message of McCalman's paper is that strengthening IPR protection beyond a certain level can retard the introduction of new products to the markets of developing countries.

In a recent paper, using data on launches of 642 new drugs in 76 countries during 1983-2002 Cockburn et al. (2014) provide an in-depth level analysis of the role patent protection plays in determining product launch decisions in the pharmaceutical industry. Like McCalman (2004), their analysis reminds us that the effect of patent protection on prices is only one side of the story; when faced with lack of patent protection pharmaceutical companies may simply not sell in certain markets or substantially delay the introduction of their new products. Cockburn et al. (2014) emphasize that diffusion of new drugs depends upon the incentives pharmaceutical companies have to make investments in establishing and expanding their marketing and distribution networks. They estimate that, controlling for a variety of economic and demographic factors, altering a country's patent regime from the complete lack of product patents to one where it provides them (for a duration of at least 18 years) increases the per-period hazard of drug launch by $23 \%{ }^{69}$ These findings are important since new drugs are launched only

\footnotetext{
${ }^{69}$ The estimated increase is substantially larger when the endogenity of pricing and patent regimes is
} 
in a handful of rich countries or become available in other parts of the world long after they are first introduced. For example, in their entire sample of 642 new drugs, 39\% were launched in ten or fewer countries and only $41 \%$ were launched in more than 25 countries. The mean number of countries that a drug was launched in equalled 22.4, out of a maximum possible of $76 .^{70}$

Of course, exporting is not the only way in which firms introduce their products in developing countries; FDI is also an important channel for serving foreign customers. I now discuss the existing evidence on how IPR protection affects FDI.

\subsection{IPRs and FDI}

It has long been known that multinationals tend to produce technically complex goods; are more pervasive in industries that invest heavily in $\mathrm{R} \& \mathrm{D}$ and product differentiation; and employ a large share of professional and technical workers (Markusen, 1995). Indeed, a central tenet of the theory of internalization is that multinationals rely on the advantages derived from their intangible assets to compete successfully in unfamiliar foreign environments. Given this, it stands to reason that global flows of FDI should react to the degree of IPR protection available in different countries.

The relationship between FDI and IPR protection has received significant empirical scrutiny in the existing literature, a nuanced and detailed discussion of which is provided by Maskus (2000). As the survey by Park (2008) notes, there appears to be a clear positive relationship between the degree of IPR enforcement in developing countries and investment by US firms - see, for example, Lee and Mansfield (1996) and Nunnenkamp and Spatz (2004). However, results derived from non-US data portray a more mixed picture: while Mayer and Pfister (2001) find a negative effect of stronger patent rights

accounted for by the use of instrumental variables. Unlike McCalman's (2003) analysis of Hollywoord movies, Cockburn et al. (2014) do not uncover a non-monotonic relationship between the strength of IPR protection and the diffusion of new drugs.

${ }^{70}$ Similar findings are reported by Kyle and Qian (2013). 
on location decisions of French multinationals, Javorcik (2004) finds a positive effect of stronger patent rights in Eastern Europe and former Soviet Union states on FDI in high-technology sectors.

Branstetter et al. (2011) investigate the responses of US multinationals to IPR reforms by sixteen countries during the 1980s and 1990s. They find that not only did US based multinationals expand their scale of production and employment in reforming countries after IPR reform but industry-level value added in reforming countries, particularly in technology-intensive industries, also increased. Branstetter et al. (2011) also examine the impact of IPR reforms on the annual count of "initial export episodes" - the number of 10-digit commodities that the US imported from a given country for the first time. Interestingly, they find that the count of such episodes increased sharply after IPR reform, suggesting that the decline in the range of imitative production resulting from IPR reform may have been more than offset by the increase in the range of production undertaken by multinational affiliates.

A major question in the theory of internalization is when and why multinational firms choose to transfer technology internally as opposed to doing it via arms-length market transactions such as technology licensing (Antràs and Yeaple, 2014). The degree of IPR protection available overseas ought to have a bearing on this choice since the international exchange of technology within the firm (i.e. from parent firms to subsidiaries) is likely to be more secure than that between unrelated parties. ${ }^{71}$ Ivus. et al. (2015b) investigate this idea using data from the US Bureau of Economic Analysis on affiliated and unaffiliated technology licensing by US multinationals in 44 developing countries over the 1993-2009 period. They focus on firms in eight high-tech manufacturing industries and classify industries into two categories based on the technological complexity

\footnotetext{
${ }^{71}$ See Maskus, Saggi, and Puttitanun (2005) for an analysis of how a reduction in the transactions costs of technology licensing brought about by a strengthening of patent protection influences the internalization decision of firms.
} 
of their products: complex and discrete, where the products of the complex industries are assumed to be harder to imitate than those of the discrete ones. ${ }^{72}$ They find that stronger patent protection shifts the composition of licensing towards unaffiliated parties with the shift being more pronounced among firms in discrete industries. ${ }^{73}$

The idea that the effects of changes in patent protection on multinational activity are likely to vary across industries also lies at the heart of an important recent contribution by Bilir (2014). Her main insight is that patent protection is of relatively less importance for a firm that sells a product with a short life cycle since imitation is less likely to succeed before the product itself becomes obsolete. For example, she notes that electronics and hard-disk drive firms often produce their latest products in countries that offer relatively weak patent protection whereas firms producing high-efficiency solar cells, which tend to have much longer product lives than electronics products, tend to locate their manufacturing operations in the US in order to lower the risk of imitation.

Bilir (2014) notes that since successive generations of the same product (such as new models of autos) tend to have substantial technological overlap, it is preferable to measure cross-industry variation in the length of product life-cycles by determining the economic durability of the underlying technologies embedded in products. The market lifetime of a patented technology is measured by the length of time for which a given patent continues to be cited by subsequent patents. Building on these insights, she develops a North-South model in which product life cycles vary across industries and

\footnotetext{
${ }^{72}$ For example, pharmaceuticals and non-pharmaceutical chemicals are classified as discrete industries while transportation, machinery and equipment, and electronics and components are classified as complex.

${ }^{73}$ Smith (2001) builds on this to estimate the relative effects of stronger patent protection in foreign markets on exports, affiliate sales, and licensing of US firms. She finds that stronger patent protection abroad leads to an increase US affiliate sales and licensing, particularly in countries that possess strong imitative capabilities. Further, the estimated effects are larger in magnitude for knowledge transfers (i.e. to unaffiliated parties) relative to internalized transfers within the boundaries of the multinational firm. In his study of the choice between FDI and licensing of Hollywood studies, McCalman (2004) finds similar effects but he also uncovers an interesting non-linearity: licensing is preferred to FDI for moderate levels of foreign IPR protection whereas FDI is preferred when such protection is either high or low.
} 
derives the prediction that the number of products that are produced in the South in a particular sector is weakly decreasing in its product-cycle length (which is common for all products in a sector). However, the model clarifies that there is a non-monotonic relationship between patent reform and the extent of multinational activity: for sectors with very short product life-cycles, patent reform has no effect on multinational activity whereas for sectors with longer product life-cycles, patent reform leads to more products being produced in the South but the increase is largest in sectors that have intermediatelength product life-cycles. Using the time duration for which a patent continues to be cited, Bilir constructs a sectoral level index of product cycle lengths. Using this index, she examines the effects of patent protection (as measured by the Ginarte-Park index) and product life-cycle lengths on the global operations of US multinationals across 37 industries and 72 countries (during 1982-2004). She finds that IPR protection indeed attracts higher levels of multinational activity in sectors whose products have longer life cycles.

\subsection{Price effects and rent transfers}

McCalman (2001) extends the Eaton and Kortum (1996) model to allow imitation risk to depend upon the national origin of innovations being patented while also permitting the sectoral coverage of patent protection to differ across countries. As he notes, prior to TRIPS many countries could exclude from patentability inventions in particular fields so certain inventions may not have been patented in some countries not because they were not of sufficiently high quality but simply because no patents were available in certain sectors. $^{74}$ McCalman utilizes data from 29 countries to estimate the welfare consequences of patent harmonization across countries (imposed in 1988). He measures international rent transfers enjoyed by a country as the difference between the increase

\footnotetext{
${ }^{74}$ For example, prior to TRIPS India and some other developing countries did not grant product patents for pharmaceuticals.
} 
in the present value of patent rights held by the residents of a country and the increase in the present value of patents granted by that country. Using this metric, he finds that of the 29 countries in his sample only six developed countries stood to gain from TRIPS, with the US being the biggest beneficiary, experiencing a net increase in the present value of patents of about $\$ 4.5$ billion. ${ }^{75}$ Significant loses included not just major developing countries such as Brazil and India, but also other countries such as Japan and the UK.

While these estimates of international rent transfers are useful for understanding the potential welfare impact of TRIPS, they are derived under the assumption that TRIPS does not affect the global rate of innovation. As a result, they do not capture any potential long run benefits of TRIPS. In a follow-up paper, McCalman (2005) allows for endogenous innovation and compares steady-state outcomes with and without TRIPS where the latter outcome is based on a counter-factual experiment: what would the steady-state outcome have been had TRIPS been in force in 1988? With the long run benefits of increased innovation accounted for, McCalman (2005) finds that all countries benefit from TRIPS. In other words, he finds that even from the perspective of developing countries, the benefits of increased innovation more than offset the international rent transfers that result from the strengthening of patent protection in the face of a highly unequal distribution of patents across the world.

Using detailed product-level data from India over a two year period (1999-2000), Chaudhuri et al. (2006) estimate the impact of introducing pharmaceutical product patents on industry equilibrium and consumer welfare. They first estimate price and expenditure elasticities for the flouroquinolone segment of systemic antibacterials and then use their estimates to conduct counter-factual simulations to evaluate what prices, profits, and consumer welfare would have been had the relevant flouroquinolone mole-

\footnotetext{
${ }^{75}$ To put things in context, McCalman (2001) notes that these transfers are estimated to be about $40 \%$ of the gains associated with trade liberalization undertaken in the Uruguay Round.
} 
cules been under patent protection in India (as they were in the US at that time). Since India did not grant product patents for pharmaceuticals prior to TRIPS, products containing these molecules were being produced and sold by a number of domestic firms (in addition to subsidiaries of multinationals). By incorporating price competition between local and foreign firms, the approach of Chaudhuri et al. (2006) is able to capture any cross-price effects resulting from changes in the pricing and/or availability of a subset of products. An important feature of their empirical model is that it allows for the possibility that local consumers differentiate between domestic and foreign products even if they contain the same patented molecule. As a result, they are able to capture any variety loss inflicted by the withdrawal of local products from the market.

Why might consumers differentiate between products based on the exact same molecule? Chaudhuri et al. (2006) argue that Indian consumers had superior access to local products because the marketing and distribution networks of local firms were much better developed than those of their foreign competitors. While this is true, it is also important to acknowledge that the lack of patent enforcement faced by foreign firms limited their incentive to invest in India. In the long run, one would imagine that foreign firms would have an incentive to expand their marketing and distribution networks if their patents were protected in India. In fact, with their superior resources and organizational know-how, it is conceivable that multinational firms would be capable of constructing an even superior distribution network than that provided by local Indian firms. Chaudhuri et al. (2006) estimate that holding prices of foreign firms constant (say via some type of price regulation), the withdrawal of the four domestic antibiotics in the flouroquinolone sub-segment in India (implied by TRIPS compliance) would inflict a welfare loss on the Indian economy equal to $50 \%$ of the sales of the entire antibiotic market in India in 2000. They estimate that the overwhelming portion of this loss would be borne by local consumers. Furthermore, while foreign firms would gain, the magnitude of these gains even in the absence of price regulations would be much smaller than 
the losses suffered by Indian consumers, making patent enforcement in this segment of the Indian pharmaceutical market a welfare-reducing deal in the short run. ${ }^{76}$

The above findings should give even ardent TRIPS supporters something to think about. In addition to the variety loss imposed by patent enforcement, a major channel behind the welfare losses estimated by Chaudhuri et al. (2006) is the increase in prices of foreign products that results from the elimination of local competition. Indeed, they estimate that prices of foreign patented products would rise between $100-400 \%$ in the absence of any price regulations. Since this is a counter-factual estimate based on data collected in 2000, it is worth knowing if TRIPS enforcement in India has actually resulted in significant price increases after India made its regime TRIPS compliant in 2005. In a recent paper, Duggan et al. (2014) study the impact of India's TRIPS induced patent reform of 2005 on local prices of pharmaceuticals. Using quarterly data on all single molecule pharmaceuticals sold in a retail setting from the first quarter of 2003 till the second quarter of 2012, they estimate that while molecules receiving patents indeed experienced price increases, the average price increase was fairly modest (about 3-6\%). The authors also find that if a molecule was produced by a single firm, the granting of a patent raised price by about $20 \%$ so that the overall modest price increase in their sample reflects a combination of a relatively large price effect for molecules produced by single firms and small effects for the rest of the market. Furthermore, while prior to 2006 there were no sales of patented molecules in their sample, the number of molecules covered by patents increased sharply during 2003-2012 so that by 2009 sales of patented molecules exceeded those of unpatented molecules. Finally, they find that the introduction of product patents had little impact on total sales or on the number of pharmaceutical companies operating in the Indian market.

\footnotetext{
${ }^{76}$ Using Indian data from 2001-2003 for 155 molecules spread across five broad therapeutic categories, Dutta (2011) estimates a structural model that she uses to simulate the effects of patent enforcement. Like Chaudhuri, Goldberg, and Jia (2006), she finds significant prices increases result from patent enforcement although her estimated magnitudes are smaller (ranging from 3.5\% to 80\%).
} 
The findings of Duggan et al. (2014) are valuable since they are based on actual product level data collected during the post-TRIPS era and they suggest that patent enforcement by itself may not result in large price increases in developing countries. It is worth noting the findings of Qian (2008) in this context who studied the effects of a reallocation of Chinese IPR enforcement resources away from monitoring footwear and fashion products to other sectors due to some episodes of food-poisoning and accidents caused by gas-explosions in the early 1990s. Qian (2008) found that prices set by manufacturers whose products became subject to increased infringement actually rose by $\$ 45$, on average, two years after counterfeiters entered the market due to lax IPR enforcement. Qian argues that when facing increased competition from counterfeiters, authentic manufacturers have an incentive to $(i)$ step up their efforts at product differentiation via innovation; (ii) increase private enforcement of brands; and (iii) signal their higher quality by raising prices.

\subsection{Dynamic effects: innovation and technology transfer}

Static welfare losses that might result from the shutting down of local firms producing imitated foreign products are not the only concern that India and other developing countries have with respect to TRIPS. These countries are also equally, if not more, concerned about the impact of TRIPS on the pace of local and/or global innovation as well as international technology transfer. While TRIPS does include a nominal clause (i.e. Article 66.2) that encourages developed countries to facilitate technology transfer to the least developed countries, it is unlikely that such statements, in of themselves, can alter the incentives of private agents and governments involved in this process. ${ }^{77}$

\footnotetext{
${ }^{77}$ More specifically, Article 66.2 states that " Developed country Members shall provide incentives to enterprises and institutions in their territories for the purpose of promoting and encouraging technology transfer to least-developed country Members in order to enable them to create a sound and viable technological base." See Hoekman, Maskus, and Saggi (2005) for a comprehensive discussion of various types of unilateral and multilateral policies that can facilitate technology transfer to developing countries.
} 
Let us first consider the effect of stronger patent protection on international technology transfer. The trade-off facing developing countries is clear cut: almost by definition, the slowing down of local imitation retards technology transfer but, in principle, this can be offset by increased flows of technology via licensing and FDI. The evidence discussed in section 7.2 shows that stronger IPR protection does indeed help attract more FDI. But does it also lead to more technology transfer? Direct evidence on this question is provided by Branstetter et al. (2006) who use firm level data from the Bureau of Economic Analysis to examine how technology transfer within US multinational firms changed in response to a series of IPR reforms undertaken by sixteen countries during 1982-1999. The find that royalty payments for technology transferred to affiliates increased at the time of reforms, as did affiliate R\&D expenditures and total levels of foreign patent applications. Furthermore, the increases in royalty payments and affiliate $R \& D$ expenditures were concentrated among affiliates of parent companies that use patents more extensively.

While these findings are encouraging, could the increase in royalty payments measure not just be a reflection of more monopoly power of IPR holders? In other words, patentholders may not have been transferring more technology but simply charging more since their rights were now better protected. To address this concern, Branstetter et al. (2006) show that R\&D spending by affiliates of multinationals - usually viewed as being complementary to technology imports from the parent - also increased after IPR reforms. Furthermore, consistent with Lerner (2002), they find that both the level and growth rate of non-resident patenting also increased in the post-reform period. Together, this evidence indicates that at least some portion of the observable increase in royalty flows was associated with the introduction of new technologies by US firms to the markets of countries that had undertaken patent reform.

By increasing international trade in technology, a strengthening of IPR protection (in countries where such protection is low) has the potential to benefit both sellers and 
buyers of technology. However, in some senses, the case for stronger IPR protection also hinges critically on whether or not it helps induce more innovation. Existing evidence on this issue does not present a clear-cut answer. For example, Sakakibara and Branstetter (2001) find no evidence that the Japanese patent reform of 1988 helped induce more innovation whereas Chen and Puttitanum (2005) do find such an effect. Lerner (2005) finds that intermediate levels of patent protection are most conducive for innovation: strengthening patents protection increases innovation when such protection is weak whereas it lowers innovation when it is strong.

Most recently, Ang et al. (2014) investigate this issue by exploiting province-level variation in the enforcement of IPRs in China. They find that high-tech firms in provinces with stronger enforcement of IPRs enjoy better access to external debt, invest a greater share of their funding in $\mathrm{R} \& \mathrm{D}$, take out more patents, and have higher sales of new products. These findings show that stronger IPR protection does have the potential to stimulate local innovation although the effects are likely to be context specific. ${ }^{78}$

In their study of $R \& D$ in the pharmaceutical industry (as measured by clinical trials undertaken) before and after TRIPS, Kyle and McGahan (2012) find that the relationship between patent protection and R\&D effort depends upon a country's income level. While there is a strong positive relationship between patents and R\&D effort targeted at diseases prevalent in high-income countries, such is not the case for diseases that primarily affect poor countries. These results fit well with those of Qian (2007) who also examined the effects of stronger patent protection on innovation in the local pharmaceutical industry (as measured by changes in citation weighted patent awards), domestic $\mathrm{R} \& \mathrm{D}$, and pharmaceutical exports. She found that stronger patent laws only stimu-

\footnotetext{
${ }^{78} \mathrm{Hu}$ et. al. (2005) study the relationship between technology transfer and indigenous R\&D in Chinese industry using data from 1995-1999 for 29 two-digit manufacturing industries and over 400 four-digit industries. They find evidence of a significant complementarity between the two: when combined with domestic $R \& D$, technology transfer significantly raises domestic firm productivity. This suggests that stronger IPR enforcement in developing countries can not only increase technology transfer directly by making it more secure but also indirectly by raising domestic incentives for R\&D.
} 
late local innovation in countries that possess high levels of development, education, and economic freedom. Thus, patent protection is certainly not sufficient for encouraging indigenous innovation in the pharmaceutical industry although it appears to be necessary.

\subsection{Historical evidence}

I now discuss a series of related papers that utilize historical data to investigate the relationship between patent laws and innovation. An extensive overview of this line of research is provided by Moser (2013). While applying the insights of these historical studies to the contemporary global economy it is important to bear in mind that the speed at which information travels globally today is radically faster than in the time periods covered by them. Furthermore, the global economy's ability to reverse-engineer and imitate novel technologies may have also increased sharply due to rapid economic development in many parts of the world, particularly in large Asian countries such as China and India. Thus, the importance of IPR protection to inventors in today's world of large-scale industrial espionage and cyber attacks may be much higher relative to that in the past.

As Moser (2005) notes, if the effectiveness of patents relative to alternative mechanisms (such as trade secrecy) as a means for preserving an inventor's technological edge varies across industries then whether or not patent protection is available in a country should affect its direction of technological change. Using exhibition data from the Crystal Palace World Fair (1851) involving 12 countries and from the Centennial Exhibition in Philadelphia (1876) involving 10 countries, she finds that innovation in countries that did not provide patent protection was concentrated in a smaller set of industries relative to those that did. ${ }^{79}$ For example, in 1851 roughly $25 \%$ of exhibits from Switzerland

\footnotetext{
${ }^{79}$ Moser (2005) finds that despite large differences in patent laws and costs of obtaining patents, the rate at which British and American inventors patented their inventions in 1851 as well as the industries in which they chose to do so were remarkably similar, suggesting that the driving forces behind the
} 
and $23 \%$ from Denmark - countries that did not provide patent protection at that time - were in scientific instruments. By contrast, the median share over all 12 countries was just around 6\%. She estimates that had these two countries had patent laws in place, the share of innovations that occurred in scientific instruments would have been between 14-15\%. Her findings suggest that the TRIPS-induced strengthening of IPRs in developing countries may trigger changes in their direction of innovative activity and not just its level.

Moser (2011) notes that until the mid 19th century, chemical innovations were rarely patented because they were difficult to reverse-engineer and inventors could rely on secrecy to preserve their technological advantages. More specifically, she notes that less than $5 \%$ of British chemical exhibits (and none of the US exhibits) on display at the Crystal Palace exhibition of 1851 were patented. But due to several key scientific advances - such as the publication of the periodic table in 1869 - reverse-engineering became easier and the share of chemical exhibits that were patented jumped to nearly $20 \%$ in 1893. By the same logic, given the rapid pace of scientific progress in the 20th century, the importance of patenting in certain sectors (such as chemicals) is also likely to have increased substantially. Moser (2011) argues that when protected by patents, inventors may be more likely to publicize their inventions beyond local networks and this can encourage technology diffusion. She shows that the increase in patenting brought about by a decline in the relative effectiveness of secrecy lowered the localization of chemical innovations after 1876 relative to innovations in the manufacturing machinery (which did not experience a shift towards patenting). ${ }^{80}$ Using difference-in-differences

decision to patent were likely to have been the same in the two countries. For example, the overall patenting rate was $11.1 \%$ in Britain and $14.2 \%$ in the US, with engines, manufacturing machinery, and agricultural machinery being the industries with the highest patenting rates in both countries. Moser (2012) finds that inventors were more likely to seek patents in industries in which innovations were easier to reverse engineer and trade secrecy was relatively ineffective.

${ }^{80}$ These world fairs were the Crystal Palace Exhibition in London (1851), the American Centennial Exhibition in Philadelphia (1893), the World's Columbia Exhibition in Chicago (1893), and the PanamaPacific International Explosion in San Francisco (1915). The total number of exhibitions on display 
regressions she estimates that a one percent increase in patenting rates was associated with a 1.3 percent decrease in the localization of inventions.

To examine the potential role an international IPR treaty can play in encouraging technology transfer, Bilir, Moser, and Talis (2011) examine the effects of the US accession to the Paris Convention of 1887 because of which the US started to offer stronger patent protection to nationals from countries that had signed the treaty before the US, without having any effect on the protection given to nationals from rest of the world. Their analysis of 86,000 US patents granted between 1865-1914 shows that the nationals from the favored countries increased their patenting in the US by over $40 \%$ as a result of the US accession and that the effects were strongest for nationals of countries that had high levels of economic development and education. To the extent that patenting facilitates technology diffusion (due to its disclosure requirement), these results - together with the observed changes in patenting behavior observed during the post TRIPS era discussed in section 2.2 and the evidence summarized in section 7.4 - are supportive of the premise that TRIPS will help facilitate technology transfer to developing countries.

Finally, I briefly discuss the findings of two related papers that address the impact of compulsory licensing of patents on innovation in the host and source countries. Taking advantage of an exogenous episode of compulsory licensing caused by the passing of the Trading with the Enemy Act (TWEA) by the US congress in 1917, Moser and Voena (2012) examine the effects of compulsory licensing of 727 enemy patents (most of which were German) to US firms. ${ }^{81}$ Their difference-in-difference analysis of almost 130,000 US chemical inventions finds that the compulsory licensing of enemy patents had a significant and positive impact on subsequent domestic innovation, although the full effects took six-nine years to realize. It is important to note that the enemy inventions that at these fairs exceeded 147,000 . More than 30 countries participated in each fair and the number of visitors ranged from roughly 6 million to 19 million.

${ }^{81}$ While over 4500 enemy-owned patents were confiscated by the US, only 727 were licensed by the Chemical foundation to one or more 326 US firms from 1919 to 1926. 
were licensed to US firms under TWEA were already patented in the US. Thus, these results do not speak to the role patenting plays in the international diffusion of international technology but rather to the importance of the learning that can take place when domestic firms have the right to produce locally by using patented foreign technologies. In a sense, these findings cast some doubt on the view that the disclosure requirement of patenting, in of itself, is sufficient for creating knowledge spillovers. Instead, they are more supportive of the argument that local production in developing countries based on the adoption of foreign technologies (either via imitation, licensing, or FDI) can help create a springboard for future indigenous innovation. Thus, compulsory licensing has the potential to indirectly act as an industrial policy.

Furthermore, it needs to be stressed that the findings of Moser and Voena (2012) capture the effects of a fairly large-scale episode of compulsory licensing. By contrast, much of the compulsory licensing we observe today involves a few patented medicines that are needed urgently to address local public health concerns in developing countries. It is doubtful that we can expect such sporadic episodes to generate the type of learning by doing that seems to underlie the findings of Moser and Voena (2012). The compulsory licensing under TWEA occurred under an environment where international relations between the principal countries concerned (US and Germany) were outright hostile. By contrast, today's developing countries have to abide by TRIPS while undertaking compulsory licensing of foreign patents and they are not in a position to force firms from industrialized countries to simply turn over their patented technologies to local firms. ${ }^{82}$

In a follow-up paper, Baten, Bianchi, and Moser (2014) examine whether and how

\footnotetext{
${ }^{82}$ The one exception to this argument is probably China. Under its indigenous innovation policy, China has been able to force many foreign firms to share their technologies with local firms (often via the formation of joint ventures) as a pre-condition for being able to do business in its market. As Maskus and Saggi (2014) note, the large size of the Chinese market and decades of sustained economic growth have given China a degree of leverage that is possessed by no other developing country. While Brazil and India have issued compulsory licenses for certain pharmaceutical patents in recent years, neither country has managed to do anything close to what China has been able to accomplish with respect to technology transfer policies.
} 
the compulsory licensing of German patents to US firms under the TWEA affected the incentives for innovation of the German chemical industry. Their key finding is that German firms whose patents had been subject to compulsory licensing under TWEA actually increased their patenting and that the increase was stronger in fields in which the level of market competition prior to compulsory licensing was low. These results suggest that the incentive for innovation is strengthened by an increase in market competition, an empirical finding that is of some importance because the theoretical literature in industrial organization does not yield an unambiguous relationship between market competition and innovation. ${ }^{83}$

\section{Conclusion: lessons learnt and what next?}

The GATT's core mandate was to facilitate trade liberalization, an objective in which it seems to have largely succeeded via rounds of multilateral negotiations conducted periodically since 1947. In 1995, the GATT was subsumed by the WTO, an organization whose mandate includes not just the liberalization of trade in goods and services but also the protection of intellectual property in the global economy. The expansion of the global trading system into the sensitive realm of intellectual property - both in terms of the establishment of an elaborate set of multilateral rules pertaining to IPRs and the potential use of the WTO's potent dispute settlement system to help enforce those rules - was controversial from the start. Though developing countries were strongly opposed to TRIPS, they signed on to it presumably because they perceived the benefits of the overall Uruguay Round bargain to outweigh its costs. In any case, the single undertaking nature of the WTO left them with little choice but to accept TRIPS since rejecting it

\footnotetext{
${ }^{83}$ Aghion et al. (2005) provide a model that helps reconcile the conflicting predictions of previous models regarding the effect of competition on innovation. In their model, the relationship between competition and innovation is monotonic (i.e. has an inverted U-shape): when market competition is weak, an increase in competition encourages innovation whereas when it is high, the effect is the opposite.
} 
was tantamount to opting out of the WTO.

It seems fair to acknowledge that many rich countries of today were free to borrow and assimilate foreign technologies during their early stages of development without having to provide much in the way of compensation to foreign inventors. Indeed, the leading proponent of stronger intellectual property protection in the global economy, i.e., the US, itself benefitted significantly from being able to access foreign technologies via imitation and large-scale compulsory licensing of patents owned by foreign firms. De to the ratification of TRIPS, similar policy freedom was irretrievably lost by developing countries of today.

Twenty years have passed since TRIPS came into force. It seems like a good time to take stock of the main lessons provided by the literature investigating the complex inter-relationships between trade, FDI, and IPR protection. So, what have we learnt?

First, the degree of IPR protection in the global economy affects trade in the very things IPRs are designed to protect - i.e. trade in intellectual property such as proprietary technologies. Furthermore, IPR protection (or the lack of it) can alter both the pattern and the extent of international trade and FDI in the global economy. In a nutshell, existing empirical evidence establishes beyond a shadow of doubt that IPRs are trade-related.

Second, to the extent international agreements are meant to internalize international externalities created by the pursuit of beggar-thy-neighbor policies (Bagwell and Staiger, 1999), international coordination of IPRs appears to be necessary. This is because the unilateral pursuit of IPR policies combined with the fact that trade and FDI spread the benefits of innovation across national boundaries leads to a classic Prisoner's dilemma type situation wherein each country deliberately chooses to offer too little IPR protection relative to what is jointly optimal. But does such international coordination over IPRs necessarily need to occur at the WTO? The position of developing countries on this question notwithstanding, given that there exist international externalities in the 
enforcement of IPRs that affect the pattern and the volume of international trade, a reasonable argument can be made that a multilateral agreement over IPRs should indeed reside at the WTO. But the difficulty with this line of reasoning is that IPRs are by no means unique in this regard. Even TRIPS proponents must concede that the set of rules and regulations that affect trade-related activities in the global economy is quite large. For example, laws and regulations relating to labor, competition, environment, as well as investment are all obviously trade-related and perhaps even more so than those pertaining to intellectual property. Should the WTO also negotiate, implement, monitor, and enforce multilateral agreements in all of these areas? ${ }^{84}$ To have an effective and manageable agenda, the WTO must draw the line somewhere. A WTO that includes multilateral rules on every major trade-related activity would almost surely be a cumbersome and ineffective organization.

Third, while the formal literature provides a rationale for international coordination over IPRs and generally supports the major TRIPS flexibilities provided by Article 6 (exhaustion policies) and Article 31 (compulsory licensing), the case for the wholesale import of core GATT principles such as non-discrimination (via the national treatment clause) into the realm of intellectual property is not clear cut. While non-discrimination has much to recommend it from an implementation perspective, one must also account for the fact that, all else equal, the presence of trade frictions makes foreign patent protection less valuable to innovating firms than domestic protection. As a result, forcing countries to treat domestic and foreign firms alike can potentially blunt the overall effectiveness of patent protection as an instrument for incentivizing innovation.

Fourth, the literature on North-South product cycle models has taught us that the overall effects of strengthening IPR protection in the global economy depend very much

\footnotetext{
${ }^{84}$ Maskus (2002) has argued that given that IPRs are part of the WTO, a strong case can be made for the inclusion of competition policy although, in his view, the case for labor and environmental standards is weaker. See also Hoekman and Saggi (2000 and 2005).
} 
on whether imitation or FDI is the major driver of international technology transfer. Indeed, from the viewpoint of developing countries, these two channels often work against each other: while increased imitation of products invented by developed countries shifts more production into indigenous hands, it simultaneously slows down the introduction of new products and technologies via FDI. Furthermore, stronger IPR protection in the South also affects prices in conflicting directions: the induced increase in FDI lowers prices of those products that would have been produced in the North (where wages tend to be higher) but it raises prices of those products that would have been produced by Southern imitators (as opposed to multinationals).

Fifth, both the concern that TRIPS enforcement can hurt developing countries by raising local prices and the hope that it would benefit them by directing more investment and technology transfer to their markets have been borne out by empirical evidence. However, whatever little evidence is currently available indicates that the observed price increases in developing countries as a result of stronger IPR protection have not been particularly large. The observed price increases may have been small due to several potential reasons. First, the enforcement of IPRs in developing countries is probably fairly imperfect even today so that local imitation continues to discipline the market power of patent-holders to some degree. Two, the pattern of local demand in developing countries and the limited buying power of local consumers may not support large price increases. Third, as noted above, as production of more patented products shifts from the developed to the developing world via FDI and arms-length licensing, one should expect a downward pressure on prices due to the resulting reduction in production costs.

Finally, there is not much evidence indicating that TRIPS has led to an increase in the pace of innovation (at least yet), particularly in areas of special concern to developing countries - such as pharmaceutical products targeting diseases that primarily exist in the developing world. While evidence strongly supports the proposition that stronger IPR protection has boosted technology transfer and FDI to developing countries, we 
cannot yet say that it has had a positive impact on the pace of indigenous innovation in the developing world. However, as one might expect, on its own patent protection can hardly be sufficient for jump-starting innovation in countries that lack the requisite factor endowments, well functioning capital markets, and/or appropriate economic policies in general.

I conclude by highlighting several areas where future research is urgently needed. First, most North-South models of technology transfer and optimal patent protection assume preferences to be symmetric across regions. While this is a useful simplifying assumption, it prevents a proper investigation of some important issues of concern to developing countries. For example, most models of parallel trade and exhaustion policies are correctly driven by the assumption that consumers in the two regions have very different demand structures and/or income distributions that naturally give rise to incentives for price discrimination on the part of IPR holders. Somewhat curiously, this insight has been mostly ignored in analysis of innovation and optimal patent protection. As a result, this branch of the literature is virtually silent on why there has been so little increase in R\&D aimed at diseases that primarily afflict developing countries and whether or not multilateral cooperation can help address this deficiency. Similarly, the possibility that owing to differences in preferences, deadweight losses from patent protection could vary substantially across countries has not been given sufficient consideration. ${ }^{85}$

While it is commonly understood that the value of patent protection varies dramatically across sectors, the current global patent system calls for a uniform patent length (of 20 years) regardless of the nature of the product. Why? Is such a patent system optimal? Could and should the system be calibrated more finely to take into account sectoral variation in the need and social value of patent protection? If the answer to this question is in the affirmative, the case against harmonization of patent protection made in the literature becomes even clearer: since the structure of comparative advantage

\footnotetext{
${ }^{85}$ See however, Diwan and Rodrik (1991) and McCalman (2002).
} 
and production differs across countries, so must the role that patent protection plays in incentivizing innovation in various parts of the world. It follows then that a globally optimal patent system would need to take such differences into account. However, the transactions costs of implementing a more flexible global patent system are also likely to be higher than that of the current system. It is quite possible that, when all is said and done, a one-size-fits-all patent system mandated under TRIPS is so much easier to implement than an alternative system that takes national differences into account that the current system emerges as being the optimal choice. However, to the best of my knowledge, such an argument has neither been investigated formally nor proven. Further research into this issue is likely to be valuable from both an academic and a policy perspective.

My final suggestion for future research is a fairly practical one: we need to learn more about the effect TRIPS has had on the actual ground realties of IPR enforcement in developing countries. It is clear that TRIPS has moved the needle; it is far less clear by how much. The various measures of IPR protection in developing countries that we have at our disposal today - such as the Ginarte-Park index of patent protection - are a good start but we simply need to know more. For example, has the aggregate government expenditure on IPR enforcement in countries like India and China changed dramatically since TRIPS? Has its allocation across sectors been affected? Have local courts through-out the world started to show a reduced tendency toward discrimination against foreign nationals? Answers to these and related questions require the careful collection and analysis of detailed data from markets, governments, and legal systems through-out the world. 


\section{References}

[1] Aghion P., Bloom N., Blundell R., Griffith R., Howitt P., 2005. Competition and innovation: an inverted U relationship. Quarterly Journal of Economics 120 (May): $701-28$

[2] Ang, J.S., Cheng, Y., Wu, C., 2014. Does enforcement of intellectual property rights matter in China? Evidence from financing and investment choices in the high-tech industry. Review of Economics and Statistics 96 (2), 332-348.

[3] Antràs, P. 2005. Incomplete contracts and the product cycle. American Economic Review 95 (4), 1054-1073.

[4] Antràs, P., Yeaple, S.R., 2014. Multinational firms and the structure of international trade. Handbook of International Economics 4, 55-130.

[5] Aoki, R., Prusa, T.J., 1993. International standards for intellectual property protection and R\&D incentives. Journal of International Economics 35(3/4): 251-273.

[6] Aoki, R., Prusa, T.J., 1996. Product development and the timing of information disclosure under U.S. and Japanese patent systems. Journal of the Japanese and International Economies 10(3): 233-249.

[7] Aoki, R., Prusa, T.J., 1997. Sequential versus simultaneous choice with endogenous quality. International Journal of Industrial Organization 15(1): 103-122.

[8] Bagwell, K., Staiger, R.W., 1999. An economic theory of GATT. American Economic Review 89 (1), 215-248.

[9] Baten, J., Bianchi, N., Moser, P., 2014. Does compulsory licensing discourage invention? Evidence from German patents after the US Trading-with-The-Enemy Act. Working Paper. 
[10] Baudenbacher, C., 1998. Trademark law and parallel imports in a globalized world - recent developments in Europe with special regard to the legal situation in the United States. Fordham International Law Journal 22 (3), 645-695.

[11] Beall, R., Kuhn, R., 2012. Trends in compulsory licensing of pharmaceuticals since the Doha Declaration: a database analysis. PLos Medicine 9 (1), 1-9.

[12] Bennato, A.R., Valletti, T., 2014. Pharmaceutical innovation and parallel trade. International Journal of Industrial Organization 33, 83-92.

[13] Bilir, L.K., 2014. Patent laws, product life-cycle lengths, and multinational activity. American Economic Review 104 (7), 1979-2013.

[14] Bilir, L.K., Moser, P., Talis, I., 2011. Do treaties encourage technology transfer? Evidence from the Paris convention. Working Paper.

[15] Boldrin, M., Levine, K. D., 2013. The case against patents. Journal of Economic Perspectives 27 (1), 3-22.

[16] Bond, E.W., 2005. The economics of international trade agreements and dispute settlement with intellectual property rights. In International Public Goods and Transfer of Technology under a Globalized Intellectual Property Regime, eds. Keith E. Maskus and Jerome H. Reichman, New York: Cambridge University Press.

[17] Bond, E.W., Saggi, K., 2014. Compulsory licensing, price controls, and access to patented foreign products. Journal of Development Economics 109, 217-228.

[18] Bond, E.W., Saggi, K., 2015a. Compulsory licensing and patent protection: a North-South perspective. Mimeo, Vanderbilt University. 
[19] Bond, E.W., Saggi, K., 2015b. International price negotiations under the threat of compulsory licensing. Mimeo, Vanderbilt University.

[20] Borota, T., 2012. Innovation and imitation in a model of North-South trade. Journal of Innternational Economics, 87(2), 365-376

[21] Branstetter, L.G., Sakakibara, M., 2001. Do stronger patents induce more innovation? Evidence from the 1988 Japanese patent law reforms. Rand Journal of Economics 32 (1), 77-100.

[22] Branstetter, L., Fisman, R., Foley, F., 2006. Does stronger intellectual property rights increase international technology transfer? Empirical evidence from U.S. firm-level data. Quarterly Journal of Economics 121 (1), 321-349.

[23] Branstetter, L.G., Fisman, R., Foley, F., Saggi, K., 2011. Does intellectual property rights reform spur industrial development? Journal of International Economics 83 (1), 27-36.

[24] Branstetter, L.G., Saggi, K., 2011. Intellectual property rights, foreign direct investment and industrial development. Economic Journal 121 (555), 1161-1191.

[25] Chaudhuri, S., Goldberg, P.K., Jia, P., 2006. Estimating the effects of global patent protection in pharmaceuticals: a case study of quinolones in India. American Economic Review 96 (5), 1477-1514.

[26] Chen, Y., Maskus, K.E., 2004. Vertical price control and parallel imports: theory and evidence. Review of International Economics 12 (4), 551-570.

[27] Chen, Y., Puttitanun, T., 2005. Intellectual property rights and innovation in developing countries. Journal of Development Economics 78, 474-493. 
[28] Chu, A.C., Cozzi, G., Galli, S., 2014. Stage-dependent intellectual property rights. Journal of Development Economics 106, 239-249.

[29] Chu, A.C., Cozzi, G., Galli, S., 2012. Does intellectual monopoly stimulate or stifle innovation? European Economic Review 56, 727-746

[30] Chung, K-S., Lu, C-H., 2014. Non-homothetic preferences and IPRs protection. Journal of Development Economics 109, 229-39.

[31] Cockburn, I.M., Lanjouw, J.O., Schankerman, M., 2014. Patents and the global diffusion of new drugs. N.B.E.R. Working Paper 20492.

[32] Cohen, W.M., Nelson, R.R., Walsh, J.P., 2000. Protecting their intellectual assets: appropriability conditions and why U.S. manufacturing firms patent (or not). N.B.E.R. Working Paper 7552.

[33] Danzon, P.M., Epstein, A.J., 2012. Effects of regulation on drug launch and pricing in interdependent markets. Advances in Health Economics and Health Services Research 23, 35-71.

[34] Dinopoulos, E., Segerstrom, P., 2010. Intellectual property rights, multinational firms and economic growth. Journal of Development Economics 92 (1), 13-27.

[35] Diwan, I. and Rodrik, D., 1991. Patents, appropriate technology and North-South trade. Journal of International Economics 30(1-2), 27-7.

[36] Dixit, A., Stiglitz, J., 1977. Monopolistic competition and optimum product diversity. American Economic Review 67 (3), 297-308.

[37] Duggan, M., Garthwaite, C., Goyal, A., 2014. The market impacts of pharmaceutical product patents in developing countries: evidence from India. N.B.E.R Working Paper 20548. 
[38] Dutta, A., 2011. From free entry to patent protection: welfare implications for the Indian pharmaceutical industry. Review of Economics and Statistics 93 (1), 160-178.

[39] Eaton, J., Kortum, S., 1996. Trade in ideas: patenting and productivity in the OECD. Journal of International Economics 40 (3-4), 1-28.

[40] Eaton, J., Kortum, S., 1999. International technology diffusion: theory and measurement. International Economic Review 40 (3), 537-570.

[41] Eicher, T., Garcia-Peñalosa, C., 2008. Endogenous strength of intellectual property rights: implications for economic development and growth. European Economic Review 52 (2), 237-258.

[42] Ethier, W.J., Markusen, J.R., 1996. Multinational firms, technology diffusion and trade. Journal of International Economics 41 (1-2), 1-28.

[43] Gallini, N., Scotchmer, S., 2002. Intellectual property: when is it the best incentive mechanism? Innovation Policy and the Economy, Vol 2, Adam Jaffe, Joshua Lerner and Scott Stern, eds, MIT Press, pp. 51-78.

[44] Ganslandt, M., Maskus, K.E., 2007. Vertical distribution, parallel trade, and price divergence in integrated markets. European Economic Review 51 (4), 943-970

[45] Geng, D., Saggi, K., 2015a. The nature of innovative activity and the protection of intellectual property in Asia. Asian Economic Policy Review 10, 71-91.

[46] Geng, D., Saggi, K., 2015b. Is there a case for non-discrimination in the international protection of intellectual property? Journal of International Economics, forthcoming. 
[47] Geng, D., Saggi, K., 2015c. External reference pricing policies, price controls, and international patent protection. Working paper.

[48] Gilbert, R., 2011. A world without intellectual property?: Boldrin and Levine, against intellectual monopoly. Journal of Economic Literature 49 (2), 421-432.

[49] Ginarte, J., Park, W., 1997. Determinants of patent rights: a cross-national study. Research Policy 26 (3), 283-301.

[50] Glass, A.J., Saggi, K., 1998. International technology transfer and the technology gap. Journal of Development Economics 55, 369-398.

[51] Glass, A.J., Saggi, K., 2002a. Intellectual property rights and foreign direct investment. Journal of International Economics 56 (2), 387-410.

[52] Glass, A.J., Saggi, K., 2002b. Multinational firms and technology transfer. Scandinavian Journal of Economics 104, 495-513.

[53] Glass, A.J., Wu, X., 2007. Intellectual property rights and quality improvement? Journal of Development Economics 82 (2), 393-415.

[54] Goldberg, P.K., 2010. Intellectual property rights protection in developing countries: the case of pharmaceuticals. Journal of the European Economic Association $8(2-3), 326-353$.

[55] Goldstein, P.A., 2001. International Copyright: Principles, Law, and Practice. New York: Oxford University Press.

[56] Grossman, G.M., Lai, Edwin L.-C., 2004. International protection of intellectual property. American Economic Review 94 (5), 1635-1653.

[57] Grossman, G.M., Lai, Edwin L.-C., 2008. Parallel imports and price controls. Rand Journal of Economics 39 (2), 378-402. 
[58] Grossman, G.M., Helpman, E., 1991a. Innovation and Growth in the Global Economy, Cambridge: MIT press.

[59] Grossman, G.M., Helpman, E., 1991b. Endogenous product cycles. Economic Journal 101 (3), 1214-1229.

[60] Grossman, G.M., Helpman, E., 1991c. Quality ladder and product cycles. Quarterly Journal of Economy, 106 (2), 557-586.

[61] Grossman, G.M., Helpman, E., 1991d. Quality ladders in the theory of growth. Review of Economic Studies, 58(1), 43-61.

[62] Gustafsson, P., Segerstrom, P., 2011. North-South trade with multinational firms and increasing product variety. International Economic Review, 52(4), 1123-1155.

[63] Gustafsson,P., Segerstrom, P., 2010. North-South trade with increasing product variety. Journal of Development Economics, 92(2), 97-106.

[64] Harhoff, D., Hoisl, K., 2007. Inventors and invention processes in Europe: results from the PatVal-EU survey. Research Policy 36 (8), 1107-1127.

[65] Helpman, E., 1993. Innovation, imitation, and intellectual property rights. Econometrica 61 (6), 1247-1280.

[66] Helpman, E., Krugman P.R., 1985. Market Structure and Foreign Trade. Increasing Returns, Imperfect Competition, and the International Economy, Cambridge, MA: MIT Press.

[67] Hoekman, B., Saggi, K., 2000. Assessing the case for extending WTO disciplines on investment-related policies. Journal of Economic Integration 15, 629-653. 
[68] Hoekman, B., Saggi, K., 2005. International cooperation on domestic policies: lessons from the WTO competition policy debate. In S. Evenett and B. Hoekman, eds., Economic Development and Multilateral Trade Cooperation, Palgrave/McMillan and the World Bank.

[69] Hoekman, B., Maskus, K., Saggi, K., 2005. Transfer of technology to developing countries: unilateral and multilateral policy options. World Development 33(10), 1587-1602.

[70] Hopenhayn, H., Llobet, G., Mitchell. M., 2006. Rewarding sequential innovators: prizes, patents, and buyouts. Journal of Political Economy 114 (6), 1041-1068.

[71] Hu, A.G., Jefferson, G.H., Qian, J., 2005. R\&D and technology transfer: firmlevel evidence from Chinese industry. Review of Economics and Statistics 87 (4), 780-786.

[72] Hu, A.G., Jefferson, G.H., 2009. A great wall of patents: What is behind China's recent patent explosion? Journal of Development Economics 90 (1), 57-68.

[73] Ivus, O., 2010. Do stronger patent rights raise high-tech exports to the developing world? Journal of International Economics 81 (1), 38-47.

[74] Ivus, O., 2011. Trade-related intellectual property rights: industry variation and technology diffusion. Canadian Journal of Economics 44 (1), 201-226.

[75] Ivus, O., 2015. Does stronger patent protection increase export variety? Evidence from U.S. product-level data. Journal of International Business Studies, forthcoming.

[76] Ivus, O., Park, K., Saggi, K., 2015a. Intellectual Property Protection and the Industrial Composition of Multinational Activity. Working paper. 
[77] Ivus, O., Park, K., Saggi, K., 2015b. Patent protection and the industrial composition of multinational activity: evidence from U.S. multinational firms. Working paper.

[78] Javorcik, B., 2004. The composition of foreign direct investment and protection of intellectual property rights in transition economies. European Economic Review 48 (1), 39-62.

[79] Jones, C.I., 1995. R\&D based models of economic growth. The Journal of Political Economy, 103(4), 759-784.

[80] Kremer, M., 1998. Patent buyouts: a mechanism for encouraging innovation. Quarterly Journal of Economics 113 (4), 1137-1167.

[81] Kremer, M., 2002. Pharmaceuticals and the developing world. Journal of Economic Perspectives 16 (4), 67-90.

[82] Krugman, P.R., 1979. A model of innovation, technology transfer, and the world distribution of income. Journal of Political Economy 87 (2), 253-266.

[83] Kyle, M., 2007. Pharmaceutical price controls and entry strategies. The Review of Economics and Statistics 89 (1), 88-99.

[84] Kyle, M., McGahan, A., 2012. Investments in pharmaceuticals before and after TRIPS. Review of Economics and Statistics 94 (4), 1157-1172.

[85] Kyle, M., Qian, Y., 2014. Intellectual property rights and access to innovation: evidence from TRIPS. N.B.E.R. Working Paper 20799.

[86] Lai, Edwin L.-C., 1998. International intellectual property rights protection and the rate of product innovation. Journal of Development Economics 55 (1), 133-153. 
[87] Lai, Edwin L.-C., Qiu, L.D., 2003. The North's intellectual property rights standard for the South? Journal of International Economics 59 (1), 183-209.

[88] Lai, Edwin L.-C., Yan, Isabel K.M., 2013. Would global patent protection be too weak without international coordination? Journal of International Economics 89 (1), 42-54.

[89] Lanjouw, J.O., 1998. The introduction of pharmaceutical product patents in India: "heartless exploitation of the poor and suffering"? N.B.E.R. Working paper 6366.

[90] Lanjouw, J.O., 2005. Patents, price controls and access to new drugs: how policy affects global market entry. N.B.E.R. Working paper 11321.

[91] Lee, J-Y., Mansfield, E., 1996. Intellectual property protection and U.S. foreign direct investment. Review of Economics and Statistics 78 (2), 181-186.

[92] Lerner, J., 2002. Patent protection and innovation over 150 years. NBER Working paper 8977.

[93] Li, C., Maskus, K.E., 2006. The impact of parallel imports on investments in costreducing research and development. Journal of International Economics 68 (2), 443-455.

[94] Li, C., Robles, J., 2007. Product innovation and parallel trade. International Journal of Industrial Organization 25 (2), 417-429.

[95] Lin, P., Saggi, K., 1999. Incentives for foreign direct investment under imitation. Canadian Journal of Economics 32, 1275-98.

[96] Malueg, D.A., Schwartz, M., 1994. Parallel imports, demand dispersion, and international price discrimination. Journal of International Economics 37 (3-4), 167 195. 
[97] Mansfield, E., 1994. Intellectual property protection, foreign direct investment, and technology transfer. Discussion Paper 19, International Finance Corporation, Washington DC.

[98] Markusen, J.R., 1995. The boundaries of multinational enterprises and the theory of international trade. Journal of Economic Perspectives 9 (2), 169-189.

[99] Markusen, J.R., 2001. Contracts, intellectual property rights, and multinational investment in developing countries. Journal of International Economics 53 (1), 189-204.

[100] Markusen, J.R. Venables, A.J., 1988. Trade policy with increasing returns and imperfect competition: contradictory results from competing assumptions. Journal of International Economics 24 (3-4), 299-316.

[101] Maskus, K.E., Penubarti, M., 1995. How trade-related are intellectual property rights? Journal of International Economics 39 (3-4), 227-248.

[102] Maskus, K.E., 2000a. Intellectual Property Rights in the Global Economy. Institute of International Economics, Washington, D.C.

[103] Maskus, K.E., 2000b. Parallel imports. The World Economy 23(9), 1269-1284.

[104] Maskus, K.E., 2002. Regulatory standards in the WTO: comparing intellectual property rights with competition policy, environmental protection, and core labor standards. World Trade Review, 1(2), 135-152.

[105] Maskus, K.E., Yang, G., 2003. Intellectual property rights, licensing, and innovation in an endogenous product-cycle model. Journal of International Economics $53(1), 169-187$. 
[106] Maskus, K.E., Puttitanun, T., Saggi, K., 2005. Patent rights and international technology transfer through direct investment and licensing. In K. Maskus and J. Reichman, eds., International Public Goods and the Transfer of Technology under a Globalized Intellectual Property Regime, Cambridge University Press.

[107] Maskus, K.E., 2012 Private Rights and Public Problems: The Global Economics of Intellectual Property in the 21st Century. Institute of International Economics, Washington, D.C.

[108] Maskus, K.E., Stähler, F., 2014. Retailers as agents and the limits of parallel trade. European Economic Review 70 (C), 186-196.

[109] Maskus, K.E., Saggi, K., 2014. International technology transfer: an analysis from the perspective of developing countries, World Intellectual Property Organization, Committee on Development and Intellectual Property.

[110] Mayer, T., Pfister, E., 2001. Do stronger patent rights attract foreign foreign direct investment? Evidence from French multinationals' location. Région et Dévelopment $13,99-122$.

[111] McCalman, P., 2001. Reaping what you sow: an empirical analysis of international patent harmonization. Journal of International Economics 55(1), 161-186.

[112] McCalman, P., 2002. National patents, innovation and international agreements. Journal of International Trade and Economic Development 11(1), 1-14.

[113] McCalman, P., 2004. Foreign direct investment and intellectual property rights: evidence from Hollywood's global distribution of movies and videos. Journal of International Economics 62 (1), 107-123.

[114] McCalman, P., 2005. International diffusion and intellectual property rights: an empirical analysis. Journal of International Economics 67 (2), 353-372. 
[115] Moser, P., 2005. How do patent laws influence innovation? Evidence from nineteenth-century world fairs. American Economic Review 95 (4), 1214-1236.

[116] Moser, P., 2011. Do patents weaken the localization of innovations? Evidence from world's fairs, 1851-1915. Journal of Economic History 71 (2), 363-382.

[117] Moser, P., 2012. Innovation without patents - evidence from world's fairs. The Journal of Law and Economics 55(1), 43-74

[118] Moser, P., 2013. Patents and innovation - evidence from economic history. Journal of Economic Perspectives 27 (1), 23-44.

[119] Moser, P. Voena, A., 2012. Compulsory licensing: evidence from the trading with the enemy act. American Economic Review 102 (1), 396-427.

[120] National Economic Research Associates (NERA), 1999. The economic consequences of the choice of regime of exhaustion in the area of trademarks. Final Report for DG XV of the European Commission.

[121] Nordhaus, W.D., 1969. Invention, Growth and Welfare: A Theoretical Treatment of Technological Change. Cambridge, MA: MIT Press.

[122] Nunnenkamp, P., Spatz, J., 2004. FDI and economic growth in developing economies: how relevant are host-economy and industry characteristics. Transnational Corporations 13 (3), 52-86.

[123] Park, W., 2008. Intellectual property rights and international innovation? (K. Maskus, ed.), Frontiers of Economics and Globalization: Intellectual Property Rights and Globalization, pp. 289-327, Amsterdam: Elsevier.

[124] Pecorino, P., 2002. Should the US allow prescription drug reimports from Canada? Journal of Health Economics 21 (4), 699-708. 
[125] Pozen, R.C., 2008. Note on compulsory licensing. Harvard Business School Case 9-609-009.

[126] Qian, Y., 2007. Do national patent laws stimulate domestic innovation in a global patenting environment? A cross-country analysis of pharmaceutical patent protection, 1978-2002. Review of Economics and Statistics 89 (3), 436-453.

[127] Qian, Y., 2008. Impacts of entry by counterfeiters. Quarterly Journal of Economics $123(4), 1577-1609$.

[128] Raff, H., Schmitt, N., 2009. Buyer power in international markets. Journal of International Economics 79 (2), 222-229.

[129] Rapp, R.T., Rozek, R.P., 1990. Benefits and costs of intellectual property protection in developing countries. Journal of World Trade 24 (5), 75-102.

[130] Richardson, M., 2002. An elementary proposition concerning parallel imports. Journal of International Economics 56 (1), 233-245.

[131] Rockett, K., 2010. Property rights and invention. Handbook of the Economics of Innovation 1, 315-380.

[132] Romer, P.M., 1990. Endogenous technological change. Journal of Political Economy 98 (5), 71-102.

[133] Roy, S., Saggi, K., 2012a. Equilibrium parallel import policies and international market structure. Journal of International Economics 87 (2), 262-276.

[134] Roy, S., Saggi, K., 2012b. Strategic competition and optimal parallel import policy. Canadian Journal of Economics 45(4), 1369-1396.

[135] Saggi, K., 2002. Trade, foreign direct investment, and international technology transfer: a survey. World Bank Research Observer 17(2), 191-235. 
[136] Saggi, K., 2013. Market power in the global economy: the exhaustion and protection of intellectual property. Economic Journal 123 (567), 131-161.

[137] Saggi, K., 2014. Regional exhaustion of intellectual property. International Journal of Economic Theory 10 (1), 125-137.

[138] Scherer F.M., Watal J., 2002. Post-TRIPS options for access to patented medicines in developing nations. Journal of International Economic Law 5(4), 913-939.

[139] Schmalensee, R., 1981. Output and welfare implications of monopolistic thirddegree price discrimination. American Economic Review 71 (1), 242-247.

[140] Scotchmer, S., 2004. The political economy of intellectual property treaties. Journal of Law, Economics and Organization 20 (2), 415-437.

[141] Smith, A., Venables, A.J., 1988. Completing the internal market in the European community: some industry simulations. European Economic Review 32 (7), 15011525.

[142] Smith, P.J., 1999. Are weak patent rights a barrier to U.S. exports? Journal of International Economics 48 (1), 151-177.

[143] Smith, P.J., 2001. How do foreign patent rights affect U.S. exports, affiliate sales, and licenses? Journal of International Economics 55 (2), 411-439.

[144] Szymanski, S., Valletti, T., 2006. Parallel trade, international exhaustion and intellectual property rights: a welfare analysis. Journal of Industrial Economics 54 (4), 499-526.

[145] Tanaka, Hitoshi \& Iwaisako, Tatsuro, 2014. Intellectual property rights and foreign direct investment: a welfare analysis. European Economic Review 67 (C), 107-124. 
[146] United Nations Conference on Trade and Development, 2010. World Investment Report. New York: United Nations.

[147] United Nations Conference on Trade and Development, 2014. World Investment Report. New York: United Nations.

[148] United States International Trade Commission, 1988. Foreign Protection of Intellectual Property Rights and the Effect on US Industry and Trade. Washington: USITC.

[149] US-Chamber of Commerce, 1987. Guidelines for Standards for the Protection and Enforcement of Intellectual Property Rights.Washington: United States Chamber of Commerce.

[150] Webster, E., Jensen, P.H., Palangkaraya, A., 2014. Patent examination outcomes and the national treatment principle. Rand Journal of Economics 45 (2), 449-469.

[151] Valletti, T.M., 2006. Differential pricing, parallel trade, and the incentive to invest. Journal of International Economics 70 (1), 314-324.

[152] Varian, H., 1985. Price discrimination and social welfare. American Economic Review 75 (4), 870-875.

[153] Venables, A.J., 1990. The economic integration of oligopolistic markets. European Economic Review 34 (4), 753-769.

[154] Vernon, R., 1966. International investment and international trade in the product cycle. Quarterly Journal of Economics 80 (2), 190-207.

[155] World Health Organization. 2013. WHO Guideline on Country Pharmaceutical Pricing Policies. Geneva: WHO. 
Table 1: Allocation of global GDP (PPP)

\begin{tabular}{llllll}
\hline \hline & 1990 & 1995 & 2005 & 2010 & 2013 \\
\hline \hline Low income countries (LICs) & $1.37 \%$ & $1.29 \%$ & $1.36 \%$ & $1.47 \%$ & $1.60 \%$ \\
Lower middle income countries (LMICs) & $11.31 \%$ & $11.54 \%$ & $12.75 \%$ & $14.23 \%$ & $14.95 \%$ \\
Upper middle income countries (UMICs) & $19.66 \%$ & $22.07 \%$ & $25.82 \%$ & $30.06 \%$ & $31.82 \%$ \\
High income countries (HICs) & $67.66 \%$ & $65.10 \%$ & $60.07 \%$ & $54.24 \%$ & $51.63 \%$ \\
\hline Global GDP (current \$, tn) & 28.49 & 36.42 & 65.00 & 87.89 & 102.85 \\
\hline
\end{tabular}

Source: World Development Indicators, 2014

Table 2: Shares of inward FDI flows

\begin{tabular}{lccccc}
\hline \hline & 1990 & 1995 & 2005 & 2010 & 2013 \\
\hline \hline Least developed & $0.27 \%$ & $0.59 \%$ & $0.75 \%$ & $1.38 \%$ & $1.92 \%$ \\
Developing & $16.59 \%$ & $34.86 \%$ & $36.76 \%$ & $49.16 \%$ & $59.12 \%$ \\
Developed & $83.14 \%$ & $64.55 \%$ & $62.49 \%$ & $49.46 \%$ & $38.96 \%$ \\
\hline Global FDI flows (current \$) & 208.17 bn & 343.28 bn & 996.71 bn & 1.42 tn & 1.45 tn \\
\hline \multicolumn{5}{c}{ Source: UNCTAD, 2014 } &
\end{tabular}

Table 3: Shares of inward FDI stock

\begin{tabular}{lccccc}
\hline \hline & 1990 & 1995 & 2005 & 2010 & 2013 \\
\hline \hline Least developed & $0.53 \%$ & $0.55 \%$ & $0.59 \%$ & $0.70 \%$ & $0.83 \%$ \\
Developing & $24.26 \%$ & $24.60 \%$ & $25.73 \%$ & $35.28 \%$ & $36.13 \%$ \\
Developed & $75.21 \%$ & $74.85 \%$ & $73.68 \%$ & $64.02 \%$ & $63.04 \%$ \\
\hline Global FDI stock (current \$, tn) & 2.08 & 3.43 & 11.74 & 20.37 & 25.46 \\
\hline
\end{tabular}

Source: UNCTAD, 2014

Table 4: Ginarte-Park index

\begin{tabular}{lcccc}
\hline \hline & 1990 & 1995 & 2005 & 2010 \\
\hline \hline Brazil & 1.28 & 1.48 & 3.43 & 3.43 \\
China & 1.33 & 2.12 & 4.08 & 4.21 \\
India & 1.03 & 1.23 & 3.76 & 3.76 \\
Japan & 3.88 & 4.42 & 4.67 & 4.67 \\
Russia & 1.41 & 3.48 & 3.68 & 3.68 \\
US & 4.68 & 4.88 & 4.88 & 4.88 \\
\hline
\end{tabular}

Source: Email communication with Walter Park 
Table 5: Allocation of total patents granted

\begin{tabular}{lccccc}
\hline \hline & 1995 & 2000 & 2005 & 2010 & 2013 \\
\hline \hline LICs & $0.09 \%$ & $0.16 \%$ & $0.73 \%$ & $0.74 \%$ & $0.10 \%$ \\
LMICs & $1.67 \%$ & $2.35 \%$ & $2.31 \%$ & $1.83 \%$ & $1.36 \%$ \\
UMICs & $6.21 \%$ & $6.72 \%$ & $13.15 \%$ & $18.90 \%$ & $21.59 \%$ \\
HICs & $92.03 \%$ & $90.77 \%$ & $83.81 \%$ & $78.53 \%$ & $76.95 \%$ \\
\hline World total & 427600 & 514600 & 631300 & 911400 & 1169900 \\
\hline \multicolumn{5}{c}{ Source: WIPO Statistics Database }
\end{tabular}

Table 6: Cumulative patent grants (1993-2013)

\begin{tabular}{llc}
\hline \hline & Number of patents & Share \\
\hline \hline LICs & 53539 & $0.38 \%$ \\
LMICs & 305452 & $2.15 \%$ \\
UMICs & 1967753 & $13.86 \%$ \\
HICs & 11865962 & $83.61 \%$ \\
\hline World total & 14192706 & $100 \%$ \\
\hline \multicolumn{2}{r}{ Source: } & WIPO Statistics Database
\end{tabular}

Table 7: Patents granted by the USPTO

\begin{tabular}{lccccc}
\hline \hline & $1995-1999$ & $2000-2004$ & $2005-2009$ & $2010-2014$ & All years (1995-2014) \\
\hline \hline Non-resident share & $45.08 \%$ & $47.61 \%$ & $49.52 \%$ & $51.74 \%$ & $49.09 \%$ \\
HICs (OECD) & $43.47 \%$ & $45.55 \%$ & $46.77 \%$ & $47.06 \%$ & $46.01 \%$ \\
UMICs & $0.38 \%$ & $0.51 \%$ & $0.96 \%$ & $2.32 \%$ & $1.25 \%$ \\
Japan & $20.82 \%$ & $20.66 \%$ & $21.21 \%$ & $19.39 \%$ & $20.35 \%$ \\
Germany & $6.23 \%$ & $6.67 \%$ & $5.75 \%$ & $5.50 \%$ & $5.96 \%$ \\
UK & $2.34 \%$ & $2.25 \%$ & $2.03 \%$ & $2.05 \%$ & $2.14 \%$ \\
South Korea & $1.82 \%$ & $2.31 \%$ & $4.11 \%$ & $5.34 \%$ & $3.73 \%$ \\
Brazil & $0.06 \%$ & $0.07 \%$ & $0.06 \%$ & $0.09 \%$ & $0.07 \%$ \\
China & $0.05 \%$ & $0.16 \%$ & $0.59 \%$ & $1.85 \%$ & $0.85 \%$ \\
India & $0.05 \%$ & $0.15 \%$ & $0.34 \%$ & $0.74 \%$ & $0.39 \%$ \\
Russia & $0.11 \%$ & $0.12 \%$ & $0.11 \%$ & $0.14 \%$ & $0.12 \%$ \\
\hline Total granted & 624050 & 824173 & 799981 & 1275787 & 3523991 \\
\hline
\end{tabular}


Table 8: R\&D as a \% of GDP and R\&D expenditures

\begin{tabular}{llllll}
\hline \hline & 1996 & 2001 & 2006 & 2011 & $\begin{array}{c}2011 \\
(\text { million } \$)\end{array}$ \\
\hline \hline Brazil & - & 1.04 & 1.00 & 1.21 & 25340 \\
China & 0.56 & 0.95 & 1.39 & 1.84 & 208171 \\
India & 0.62 & 0.72 & 0.80 & 0.81 & 24305 \\
Japan & 2.77 & 3.07 & 3.41 & 3.39 & 146537 \\
Russia & 0.97 & 1.18 & 1.07 & 1.09 & 35045 \\
US & 2.44 & 2.64 & 2.54 & 2.76 & 429143 \\
\hline \multicolumn{4}{l}{ Source: }
\end{tabular}

Source: World Development Indicators, 2015 
Figure 1: Indices of Global Exports and Royalty Payments (Shares of GDP)

Exports as a \% of GDP $\longrightarrow$ Royalties as a \% of GDP

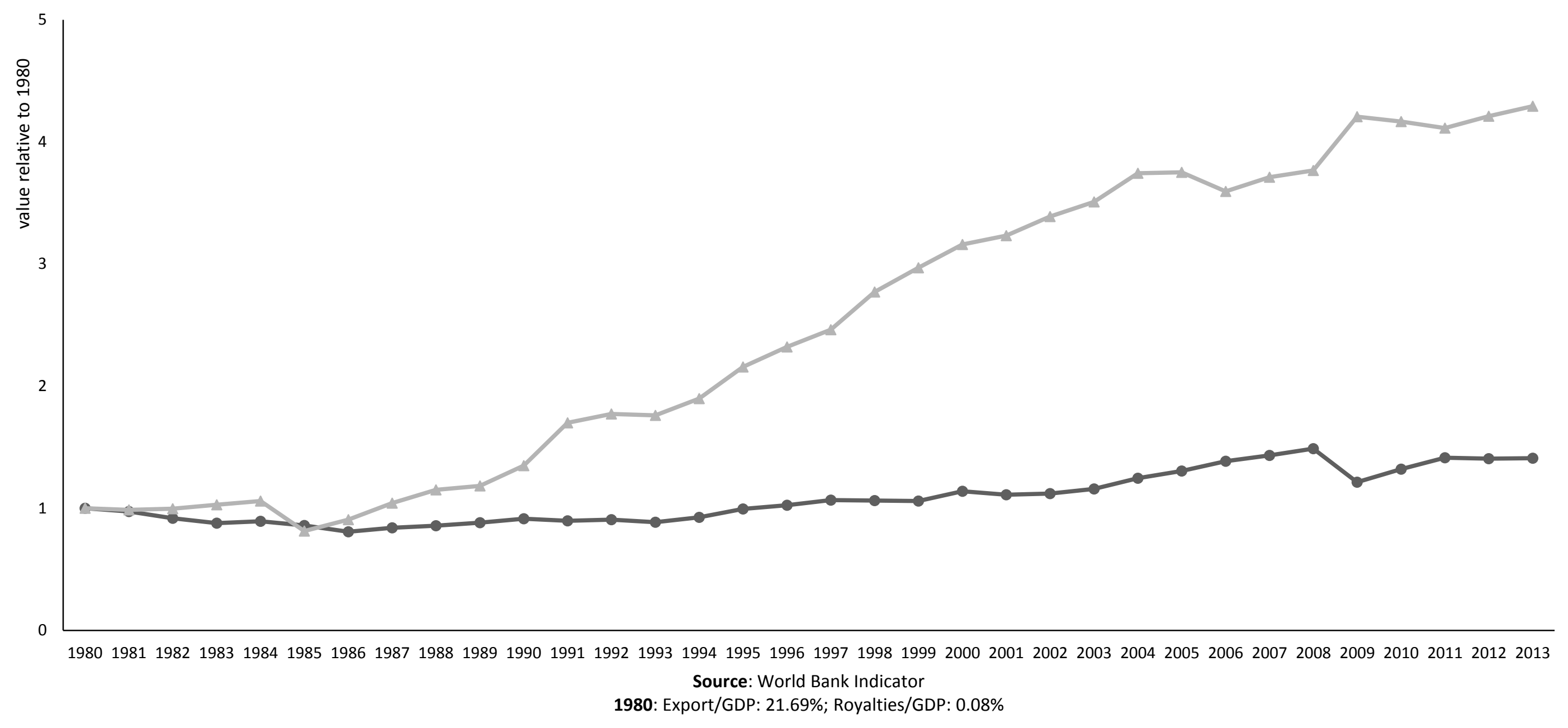


Figure 2: Non-resident Shares of Patents Granted

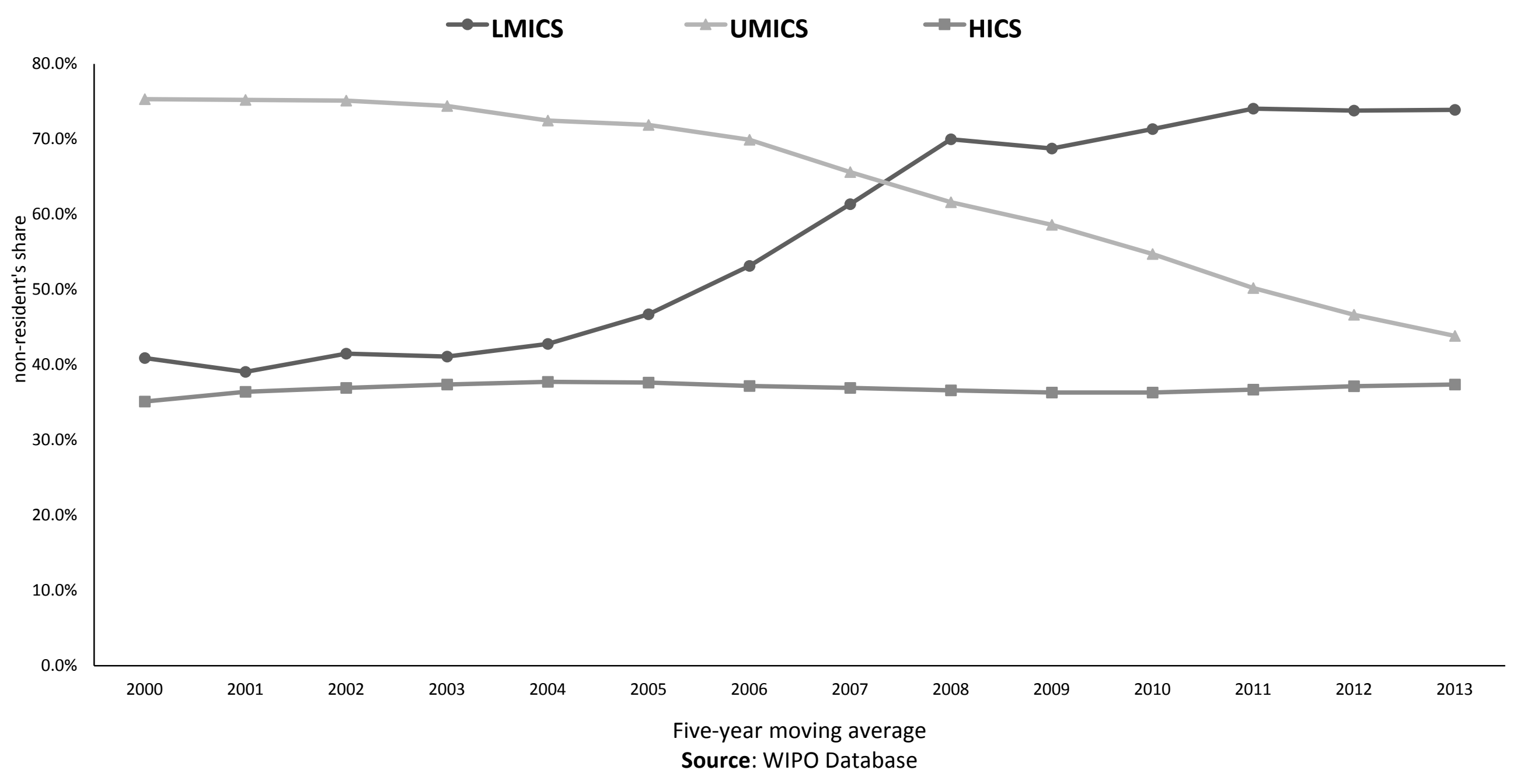


Figure 3: Patents Granted by LMICs (Residents and Non-residents)

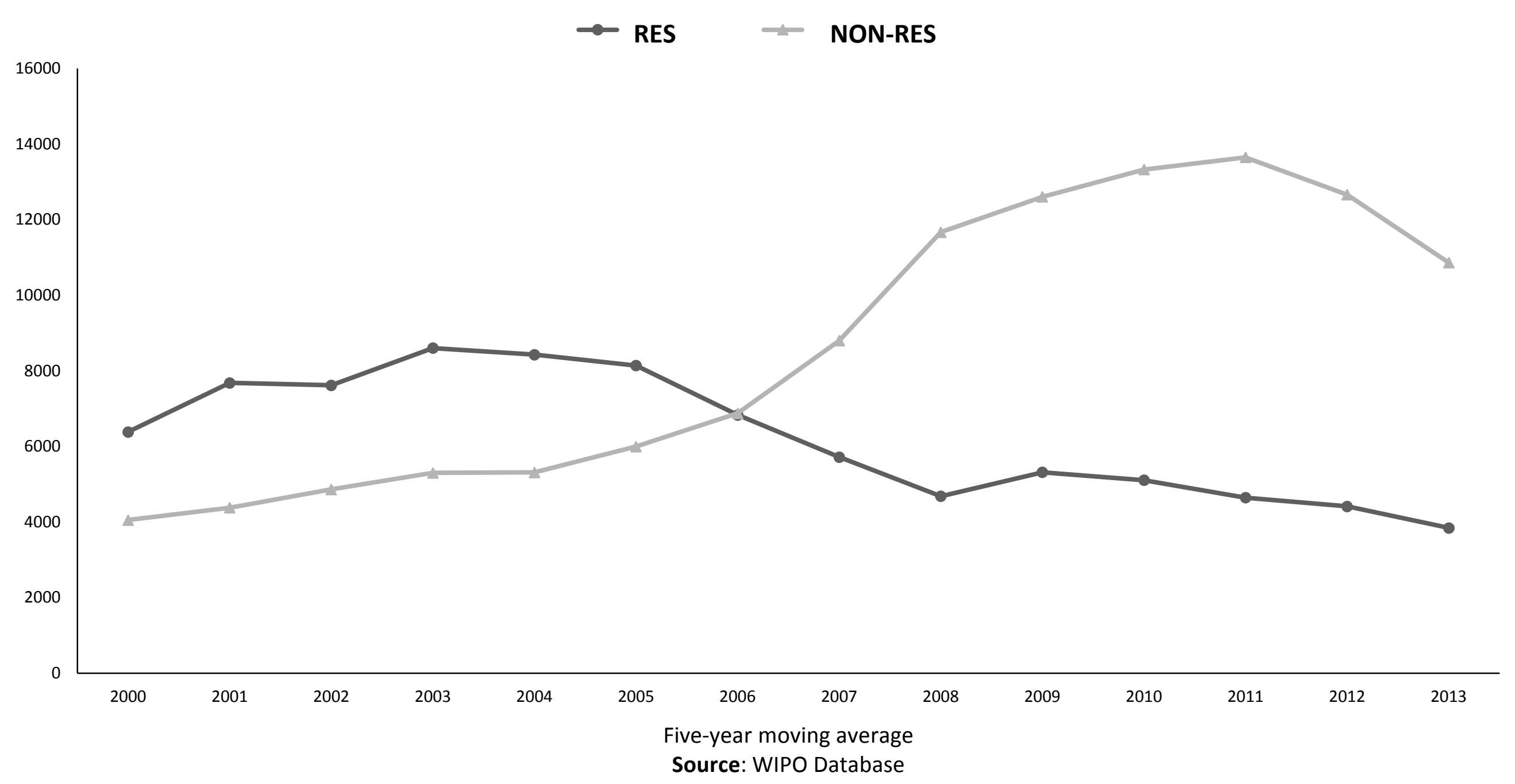

